RICARDO NAKAMURA

\title{
VÍDEO-AVATAR COM DETECÇÃO DE COLISÃO PARA REALIDADE AUMENTADA E JOGOS
}

Tese apresentada à Escola Politécnica da Universidade de São Paulo para obtenção do título de Doutor em Engenharia 
RICARDO NAKAMURA

\section{VÍDEO-AVATAR COM DETECÇÃO DE COLISÃO PARA REALIDADE AUMENTADA E JOGOS}

Tese apresentada à Escola Politécnica da Universidade de São Paulo para obtenção do título de Doutor em Engenharia

Área de Concentração:

Engenharia de Computação e Sistemas Digitais

Orientador:

Prof. Livre-Docente Romero Tori 
Este exemplar foi revisado e alterado em relação à versão original, sob responsabilidade única do autor e com a anuência de seu orientador.

São Paulo, 31 de Julho de 2008.

Autor: Ricardo Nakamura

Orientador: Prof. Livre-Docente Romero Tori

\section{Nakamura, Ricardo}

Vídeo-Avatar com detecção de colisão para realidade aumentada e jogos / R. Nakamura. -- ed. rev. São Paulo, 2008. $109 \mathrm{p}$.

Tese (Doutorado) - Escola Politécnica da Universidade de São Paulo. Departamento de Engenharia de Computação e Sistemas Digitais.

1. Jogos eletrônicos 2. Colisões (Detecção) 3. Realidade aumentada 4. Vídeo-Avatar I. Universidade de São Paulo. Escola Politécnica. Departamento de Engenharia de Computação e Sistemas Digitais II. t. 
DedicatóRIA

Dedico este trabalho aos meus pais. 


\section{AGRADECIMENTOS}

Ao professor Romero Tori, pela orientação e estímulo durante a realização deste trabalho e pela confiança depositada.

Aos amigos participantes do Interlab: João Luiz Bernardes Jr., Roberto Bianchini, Mariza Ushijima Leone, Eduardo Costa Jacober, Daniel Calife, Alexandre Tomoyose, Daniel Makoto Tokunaga, Lucas Trias, Silvio Ricardo Sanches e a todos que colaboraram, direta ou indiretamente, na elaboração deste trabalho.

Este trabalho foi realizado com o auxílio do Conselho Nacional de Desenvolvimento Científico e Tecnológico, através da concessão de Bolsa de Doutorado, processo 141852/2004-6. 


\section{RESUMO}

A proposta deste trabalho é demonstrar a viabilidade de um sistema para inserção de um vídeo-avatar interativo em um ambiente virtual 3D, utilizando-se somente um computador pessoal e câmeras domésticas. Sua contribuição, em relação a trabalhos similares, consiste em integrar técnicas e algoritmos em uma solução inovadora de baixo custo computacional, voltada principalmente para aplicações de educação e entretenimento.

Este trabalho expande as pesquisas realizadas anteriormente no Laboratório de Tecnologias Interativas sobre vídeo-avatares para teleconferência. O vídeo-avatar proposto é posicionado corretamente em relação a outros objetos do ambiente virtual e pode interagir com eles, sem a utilização de técnicas de reconstrução geométrica que apresentam altos custos de processamento. A demonstração da viabilidade da proposta é feita através da implementação de protótipos.

Palavras-chave: Jogos eletrônicos, Detecção de Colisões, Realidade aumentada, Vídeo-avatar. 


\begin{abstract}
The proposal of this work is to demonstrate the feasibility of a system for the insertion of an interactive video avatar in a $3 \mathrm{D}$ virtual environment, using a single personal computer and home-use cameras. Its contribution, relative to similar works, consists in integrating techniques and algorithms in an innovative solution with low computational cost, aimed mainly at educational and entertainment applications.

This work extends research previously performed at the Laboratório de Tecnologias Interativas about video avatars for teleconferencing. The proposed video avatar is correctly positioned in relation to other objects in the virtual environment and is capable of interacting with them, without resorting to geometric reconstruction techniques that present high processing costs. The demonstration of the feasibility of the proposal is performed through the implementation of prototypes.
\end{abstract}

Keywords: Electronic games, Collision detection, Augmented reality, Video avatar. 


\section{LISTA DE ILUSTRAÇÕES}

Figura 1 - Diagrama simplificado de um sistema de vídeo-avatar ...........................15

Figura 2 - Espaço contínuo da Virtualidade (MILGRAM; KISHINO, 1994)... .21

Figura 3 - Aplicação que une realidade aumentada e virtualidade aumentada (PRINCE et al., 2002).

Figura 4 - Equipamento necessário para jogar o ARQuake (THOMAS et al.,

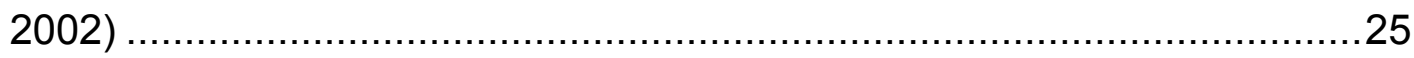

Figura 5 - Visão de um jogador do ARQuake (PIEKARSKI; THOMAS, 2002) .........25 Figura 6 - AR-Bowling (MATYSCZOK; RADKOWSKI; BERSSENBRUEGGE, 2004)

Figura 7 - Ambiente de jogos de tabuleiro com RA (MAGERKURTH;

ENGELKE; MEMISOGLU, 2004)

Figura 8 - Modelo de câmera de orifício (baseado em Gonzales e Woods (2000))

Figura 9 - (a) Percepção de imagens estereoscópicas; (b) Visão do olho esquerdo (vermelho); (c) Visão do olho direito (azul)

Figura 10 - Arranjo para imageamento estéreo.

Figura 11 - A profundidade D correspondente a um ponto I da imagem

Figura 12 - Exemplos de configurações de câmera que não permitem o uso de relações da linha Epipolar. (a) Eixos ópticos coincidentes; (b) Não há sobreposição das imagens.

Figura 13 - Determinação da linha epipolar 36

Figura 14 - Para câmeras com mesma orientação e somente translação horizontal, as linhas epipolares serão paralelas e horizontais.

Figura 15 - llustração do processo de retificação de imagens obtidas a partir

de um par de câmeras em uma configuração arbitrária

Figura 16 - Reconstrução a partir do mapa de profundidade

Figura 17 - Geração de um volume cônico a partir da silhueta 42

Figura 18 - Construção do visual hull (MATUSIK et al., 2000) .42

Figura 19 - Exemplos de configurações de billboard, em vista superior. (a) Configuração arbitrária, ilustrando a orientação do plano do billboard; 
(b) Configuração em que o plano do billboard fica paralelo ao plano de imagem.

Figura 20 - Subdivisão do espaço através de uma octree.

Figura 21 - Testes de colisão com uma quadtree. (a) Não ocorre colisão; (b)

Colisão é detectada. .46

Figura 22 - Vídeo-avatar do sistema 3D-Live (PRINCE et al., 2002). 49

Figura 23 - O jogo AR-Soccer (PAELKE; REIMAN; STICHLING, 2004). 51

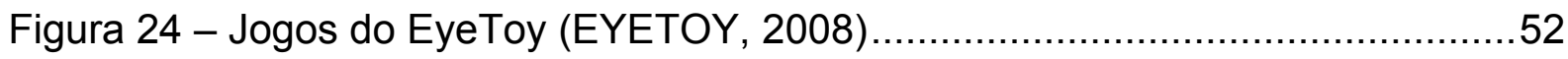

Figura 25 - Arranjo do projeto Kick-Ass Kung Fu (HÄMÄLÄINEN et al., 2005) ........52

Figura 26 - Diagrama ilustrando a configuração de equipamentos para utilização do vídeo-avatar proposto neste trabalho

Figura 27 - Diagrama de blocos do processamento dos quadros de vídeo para

a produção do mapa de profundidade 58

Figura 28 - Pseudo-código para o cálculo de disparidades. .60

Figura 29 - Diagrama ilustrativo da execução paralela do cálculo do mapa de profundidade em regiões distintas da imagem

Figura 30 - Volume envolvido pela octree para deteç̧ão de colisão do vídeo-

avatar.

Figura 31 - Representação de uma árvore utilizando-se um vetor em memória ......63

Figura 32 - Visualização da ferramenta configurável de testes

Figura 33 - Resultado do teste com a figura de referência "Sawtooth" (SCHARSTEIN; SZELIKSI, 2002). (a) Uma das imagens de referência; (b) mapa de disparidades de referência; (c) mapa de disparidades com uma janela $9 \times 9$.

Figura 34 - Resultado do teste com a figura de referência "Venus" (SCHARSTEIN; SZELIKSI, 2002). (a) Uma das imagens de referência; (b) mapa de disparidades de referência; (c) mapa de disparidades com uma janela $15 \times 15$.

Figura 35 - Ganho de qualidade $x$ aumento do processamento com diferentes tamanhos de janela de avaliação, considerando-se a figura de referência "Sawtooth".

Figura 36 - Ganho de qualidade $\mathrm{x}$ aumento do processamento com diferentes tamanhos de janela de avaliação, considerando-se a figura de referência "Sawtooth". 
Figura 37 - Resultados do teste de desempenho do algoritmo de mapa de profundidade.

Figura 38 - Tempos médios de execução do algoritmo de construção da octree

Figura 39 - Ganho de desempenho relativo com a execução do algoritmo com múltiplas threads

Figura 40 - Visualização da configuração da octree para avaliação de desempenho do algoritmo de teste de colisão 76

Figura 41 - Tempos médios de execução dos testes de colisão do videoavatar com mil objetos 76

Figura 42 - Subsistemas da arquitetura do sistema AVMIX. .80

Figura 43 - Objeto de calibração utilizado na calibração das câmeras

Figura 44 - Exemplo de configurações do objeto de calibração que levam a um bom desempenho do algoritmo de Zhang (2000).

Figura 45 - Exemplo do algoritmo de segmentação: (a) imagem de referência; (b) quadro capturado; (c) máscara obtida por subtração e limiarização; (d) imagem segmentada resultante. 84

Figura 46 - A aplicação de teste do sistema AVMix .88

Figura 47 - Exibição da octree utilizada para colisão na aplicação de teste do sistema AVMix 88 


\section{LISTA DE TABELAS}

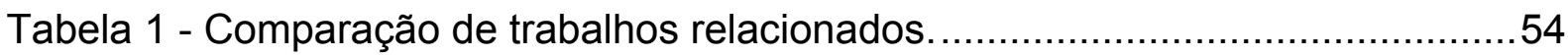

Tabela 2 - Comparação do número de operações para construção de octree.........65

Tabela 3 - Resultados dos testes com a imagem "Sawtooth" (434×380 pixels) .......70

Tabela 4 - Resultados dos testes com a imagem "Venus" (434x383 pixels) ............71

Tabela 5 - Tempo de processamento por quadro da aplicação de teste do sistema AVMix, em função do número de threads ......................................89 


\section{Lista de AbReViaturas e Siglas}

API: $\quad$ Application Programming Interface.

AVMix: $\quad$ Sistema de Vídeo-Avatar com Detecção de Colisão para Realidade Aumentada e Jogos.

AVTC: $\quad$ Ambiente Virtual para Teleconferência

CAVE: $\quad$ Cave Automatic Virtual Environment

CSCW: $\quad$ Computer Supported Collaborative Work.

GLFW: OpenGL Framework

GLSL: $\quad$ OpenGL Shading Language.

GPGPU: General Programming on the Graphics Processor Unit

GPS: $\quad$ Global Positioning System.

HMD: $\quad$ Head-mounted Display.

HLSL: $\quad$ High Level Shading Language.

INTERLAB: Laboratório de Tecnologias Interativas.

JNI: Java Native Interface.

RA: $\quad$ Realidade Aumentada.

RV: $\quad$ Realidade Virtual.

UML: $\quad$ Unified Modeling Language.

XML: $\quad$ Extensible Markup Language. 


\section{SUMÁRIO}

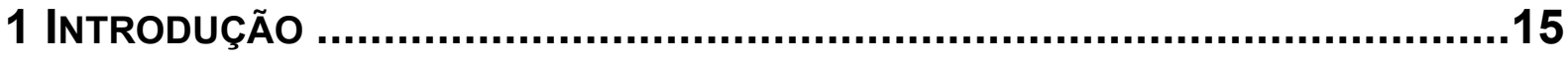

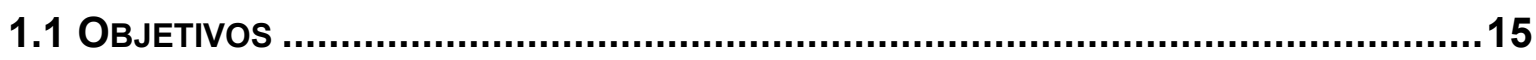

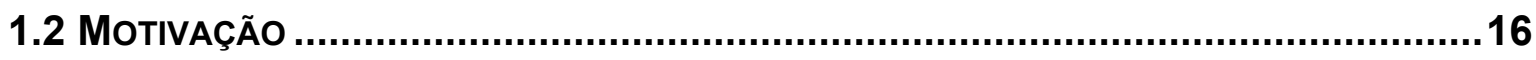

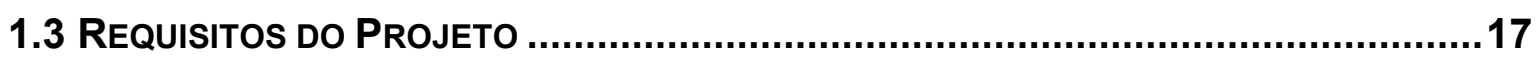

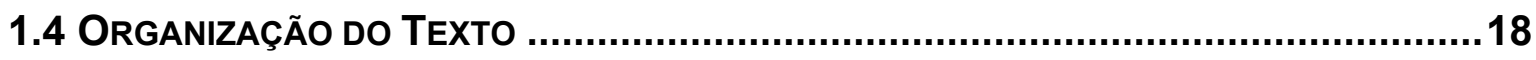

2 ConCEITOS FundAMENTAIS.............................................................19

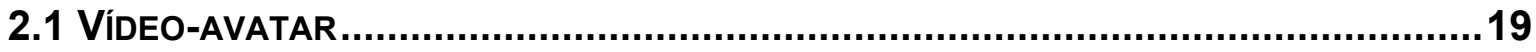

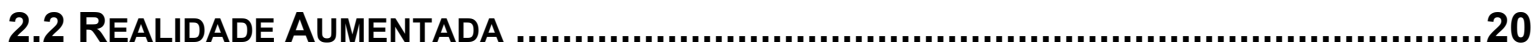

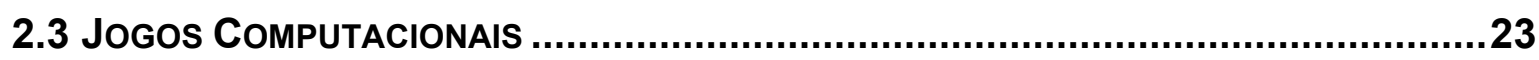

2.4 Realidade Aumentada APLICAda A Jogos Computacionais...........................24

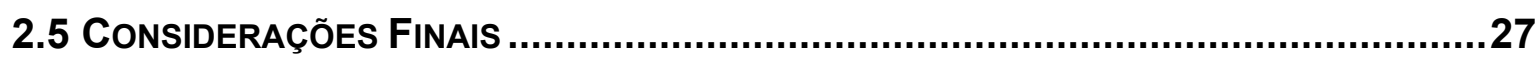

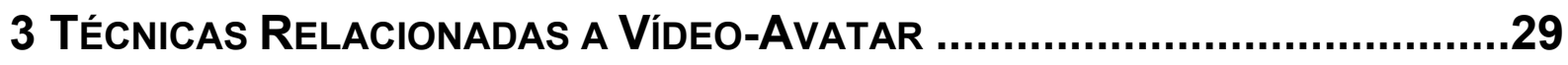

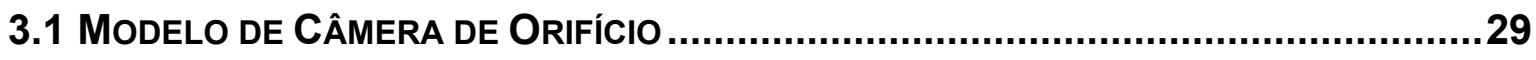

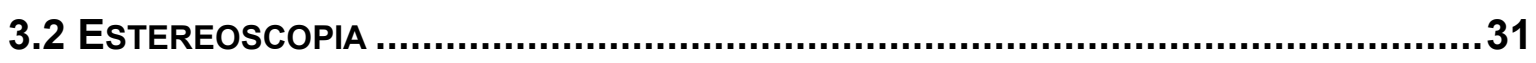

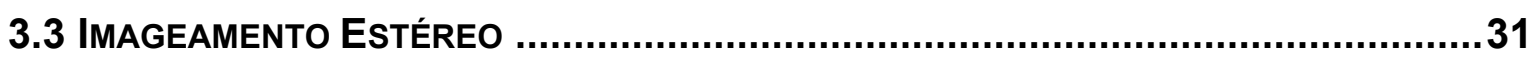

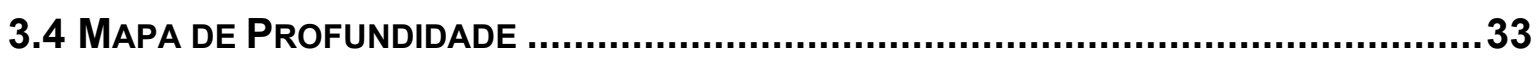

3.4.1 Geometria Epipolar para Imageamento Estéreo …..................................34

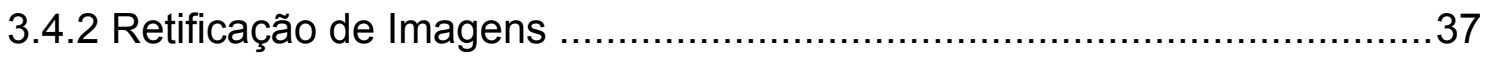

3.4.3 Determinação de pontos correspondentes em um par de imagens

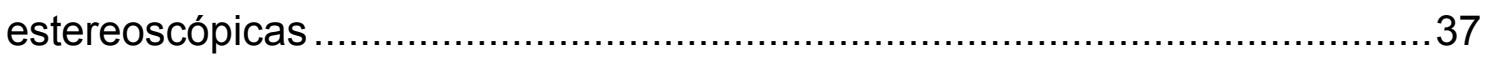

3.4.4 Limitações dos algoritmos de mapa de profundidade baseados em

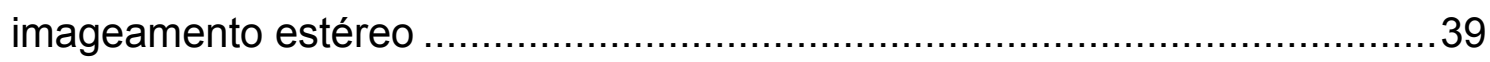

3.5 RePRESENTAÇÃo VISUAL do Vídeo-AVATAR.......................................................39

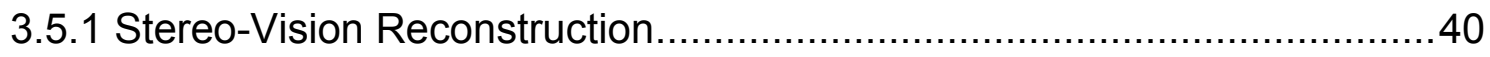

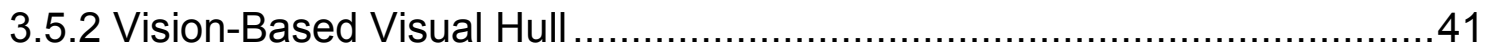

3.5.3 Representações Bidimensionais do Vídeo-Avatar ..................................42

3.6 Deteç̧ão de Colisão em Ambientes Virtuais ............................................43

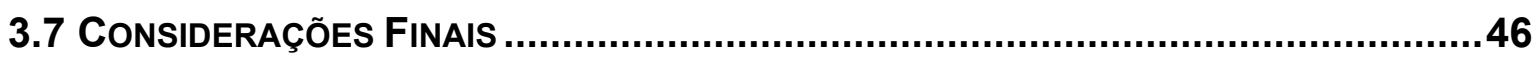

4 AnÁlise Comparativa de Sistemas de Vídeo-Avatar........................48

4.1 AVTC - AMBIENTE VIRTUAL PARA TELECONFERÊNCIA …...................................48 
4.2 3D-LIVE

4.3 BLUE-C

4.4 ITS - IMMERSIVE TELECOMMUNICATION SYSTEM .............................................5

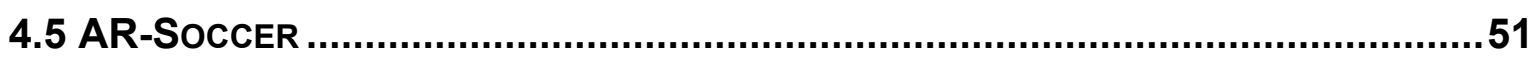

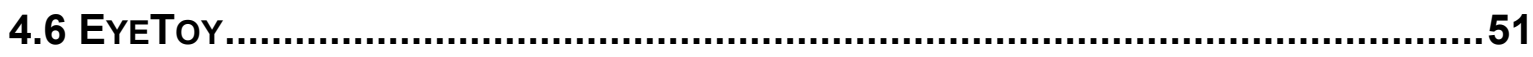

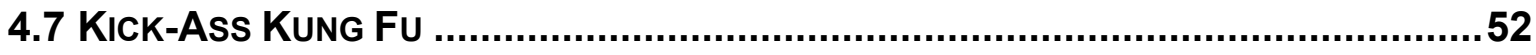

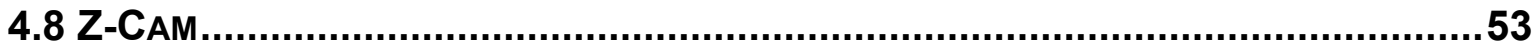

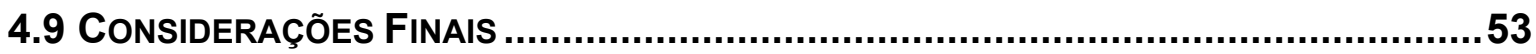

5 Inovações Tecnológicas Propostas para Vídeo-Avatar de

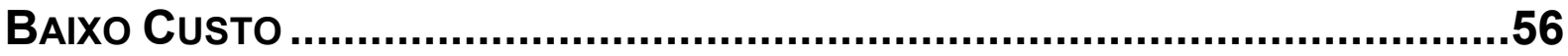

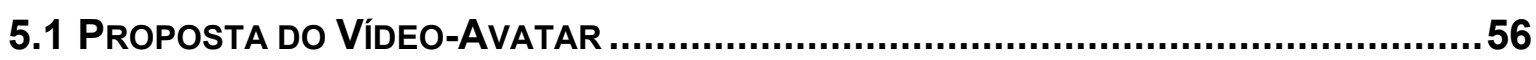

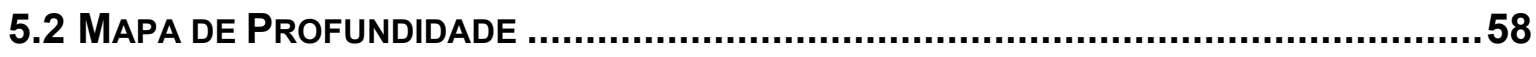

5.3 DetecÇão de Colisão Para Interação no Ambiente ViRTUal ........................61

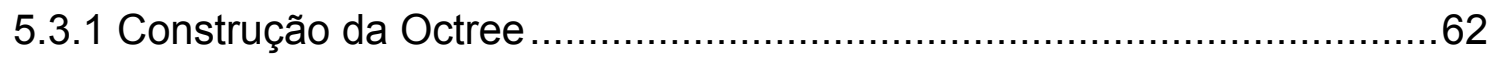

5.3.2 Detecção de Colisão com Objetos do Ambiente Virtual............................66

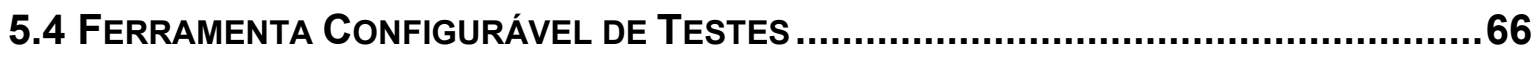

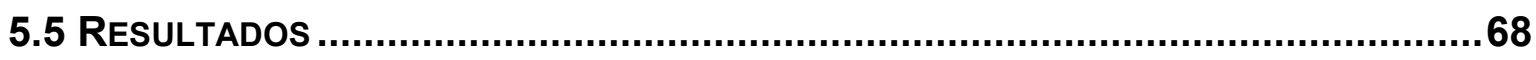

5.5.1 Qualidade do Subsistema de Mapa de Profundidade ..............................68

5.5.2 Desempenho do Subsistema de Mapa de Profundidade ..........................72

5.5.3 Desempenho da Construção da Octree ................................................73

5.5.4 Desempenho dos Testes de Detecção de Colisão ..................................75

5.6 CONSIDERAÇÕES FINAIS ..........................................................................77

6 AVMIX: SiSTEMA DE VídEO-AVATAR..................................................79

6.1 VISÃo GERAL DO SISTEMA AVMIX...............................................................

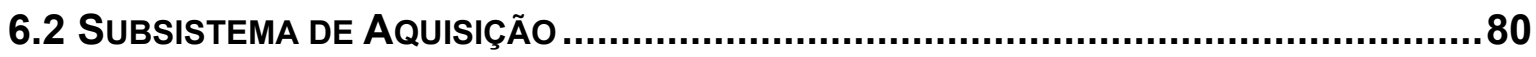

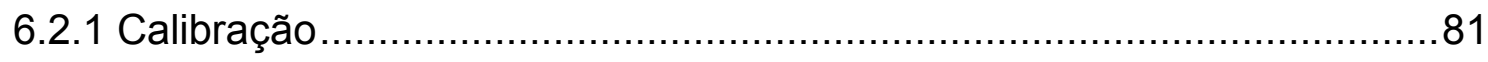

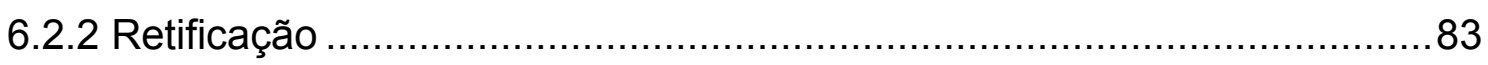

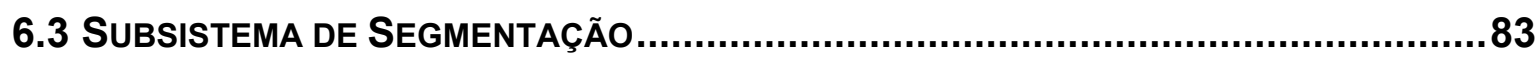

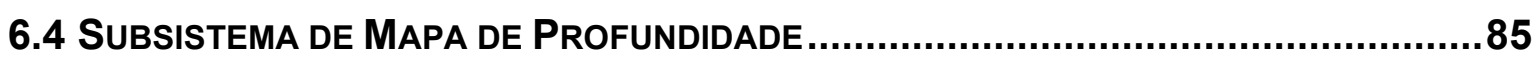

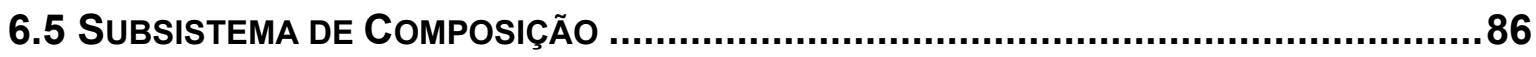

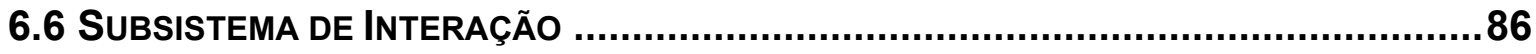

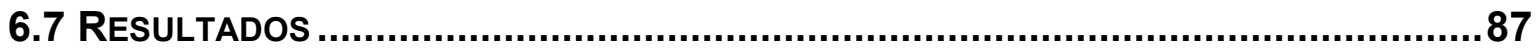

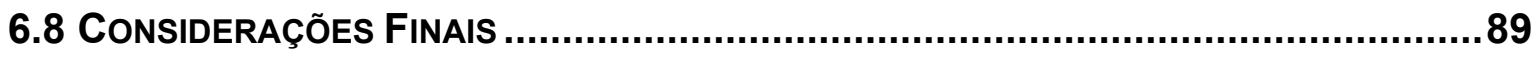




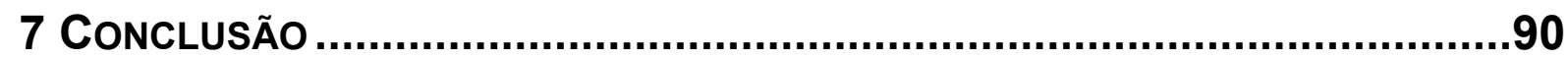

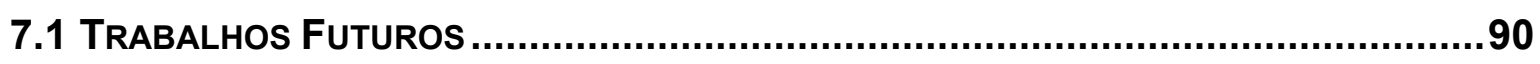

7.1.1 Calibração dinâmica de cores das webcams ......................................90

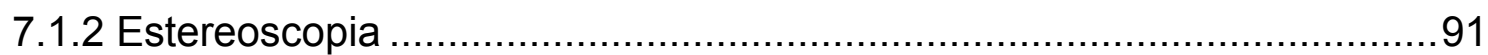

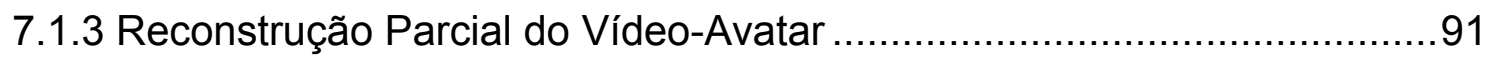

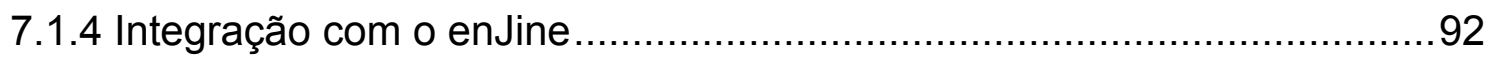

7.1.5 Implementações Paralelizadas e Utilização de GPGPU ...........................92 


\section{INTRODUÇão}

O presente trabalho propõe e demonstra a viabilidade de técnicas para visualização e interação em três dimensões, em tempo real, de um vídeo-avatar em ambientes virtuais 3D utilizando-se somente um computador pessoal e duas câmeras de vídeo digitais domésticas (webcams). De forma simplificada, vídeo-avatar é uma representação realista de uma pessoa, em ambiente virtual 3D, baseada na sua imagem obtida através de câmeras de vídeo. A Figura 1 apresenta um diagrama simplificado de um sistema para inserção de vídeo-avatar em um ambiente virtual.

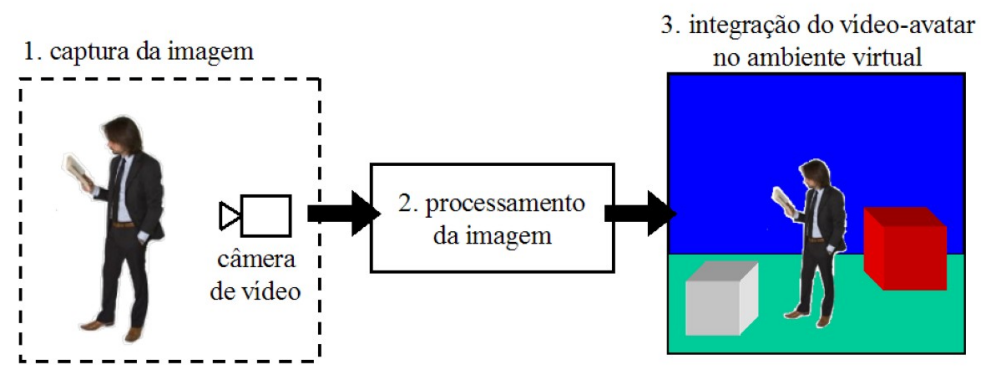

Figura 1 - Diagrama simplificado de um sistema de vídeo-avatar

Este trabalho também inclui, entre suas contribuições, a especificação do sistema de software AVMix, que integra as técnicas propostas, criando uma infraestrutura para a utilização do vídeo-avatar em aplicações de educação e entretenimento. Desta forma, este trabalho envolve as linhas de pesquisa de Realidade Aumentada e Entretenimento Digital, em especial jogos computacionais.

\subsection{Objetivos}

O objetivo principal deste trabalho é demonstrar a viabilidade de um sistema para exibição e interação de um vídeo-avatar em um ambiente virtual tridimensional em uma plataforma de hardware doméstico, voltado para aplicações de educação e entretenimento. As contribuições desta tese, em relação aos sistemas de vídeoavatar existentes, são:

- Propor uma técnica para recuperar informações de distância de cada ponto da imagem observada através de um par de câmeras, que seja adequada para 
utilização com câmeras de vídeo digitais domésticas, também conhecidas como webcams. Este conjunto de informações, também conhecido como mapa de profundidade, pode ser utilizado como base para a interatividade do vídeo-avatar;

- Propor uma técnica para a construção de um modelo de colisão para o vídeoavatar, que permita sua interação tridimensional, em tempo real, com elementos de um ambiente virtual, atendendo ao requisito de baixo custo computacional;

- Especificar um sistema de vídeo-avatar interativo, baseado nas técnicas propostas, voltado para uso doméstico, em um computador pessoal com duas câmeras de vídeo digitais domésticas.

\subsection{Motivação}

A utilização de vídeo-avatares em aplicações de realidade virtual ou realidade aumentada é motivada por proporcionar maior imersão e interatividade. Kato e Billinghurst (1999) observam que a transmissão de vídeo dos usuários em aplicações de trabalho cooperativo intermediado por computadores (Computer Supported Collaborative Work, CSCW permite a comunicação natural entre tais usuários através de gestos e expressões faciais. Os autores sugerem a construção de ambientes de CSCW utilizando Realidade Aumentada, o que implica na utilização de alguma forma de vídeo-avatar.

Atualmente, também existe interesse na utilização de vídeo-avatares em aplicações de entretenimento, incluindo jogos nos quais o usuário interage através de sua representação em vídeo (EYETOY, 2008; HÄMÄLÄINEN et al, 2005; MUELLER; AGAMANOLIS, 2005). Neste caso, a principal motivação para o uso dessa técnica é permitir uma interação natural do jogador através de gestos, movimentos corporais e expressões capturados em vídeo no lugar de dispositivos de entrada convencionais, tais como joystick, teclado e mouse. Existe também o aspecto de imersão, pois mesmo com o uso de dispositivos convencionais de exibição, como um televisor ou monitor de vídeo, o usuário pode ter a sensação de interagir com elementos virtuais do jogo. $\mathrm{Na}$ área educacional, pode-se citar a arquitetura para videoconferência de Siscoutto (2003); como nos outros casos, a motivação para aplicações envolvendo vídeo-avatar é a imersão dos usuários. 
Pode-se encontrar uma variedade de trabalhos que propõem sistemas de vídeoavatar. No entanto, atualmente a maioria destes projetos utiliza técnicas de reconstrução geométrica que, embora produzam um vídeo-avatar de alta qualidade, demandam grande poder de processamento computacional e requerem quantidades consideráveis de equipamentos, tais como câmeras de vídeo digitais de alta qualidade, em montagens precisas. Estes requisitos de espaço físico (para os equipamentos), calibração precisa, custo monetário dos equipamentos e capacidade de processamento tornam tais soluções pouco viáveis para o uso doméstico. As soluções existentes para este problema apresentam, em geral, limitações na interação do vídeo-avatar por utilizarem um modelo bidimensional do mesmo.

A existência de um sistema de vídeo-avatar com interação tridimensional, portátil e de baixo custo monetário poderia ser explorada para a implementação de aplicações em diferentes áreas, como entretenimento e educação à distância. A inadequação das soluções atuais motiva a pesquisa de uma nova solução de vídeo-avatar com essas características.

\subsection{Requisitos do Projeto}

Partindo-se dos objetivos delineados anteriormente, pode-se estabelecer um conjunto de requisitos que a solução proposta para o problema deve satisfazer:

- Interação: a solução proposta deve permitir a detecção de colisões em três dimensões entre o vídeo-avatar e outros elementos do ambiente virtual, para fins de interação com estes objetos;

- Equipamento: a solução proposta deve executar em um único computador pessoal, utilizando no máximo duas câmeras de vídeo digitais de uso doméstico (webcams);

- Portabilidade: a solução deve ter um procedimento de configuração e calibração tais que não seja necessário alocar um espaço físico permanente para o conjunto de equipamentos utilizados para o sistema;

- Taxa de atualização do vídeo-avatar: Diferentes autores, como Diot e Gautier (1999) e Singhal e Zyda (1999) definem o valor de latência de $100 \mathrm{~ms}$ como limite tolerável para ambientes virtuais. Este limite se refere 
à atualização da representação visual de um elemento do ambiente virtual em resposta a uma mudança de estado no mesmo. Naqueles trabalhos, este limite é utilizado no contexto da transmissão de informações através de uma rede de computadores. No entanto, o mesmo limite pode ser aplicado para o tempo de atualização do vídeo-avatar, por se tratar de um caso análogo de percepção visual de uma mudança de estado. Desta forma, a implementação da solução deve realizar o mínimo de 10 atualizações por segundo, ou uma atualização a cada $100 \mathrm{~ms}$, do estado do vídeo-avatar, incluindo sua representação visual e modelo de colisão.

\subsection{Organização do Texto}

Esta tese se encontra organizada em um total de sete capítulos. Terminada a apresentação do tema e objetivos deste projeto de pesquisa, o texto continua no capítulo 2 com a visão do contexto em que esta tese se insere. O capítulo 3 é dedicado a uma discussão de técnicas relacionadas a sistemas de vídeo-avatar, com detalhamento maior daquelas empregadas neste projeto. Uma vez que o contexto do trabalho foi exposto, o capítulo 4 traz uma análise comparativa de outras soluções existentes para a exibição e interação de vídeo-avatar em ambientes virtuais.

A partir deste ponto, a solução proposta para o problema é detalhada. O capítulo 5 apresenta as técnicas propostas para viabilizar o vídeo-avatar interativo em equipamentos domésticos, incluindo os resultados de testes quantitativos. O capítulo 6 traz a especificação do AVMix, um sistema de vídeo-avatar baseado nas técnicas propostas, bem como resultados qualitativos de um protótipo implementado.

O capítulo 7 encerra a tese, com uma análise dos resultados obtidos e uma discussão sobre trabalhos que podem dar continuidade a este projeto. 


\section{Conceitos Fundamentals}

Este capítulo é dedicado a apresentar as definições fundamentais e o contexto em que se insere o projeto desta tese. Desta forma, a exposição se inicia com os conceitos de vídeo-avatar, realidade aumentada e registro, que são necessários para a discussão do restante do texto. Como este trabalho envolve a união das áreas de pesquisa de Realidade Aumentada e Entretenimento Digital, este capítulo também inclui uma visão geral da área de Jogos Computacionais, seguida de uma discussão sobre a união desta área com Realidade Aumentada. Os capítulos subseqüentes contêm os detalhes sobre as técnicas e tecnologias relacionadas ao projeto.

\subsection{Vídeo-avatar}

Na área de Realidade Virtual, um avatar pode ser definido como uma representação, humanóide ou não, de um usuário dentro do ambiente virtual (KIRNER, 2001). Podese dizer que um vídeo-avatar, por sua vez, é um avatar criado a partir de imagens de vídeo capturadas do usuário. Neste trabalho, será adotada a seguinte definição: vídeo-avatar é uma representação virtual baseada na imagem de um usuário humano obtida através de um dispositivo de aquisição de vídeo e atualizada em tempo real. Desta forma, as imagens utilizadas pelo vídeo-avatar são atualizadas com uma freqüência compatível com a velocidade de interação do usuário. Esta definição não limita o vídeo-avatar a uma representação completa do corpo do usuário. Por exemplo, Chen et al. (2002) apresentam um projeto no qual um vídeoavatar correspondente à cabeça do usuário é utilizado em uma aplicação de teleconferência. Da mesma forma, o vídeo-avatar não é restrito a uma forma de representação.

$\mathrm{Na}$ literatura, pode-se encontrar projetos que empregam técnicas de reconstrução geométrica para produzir uma representação tridimensional do usuário, assim como técnicas que utilizam uma representação bidimensional do mesmo. Siscoutto (2003) propõe um vídeo-avatar estereoscópico construído pelo mapeamento de uma textura 
contendo a imagem de vídeo do usuário sobre um modelo geométrico plano que é colocado dentro do ambiente virtual. O vídeo-avatar resultante é bidimensional, porém o efeito estereoscópico (vide seção 3.2 ), em conjunto com técnicas de detecção de colisão entre objetos, faz com que este pareça ter volume. Hoshnio (2002) propõe uma abordagem híbrida para a construção do vídeo-avatar. Neste caso, as imagens de vídeo do usuário são mapeadas sobre um modelo tridimensional simplificado. Por fim, existem as técnicas de reconstrução geométrica, nas quais as imagens capturadas a partir de um conjunto de câmeras são processadas para se produzir uma representação geométrica do usuário normalmente na forma de uma malha poligonal ou uma nuvem densa de pontos (NAEF; STAADT; GROSS, 2004; PRINCE et al., 2002).

\subsection{Realidade Aumentada}

Alguns autores, como Billinghurst, Grasset e Looser (2005) afirmam que as primeiras aplicações de Realidade Aumentada (RA) foram propostas na década de 60. No entanto, assim como ocorreu com a Realidade Virtual, este campo foi limitado durante anos pela falta de recursos computacionais que viabilizassem a implementação de aplicações e sistemas mais elaborados. Azuma (1997) observa que na década de 90 muitas aplicações de RA surgiram em campos como a medicina, manutenção de equipamentos, visualização de dados, entretenimento e sistemas militares. Também são desse período as iniciativas como a de Milgram e Kishino (1994), que propõem uma taxonomia para classificar sistemas computacionais que exibem diferentes combinações de elementos reais e sintéticos em um mesmo ambiente, formando o espaço contínuo da virtualidade mostrado na Figura 2. 


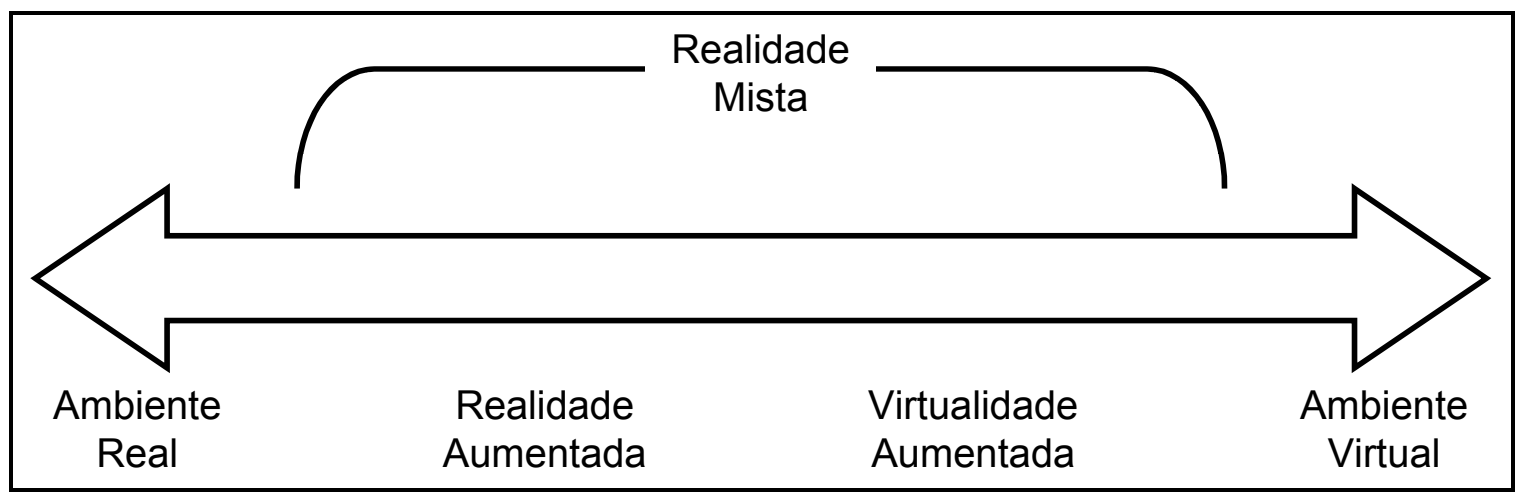

Figura 2 - Espaço contínuo da Virtualidade (MILGRAM; KISHINO, 1994)

Segundo esta taxonomia, os extremos do contínuo da virtualidade são representados por sistemas de tele-operação, nos quais o usuário observa remotamente um ambiente do mundo real e os ambientes virtuais, aplicações da Realidade Virtual nas quais o usuário é imerso em um espaço totalmente sintético. Sistemas compostos de elementos reais e sintéticos que interagem entre si são classificados por aqueles autores como ambientes de Realidade Misturada (Mixed Reality), sendo possível distinguir dois casos principais: Realidade Aumentada, no qual objetos virtuais gerados através de computação gráfica são inseridos em um ambiente predominantemente real e Virtualidade Aumentada (VA) - neste caso, representações de objetos do mundo real são acrescentados a um ambiente sintético. De acordo com esta classificação, pode-se dizer que os sistemas de vídeoavatar abordados nesta tese são aplicações de Virtualidade Aumentada.

Essa taxonomia é útil para auxiliar na compreensão das técnicas e soluções existentes para diferentes aplicações. No entanto, a distinção entre as subcategorias de ambientes de Realidade Misturada tende a se tornar mais difícil à medida que surgem sistemas mais sofisticados. Um exemplo interessante é a aplicação apresentada por Prince et al. (2002) mostrada na Figura 3. Como se pode observar, existe um usuário real inserido em um ambiente sintético (Virtualidade Aumentada). No entanto, a imagem deste ambiente é exibida no mundo real e um segundo usuário pode interagir com esta representação (Realidade Aumentada). Neste caso, Prince et al. (2002) optaram por classificar seu trabalho apenas como Realidade Misturada. 


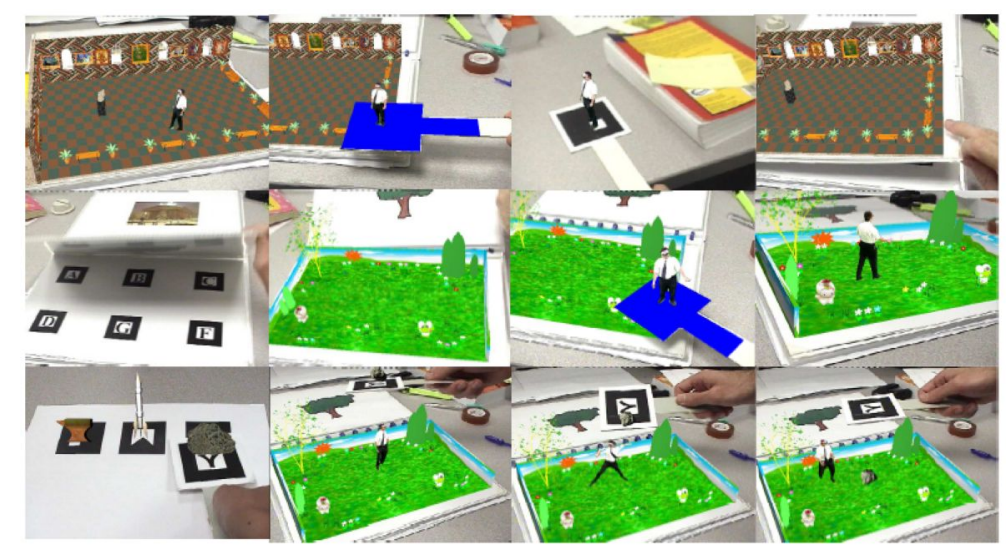

Figura 3 - Aplicação que une realidade aumentada e virtualidade aumentada (PRINCE et al., 2002)

Em função desta dificuldade de classificação, durante a elaboração deste trabalho ainda prevalece na comunidade científica o uso abrangente do termo Realidade Aumentada para designar todos os ambientes classificados como Realidade Misturada por Milgram e Kishino (1994). O termo Realidade Aumentada é empregado desta forma neste texto.

O conceito de registro na área de processamento digital de imagens se refere a determinar a correspondência entre duas imagens distintas mas relacionadas - por exemplo, duas imagens da mesma cena obtidas de diferentes pontos de vista (GONZALES; WOODS, 2000). Neste caso, o registro pode ser realizado a partir da detecção de elementos correspondentes nas diferentes imagens. De forma análoga, na área de Realidade Aumentada, o termo "registro" é utilizado para descrever os alinhamentos geométricos entre elementos reais e virtuais que devem coexistir em uma mesma cena.

Segundo Azuma (1997), manter um registro preciso é um dos desafios no desenvolvimento de aplicações de RA. Azuma observa ainda que um registro preciso é importante não apenas para evitar conflitos de percepção visual do usuário, que resultam em menor imersão, mas também porque erros de registro podem induzir o usuário a erros. Por exemplo, no caso de uma aplicação de medicina em que imagens dos órgãos são sobrepostas ao corpo de um paciente para auxiliar em um procedimento cirúrgico, mesmo erros de registro da ordem de milímetros podem ter conseqüências sérias.

Azuma (1997) divide os erros de registro em duas categorias: estáticos e dinâmicos, observando que a segunda categoria tende a ser a fonte mais significativa de erros. Os erros estáticos são causados por imperfeições construtivas e distorções nos sistemas de aquisição ou rastreamento de posição, sejam eles ópticos, magnéticos 
ou baseados em outras tecnologias. Pela sua natureza, estes erros podem ser reduzidos através de procedimentos de calibração. Por exemplo, em um sistema de RA baseado em câmeras de vídeo, os erros estáticos incluem distorções devido a imperfeições das lentes e imprecisões no posicionamento relativo das câmeras. Os erros dinâmicos são oriundos de latência no sistema de RA para atualizar a posição e orientação dos objetos virtuais de acordo com informações obtidas dos mecanismos de rastreamento. Em função deste fato, erros dinâmicos tendem a ser proporcionais à velocidade dos movimentos dos objetos na cena - em particular, uma cena completamente estática não sofre os efeitos de erros dinâmicos de registro.

\subsection{Jogos Computacionais}

Neste trabalho, será adotada a definição de Jogo Computacional apresentada por Bianchini (2005): "um jogo que pode ser simulado em um Dispositivo Computacional". A definição mais abrangente de jogo é problemática, inclusive devido a questões culturais e de lingüística. No contexto deste trabalho, é suficiente entender que um jogo é uma forma de entretenimento (embora jogos possam também ser empregados com outras finalidades). Bianchini (2005) e Jacober (2007) apresentam discussões mais aprofundadas sobre este assunto.

Assim como no caso da Realidade Aumentada, a história dos jogos computacionais se inicia na década de 60, mais especificamente em 1961, com a criação do jogo "Spacewar!" no Massachusetts Institute of Technology (MIT), programado por Steve Russell para demonstrar as capacidades do computador PDP-1 adquirido pela instituição (HISTORY, 2008). Durante um longo período, o desenvolvimento de jogos computacionais foi realizado por pequenas equipes, de até dez participantes, freqüentemente compostas por indivíduos autodidatas com pouco conhecimento de metodologias de projeto ou produção de software. Na última década, entretanto, os jogos computacionais tornaram-se complexos o bastante para tornar abordagens ad hoc inviáveis (BLOW, 2004). Em 2006, o faturamento da indústria de jogos computacionais nos Estados Unidos foi superior a 13,5 bilhões de dólares (NPD, 2008). 
A crescente complexidade dos jogos computacionais tem atraído a comunidade científica a pesquisar tanto aspectos do seu desenvolvimento como também a sua utilização em áreas como a educação e a visualização científica (LEWIS; JACOBSON, 2002; SWARTOUT; VAN LENT, 2003). Da mesma forma, o crescimento do mercado de jogos computacionais tem sido um motivador para a evolução das plataformas de hardware para consumidores domésticos, particularmente na área de adaptadores gráficos (RHYNE, 2002).

\subsection{Realidade Aumentada aplicada a Jogos Computacionais}

Nos últimos anos, tanto a indústria dos jogos computacionais como os pesquisadores interessados na área têm feito experimentos envolvendo a aplicação de tecnologias de Realidade Aumentada. Os motivos para isso são diversos: em primeiro lugar, a aplicação de técnicas de RA permite formas de interação mais intuitivas do que o uso de dispositivos como teclado, mouse e joystick. Magerkurth, Engelke e Memisoglu (2004) argumentam que o uso de tecnologias de RA pode ser uma fonte de inovação para os jogos computacionais, que têm apresentado uma convergência para um número limitado de estilos nos últimos anos.

O exemplo mais conhecido na indústria é o produto EyeToy, que consiste em uma câmera de vídeo digital com características técnicas semelhantes a uma webcam e que se comunica com um console de videogame através de uma conexão USB. Uma biblioteca de software voltada para o processamento de imagens é disponibilizada para os desenvolvedores, permitindo que sejam criados jogos que utilizam o vídeo capturado através da câmera (EYETOY, 2008). Este projeto será abordado em maiores detalhes no capítulo 4.

$\mathrm{Na}$ área acadêmica podem ser encontrados vários projetos envolvendo jogos computacionais e RA com diferentes abordagens. Um dos projetos mais conhecidos é o ARQuake (PIEKARSKI; THOMAS, 2002; THOMAS et al., 2002), no qual o jogo Quake (ID SOFTWARE, 2008) foi adaptado para executar em uma plataforma de hardware e software para aplicações de RA. 


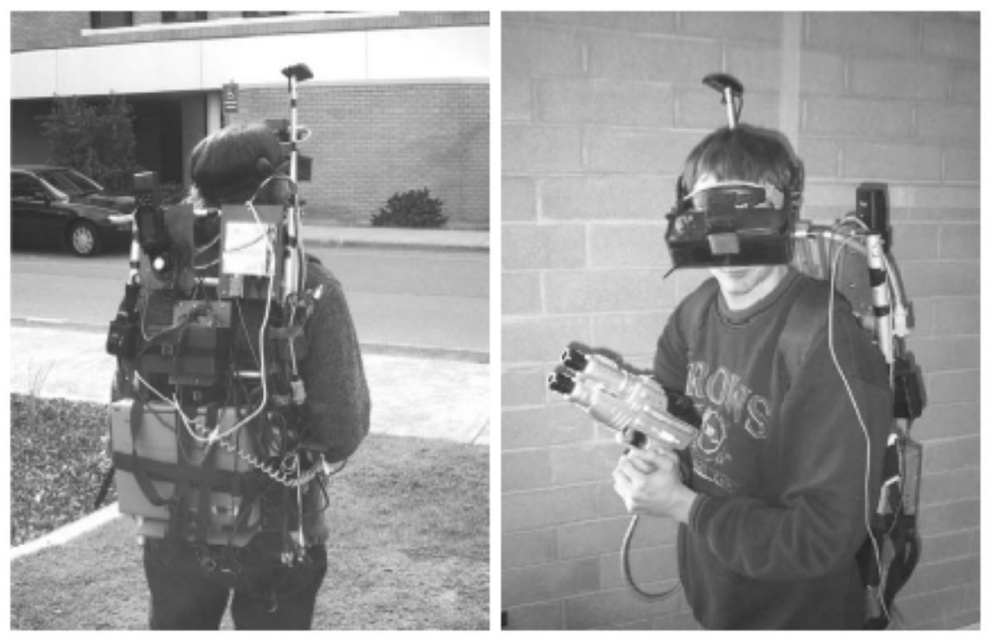

Figura 4 - Equipamento necessário para jogar o ARQuake (THOMAS et al., 2002)

No jogo Quake, os participantes exploram cenários futuristas, devendo atirar em monstros alienígenas para sobreviver, sendo que a interface é realizada através de teclado e mouse. No ARQuake, um ou mais jogadores podem caminhar por uma área do mundo real previamente estabelecida - no caso, parte do campus da University of South Australia. A funcionalidade do jogo Quake é utilizada para controlar um modelo virtual do campus e para apresentar monstros virtuais em um HMD (Head-Mounted Display) semitransparente utilizado pelos jogadores. Para estabelecer o registro entre a posição do jogador no mundo real e no modelo virtual, o ARQuake utiliza uma combinação de rastreamento por GPS (Global Positioning System) e processamento de imagens. Uma arma de brinquedo, equipada com um sensor de toque no gatilho e sensores de orientação, é utilizada para detectar os disparos realizados pelo jogador. Isso tudo resulta em um conjunto de equipamentos que precisam ser carregados pelos jogadores, como pode ser visto na Figura 4.

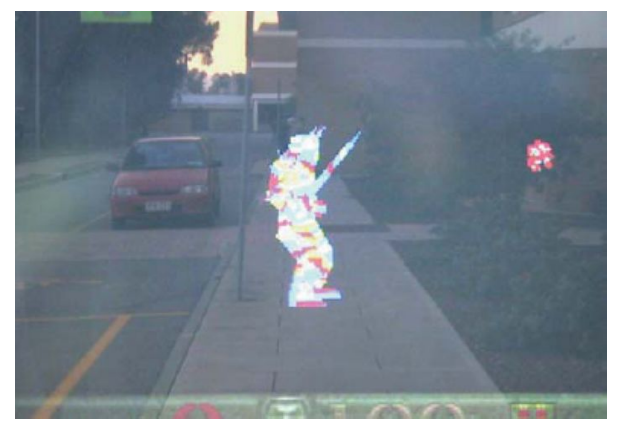

Figura 5 - Visão de um jogador do ARQuake (PIEKARSKI; THOMAS, 2002)

A Figura 5 traz uma imagem correspondente à visão de um jogador, com os elementos virtuais do jogo justapostos ao cenário real do campus. Thomas et al. (2002) observam que as maiores dificuldades no projeto estão relacionadas a 
atrasos na atualização das imagens no HMD e à precisão das tecnologias de rastreamento, sendo este último um desafio sempre presente em aplicações de RA em que o usuário pode se deslocar por uma área de grandes dimensões. Outros projetos similares ao ARQuake incluem o Human Pacman (CHEOK et al., 2004) e o projeto NetAttack (FRAUNHOFER, 2006).

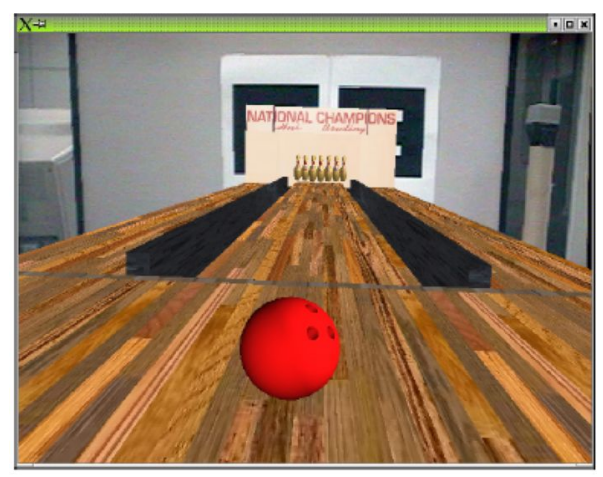

Figura 6 - AR-Bowling (MATYSCZOK; RADKOWSKI; BERSSENBRUEGGE, 2004)

Uma outra abordagem adotada para jogos computacionais com RA envolve projetos nos quais os jogos são localizados em um ambiente restrito, tais como os projetos AR-Bowling (MATYSCZOK; RADKOWSKI; BERSSENBRUEGGE, 2004), mostrado na Figura 6, os jogos esportivos de Mueller e Agamanolis (2005) e o jogo de golfe com Realidade Aumentada proposto por Govil, You e Neumann (2000). Nos diferentes projetos, o jogador utiliza um HMD opaco no qual são apresentadas as imagens combinadas do vídeo do mundo real com os objetos sintéticos do jogo. Marcadores especiais são posicionados no ambiente real para rastrear a posição e orientação do usuário, o que é viável porque o espaço de jogo é limitado e controlado, em comparação com os projetos discutidos anteriormente. Enquanto no AR-Bowling todos os elementos de jogo tais como bola, pista e pinos são virtuais, no jogo de golfe de Govil, You e Neumann (2000) a bola é um objeto real que se move sobre um campo virtual. Os autores indicam que foi necessário desenvolver um algoritmo específico para realizar o rastreamento do movimento da bola de golfe nas imagens capturadas em vídeo, devido à sua velocidade. 


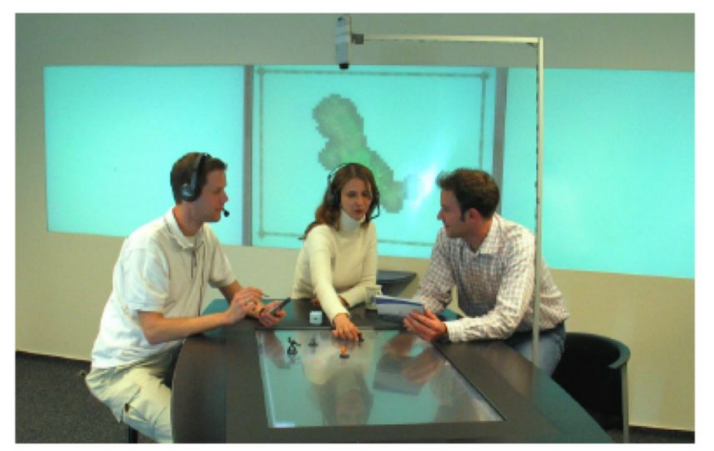

Figura 7 - Ambiente de jogos de tabuleiro com RA (MAGERKURTH; ENGELKE; MEMISOGLU, 2004) Pode-se citar, ainda na categoria dos jogos computacionais com tecnologia de RA em ambientes restritos, os jogos de tabuleiro com RA desenvolvidos por Magerkurth, Engelke e Memisoglu (2004). Neste caso, os autores estudam a utilização de recursos de RA para criar jogos computacionais que permitam uma maior interação social entre os jogadores. A Figura 7 mostra o ambiente de jogo com realidade aumentada utilizado pelos autores desse projeto para implementar seus jogos. Além das imagens projetadas na mesa, cada jogador utiliza um computador palmtop que apresenta uma interface privativa, para as informações que não devem ser compartilhadas com os demais jogadores.

\subsection{Considerações Finais}

Neste capítulo, foram apresentados os tópicos que definem o contexto necessário para a discussão do projeto desta tese, começando pelas definições de vídeo-avatar e Realidade Aumentada.

O problema de registro foi discutido, no contexto de RA. Em sistemas voltados para a inserção de um vídeo-avatar em um ambiente virtual, como no caso desta tese, a percepção dos erros estáticos de registro é reduzida. O motivo para isto é a falta de referências para que o usuário note os erros de registro. Esta é uma situação diferente dos sistemas de RA que inserem elementos virtuais em um ambiente real. Pode-se estimar que em sistemas de vídeo-avatar, os erros de registro mais significativos são erros dinâmicos provocados pela latência na atualização da imagem do vídeo-avatar, fazendo com que o usuário perceba uma discrepância entre sua pose atual e aquela apresentada dentro do ambiente virtual. 
Por fim, como esta tese também se insere na área de entretenimento digital, este capítulo apresentou uma visão geral de jogos computacionais e uma discussão da aplicação de técnicas de RA nesta área. É interessante observar que poucos projetos acadêmicos sobre jogos computacionais com RA são voltados para a inclusão de vídeo-avatar em um ambiente sintético, que é a proposta desta tese. Podem ser citados o jogo de artes marciais desenvolvido por Hämäläinen et al. (2005) e o jogo AR-Soccer desenvolvido por Paelke, Reimann e Stichling (2004), que serão analisados no capítulo 4. No entanto, o vídeo-avatar implementado nestes jogos não apresenta interação 3D, que é uma das características da proposta desta tese. 


\section{TÉcnicas ReLacionadas a Vídeo-AvataR}

O capítulo 2 foi dedicado a apresentar o contexto necessário para a discussão do projeto desta tese. Neste capítulo, técnicas específicas para vídeo-avatar relacionadas à recuperação de informações de profundidade, visualização e detecção de colisão são apresentadas. O capítulo se inicia com a exposição do modelo de câmera de orifício, que é adotado pelas técnicas apresentadas em seguida.

\subsection{Modelo de Câmera de Orifício}

Nesta seção será apresentado o modelo de câmera de orifício, que é utilizado na discussão de diferentes algoritmos de visão computacional no restante deste texto, assim como os termos utilizados para identificar seus parâmetros. A Figura 8 ilustra este modelo, segundo o qual os raios luminosos provenientes da cena observada convergem sobre centro da lente, indicado pelo ponto $C$, e atingem o plano de imagem.

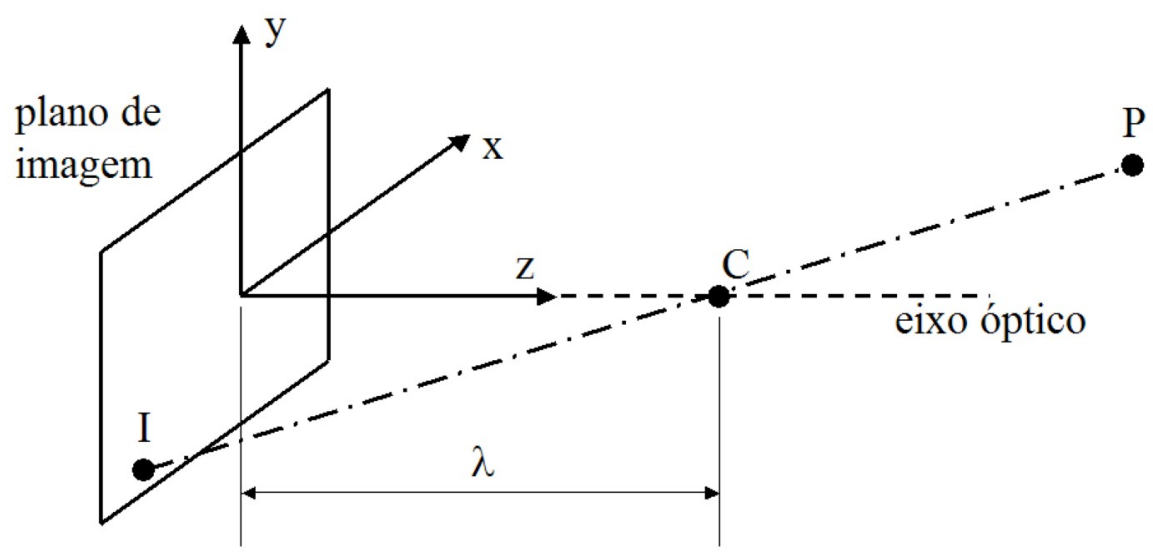

Figura 8 - Modelo de câmera de orifício (baseado em Gonzales e Woods (2000))

O sistema de coordenadas da câmera é definido de forma que os eixos $x$ e y se encontrem no plano de imagem. $\mathrm{O}$ eixo $\mathrm{z}$ é perpendicular ao plano de imagem e passa pelo centro da lente, sendo também chamado de eixo óptico da câmera. A 
distância $\lambda$ entre o plano de imagem e o centro da lente é denominada distância focal da câmera.

A relação entre as coordenadas de um ponto $P$, observado pela câmera, e do ponto I correspondente, projetado no plano de imagem, é dada por uma transformação de perspectiva. Se, na Figura 8, assumir-se que o sistema de coordenadas da câmera e o sistema de coordenadas global (no qual a posição do ponto $P$ é medida) são coincidentes, então a relação entre as coordenadas dos pontos $\mathrm{P}$ e I pode ser obtida através de semelhanças de triângulos, conforme as eq.(1) e (2). Esta relação também pode ser expressa como uma matriz de transformação para coordenadas homogêneas, dada pela eq.(3) (GONZALES; WOODS, 2000).

$$
\begin{gathered}
\frac{x_{I}}{\lambda}=-\frac{x_{P}}{z_{p}-\lambda} \\
\frac{y_{I}}{\lambda}=-\frac{y_{P}}{z_{p}-\lambda} \\
P=\left[\begin{array}{cccc}
1 & 0 & 0 & 0 \\
0 & 1 & 0 & 0 \\
0 & 0 & 1 & 0 \\
0 & 0 & -1 / \lambda & 1
\end{array}\right]
\end{gathered}
$$

No caso geral, em que os sistemas de coordenadas não se encontram alinhados, é preciso determinar a matriz de transformação que converte as coordenadas do sistema global para o sistema da câmera. Multiplicando-se as coordenadas do ponto $\mathrm{P}$ por esta matriz, obtém-se um ponto $\mathrm{P}^{\prime}$ expresso no sistema de coordenadas da câmera e, novamente, a eq.(3) pode ser aplicada. Gonzales e Woods (2000) apresentam os detalhes para se obter esta matriz de transformação. É importante observar que a transformação de perspectiva projeta um conjunto de pontos sobre um mesmo ponto do plano de imagem. Por este motivo, dado um ponto I da imagem, não é possível recuperar as três coordenadas do ponto $P$ que $O$ originou, simplesmente aplicando a transformada perspectiva inversa. 


\subsection{Estereoscopia}

Diversas informações são utilizadas pelo sistema de visão humana para estimar a distância dos objetos observados em uma cena, tais como diferenças no foco e iluminação dos objetos e oclusão de um objeto por outro. Além destas informações, que estão presentes nas imagens observadas separadamente em cada olho, o cérebro também é capaz de estimar a distância de um objeto a partir das diferenças de posição do mesmo nas imagens captadas pelos dois olhos. Este mecanismo é chamado de estereoscopia e ilustrado na Figura 9 , em que os olhos são representados como duas câmeras. As figuras (b) e (c) são imagens sintéticas geradas em um programa de modelagem 3D, a partir de pontos de observação correspondentes às câmeras vermelha e azul. Como se pode notar, os objetos aparecem nas duas imagens com um deslocamento horizontal. Este deslocamento ou paralaxe é proporcional à distância entre o objeto e o observador. A partir da disparidade dos diferentes elementos da cena, o cérebro estima a profundidade dos objetos observados. A apresentação de imagens estereoscópicas de um ambiente virtual pode ser utilizada para aumentar a sensação de imersão do usuário. Siscoutto (2003) apresenta um tratamento abrangente das técnicas e desafios para geração de imagens estereoscópicas.

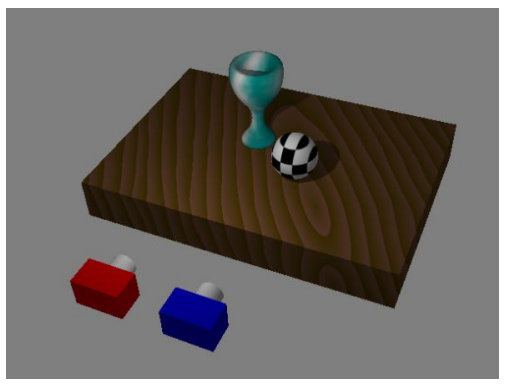

(a)

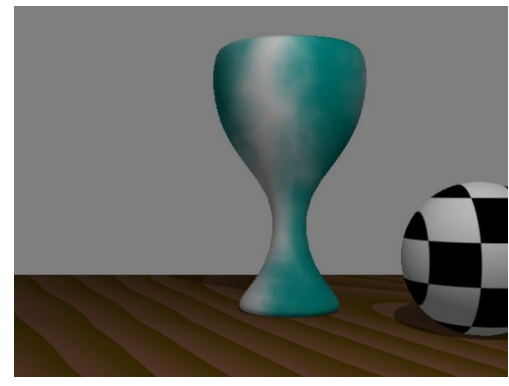

(b)

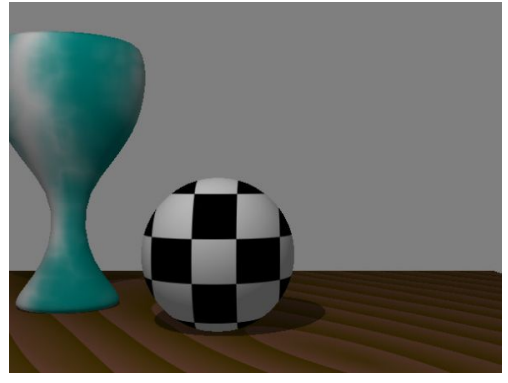

(c)

Figura 9 - (a) Percepção de imagens estereoscópicas; (b) Visão do olho esquerdo (vermelho); (c) Visão do olho direito (azul)

\subsection{Imageamento Estéreo}

De forma análoga ao que ocorre na visão humana, é possível construir um arranjo de duas câmeras para captar um par de imagens estereoscópicas. A principal 
motivação para isto é a possibilidade de se recuperar informações sobre a distância dos objetos observados na cena. Este processo é conhecido como imageamento estéreo.

Idealmente, no imageamento estéreo as câmeras devem ser posicionadas de forma que a diferença entre seus sistemas de coordenadas seja somente uma translação no eixo $x$ de uma distância $t$, denominada linha de base. Ou seja, as duas câmeras possuem mesma distância focal, os eixos ópticos se encontram paralelos e as posições dos centros das lentes são coincidentes em relação aos eixos y e z. A Figura 10 ilustra este arranjo.

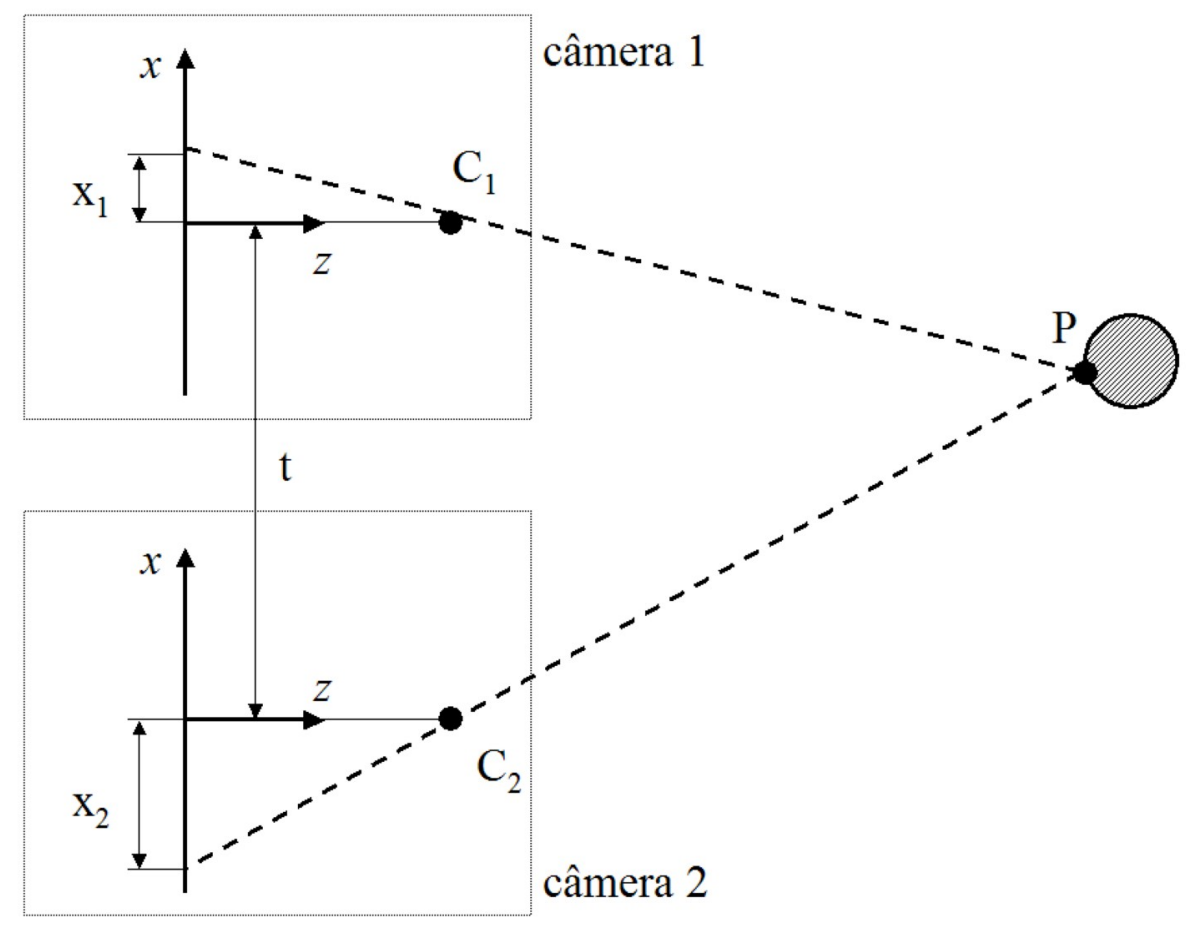

Figura 10 - Arranjo para imageamento estéreo.

Na condição mostrada na Figura 10, se o sistema de coordenadas global coincidir com o sistema de coordenadas da câmera 1, pode-se escrever as eq.(4) e (5) a partir de relações geométricas de semelhanças de triângulos, onde $\left(x_{p}, y_{p}, z_{p}\right)$ são as coordenadas do ponto $P$.

$$
\begin{gathered}
x_{P}=\frac{x_{1}\left(\lambda-z_{p}\right)}{\lambda} \\
x_{P}+t=\frac{x_{2}\left(\lambda-z_{p}\right)}{\lambda} \\
z_{p}=\lambda-\frac{\lambda t}{\left(x_{2}-x_{1}\right)}
\end{gathered}
$$


Subtraindo-se a eq.(5) da eq.(4), chega-se à eq.(6) que mostra que, dados os parâmetros de distância focal e linha de base, é possível recuperar a informação de distância de um ponto observado nas imagens de duas câmeras no arranjo da Figura 10 (GONZALES; WOODS, 2000). A diferença $\left(x_{2}-x_{1}\right)$ é conhecida como disparidade entre os pontos que correspondem às projeções do ponto $P$ nas imagens.

\subsection{Mapa de Profundidade}

Uma imagem capturada por uma câmera contém a projeção da cena observada por aquela câmera. Seja $\mathrm{P}$ um ponto do mundo real e I o ponto correspondente à sua projeção sobre o plano de imagem, como ilustrado na Figura 11. Pode-se definir a profundidade do ponto I como a distância $D$ entre $P$ e um plano que contém $O$ centro da lente da câmera e é paralelo ao plano de imagem. Desta forma, dada uma imagem bidimensional, seu mapa de profundidade é uma matriz $M$ de mesmas dimensões tal que o elemento $\mathrm{m}_{\mathrm{yx}}$ contém a profundidade correspondente ao ponto com coordenadas $(x, y)$ da imagem.

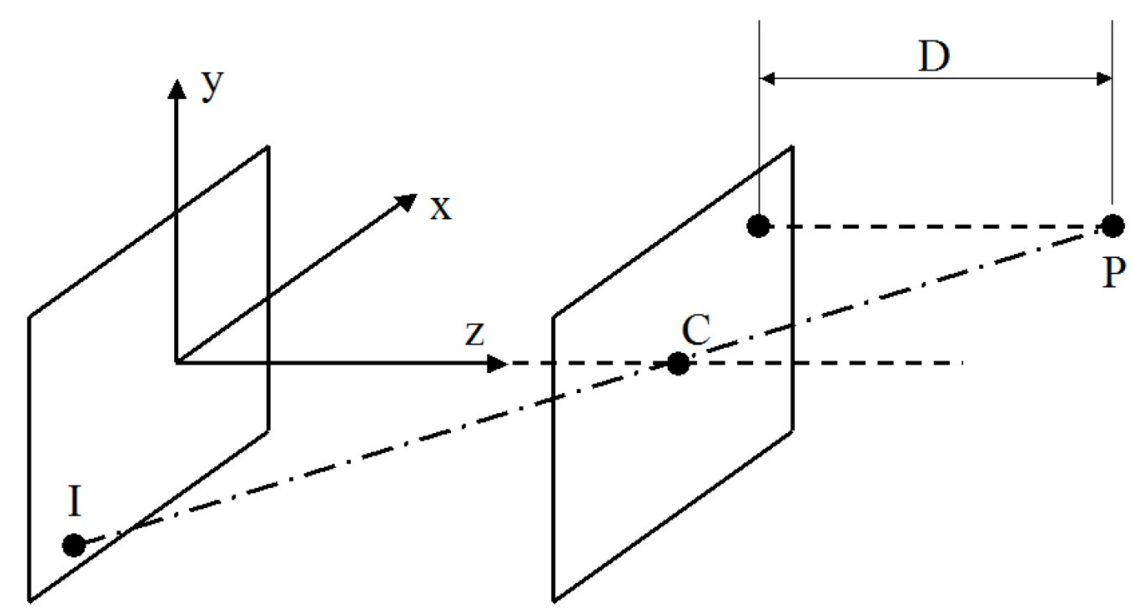

Figura 11 - A profundidade D correspondente a um ponto I da imagem

Existem diferentes maneiras de se obter um mapa de profundidade de uma imagem bidimensional, sendo um tema de muita pesquisa nos campos de robótica e visão computacional. Entre eles, pode-se citar técnicas baseadas no processamento de 
conjuntos de imagens obtidas a partir de uma mesma câmera com variações na distância focal (SUBARAO; SURYA, 1994; ZHANG; NAYAR, 2006) ou variações nas condições de iluminação (BASRI; JACOBS, 2007; LIAO et al., 2007). No entanto, estas técnicas possuem limitações que dificultam sua utilização no contexto de aplicações domésticas e de baixo custo, que são o objetivo desta tese. Técnicas baseadas na variação da distância focal da câmera exigem uma câmera digital cujo foco possa ser controlado de maneira precisa e, preferencialmente, automática. Esta é uma característica raramente presente em câmeras domésticas do tipo webcam. Técnicas baseadas em informações de luminosidade dependem de fontes de luz controladas, com características conhecidas de intensidade luminosa. Isto implica na necessidade de equipamentos adicionais que não estão disponíveis para um usuário doméstico. Além disso, estas técnicas podem também necessitar de um ambiente com iluminação controlada.

Uma alternativa relativamente mais simples para a obtenção de um mapa de profundidade consiste no uso de técnicas baseadas no imageamento estéreo. $\mathrm{O}$ maior desafio para a aplicação do imageamento estéreo na construção de mapas de profundidade é a determinação dos pares de pontos $\left(I_{E}, I_{D}\right)$ presentes em um par de imagens estereoscópicas $\left(Q_{E}, Q_{D}\right)$ que correspondem a um mesmo ponto $P$ da cena observada naquelas imagens. Como, a princípio, não existe nenhuma informação adicional sobre a cena, esta busca deve ser efetuada sobre todos os pontos de $Q_{D}$ para cada ponto $I_{E}$ resultando em um algoritmo de aproximadamente $\mathrm{O}\left(\mathrm{N}^{4}\right)$ onde $\mathrm{N}$ é a largura ou altura das imagens (assumindo-se que as duas dimensões da imagem possuem a mesma ordem de grandeza). Uma maneira de limitar o espaço de busca consiste em se utilizar as relações da Geometria Epipolar, que são detalhadamente discutidas em Faugeras (1993) e apresentadas na próxima seção.

\subsubsection{Geometria Epipolar para Imageamento Estéreo}

Uma das técnicas apresentadas por Faugeras (1993) para auxiliar na construção de mapas de profundidade se baseia nas propriedades da linha epipolar e requer duas imagens da mesma cena obtidas de pontos de vista distintos. A configuração das câmeras deve ser tal que os seus eixos ópticos não sejam coincidentes e exista 
sobreposição dos campos de visão, isto é, existem pontos nas duas imagens que correspondem a um mesmo ponto da cena. A Figura 12 ilustra duas configurações de câmera que não satisfazem a estes requisitos. Na figura, cada câmera é representada pelo centro da lente e plano de imagem, usando as cores azul e vermelho. No caso (a) os eixos ópticos coincidem, enquanto no caso (b) não existe nenhuma região de sobreposição entre as imagens obtidas pelas duas câmeras.

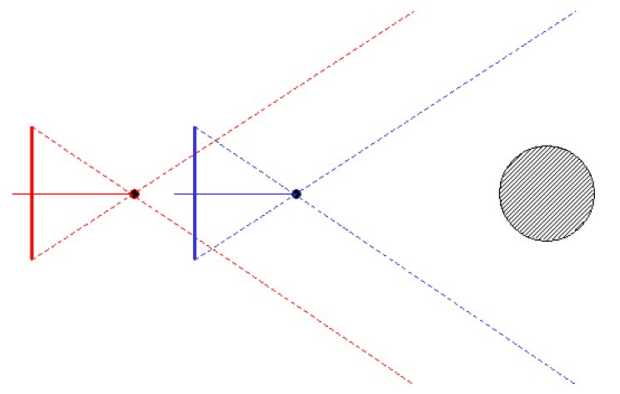

(a)

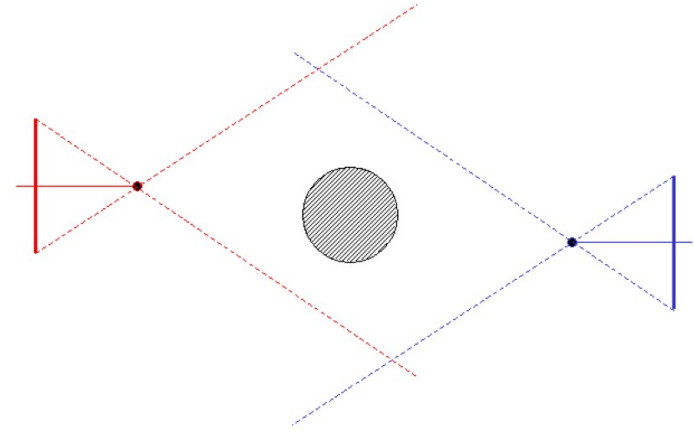

(b)

Figura 12 - Exemplos de configurações de câmera que não permitem o uso de relações da linha Epipolar. (a) Eixos ópticos coincidentes; (b) Não há sobreposição das imagens.

Outra técnica de geometria epipolar requer três imagens distintas com requisitos semelhantes aos descritos anteriormente e se baseia na determinação de uma entidade matemática denominada tensor tri-focal. Embora as técnicas envolvendo o tensor tri-focal sejam mais robustas, elas requerem mais equipamentos, calibração e processamento computacional. Por este motivo, não serão abordadas neste trabalho.

A teoria da linha epipolar auxilia a solução do problema ao reduzir o espaço de busca a somente uma linha da imagem. Em configurações específicas esta linha coincide com as linhas horizontais da imagem, como será explicado adiante. A Figura 13 ilustra a teoria da linha epipolar. Nesta figura, duas câmeras em posições e orientações arbitrárias observam um mesmo objeto. Para maior clareza, os planos de imagem foram desenhados à frente das câmeras. Dado um ponto I que é a projeção do ponto $\mathrm{P}$ na imagem observada pela câmera $\mathrm{C}$, o ponto I' correspondente na imagem observada pela câmera $C^{\prime}$ deve pertencer a uma reta definida pela interseção entre o plano de imagem de C' e o plano CC'P, que é coincidente com o plano CC'I. Esta reta é chamada de linha epipolar. Como C, C' e I são conhecidos, é possível calcular a linha epipolar e com isso restringir o espaço de busca aos pontos da imagem observada por C' que pertencem a esta reta. 


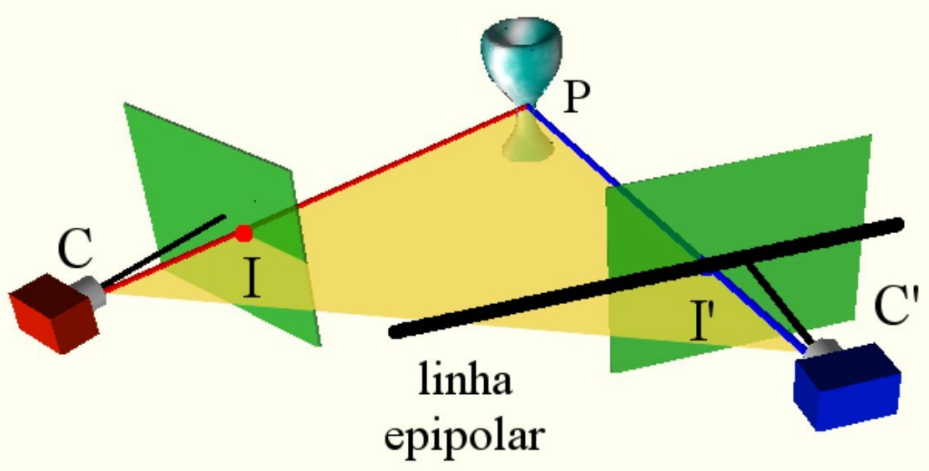

Figura 13 - Determinação da linha epipolar

Para o caso particular em que as câmeras C e C' se encontram com eixos ópticos paralelos e planos de imagem coincidentes, apresentando somente uma separação horizontal, isto é, a transformação entre seus sistemas de coordenadas corresponde a uma translação horizontal, as linhas epipolares são linhas horizontais paralelas. Neste caso, para um ponto I de coordenadas $\left(\mathrm{x}_{\mathrm{l}}, \mathrm{y}_{\mathrm{l}}\right)$, basta procurar o ponto I' correspondente na linha $y=y_{1}$ da imagem observada pela câmera $C^{\prime}$, conforme ilustrado pela Figura 14.

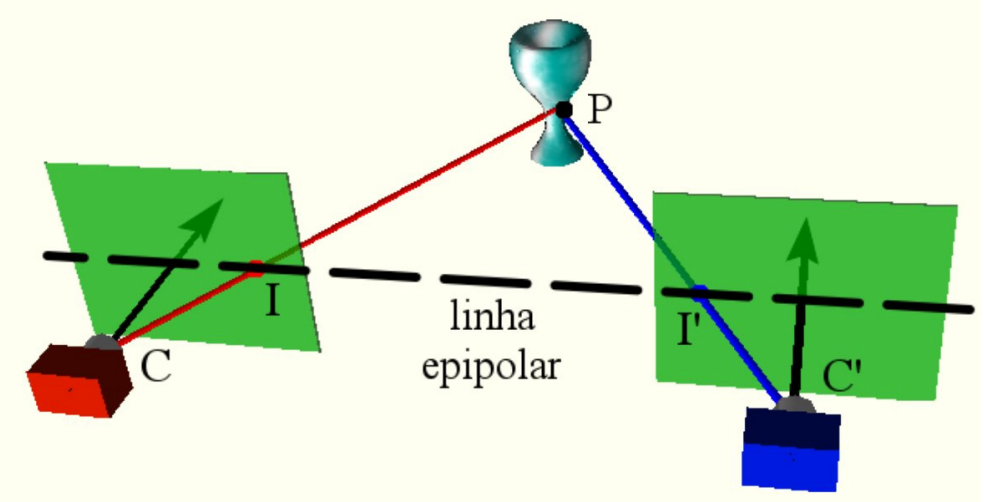

Figura 14 - Para câmeras com mesma orientação e somente translação horizontal, as linhas epipolares serão paralelas e horizontais

Esta configuração é conveniente porque torna desnecessário calcular a equação de cada linha epipolar e permite uma simples iteração sobre os pontos da imagem. Pode-se recorrer a uma técnica denominada retificação das imagens, explicada na próxima seção, para converter as imagens capturadas para esta configuração. 


\subsubsection{Retificação de Imagens}

O processo de retificação de duas imagens capturadas por câmeras distintas C e C' é ilustrado na Figura 15 e consiste, inicialmente, em determinar um novo plano de imagem $\gamma$ que corresponderia à configuração daquelas câmeras caso estivessem com suas lentes alinhadas e eixos ópticos paralelos. Em seguida, deve-se calcular a transformação de projeção do plano de imagem de cada câmera para este novo plano de imagem. Aplicando-se estas transformações sobre as imagens capturadas, obtém-se um novo par de imagens em que as linhas epipolares são paralelas e horizontais (FUSIELLO; TRUCCO; VERRI, 2000).

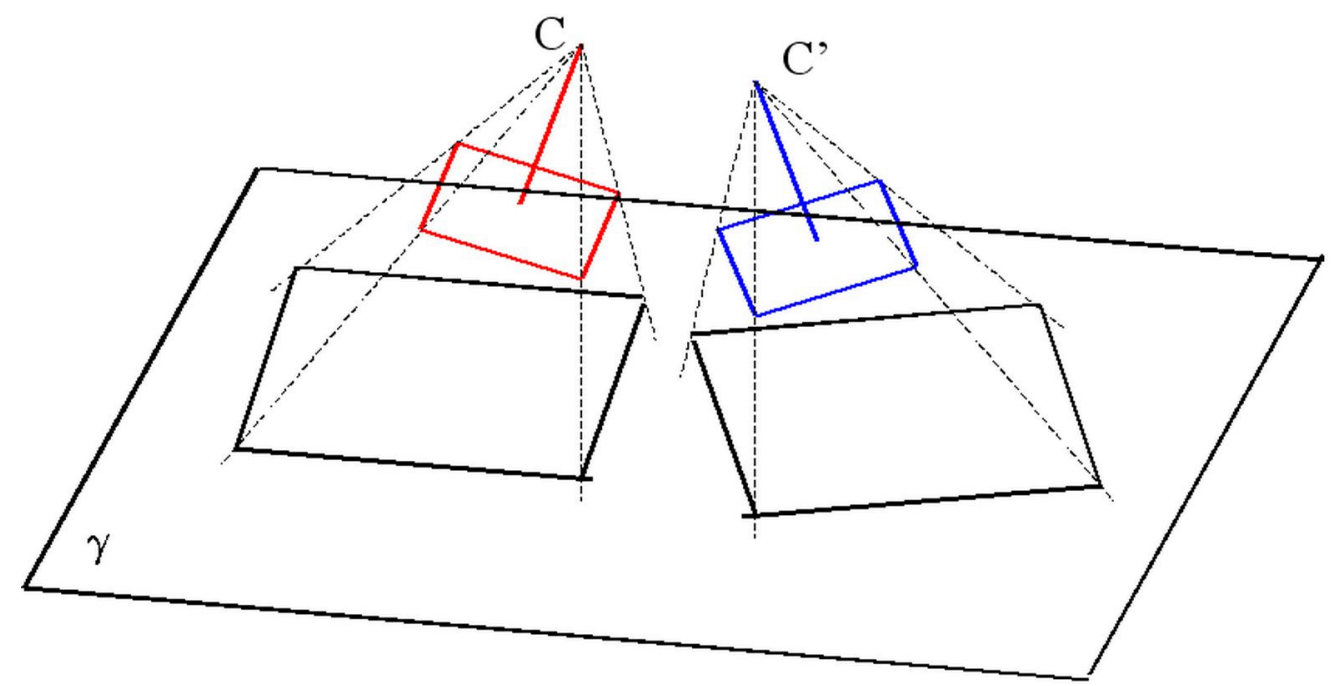

Figura 15 - llustração do processo de retificação de imagens obtidas a partir de um par de câmeras em uma configuração arbitrária

3.4.3 Determinação de pontos correspondentes em um par de imagens estereoscópicas

Dado um par de imagens estereoscópicas $Q_{E}$ e $Q_{D}$, existem diferentes abordagens para se determinar o ponto $I_{D}$ de $Q_{D}$ correspondente a um ponto $I_{E}$ de $Q_{E}$. Uma vez que esta relação seja conhecida, é possível calcular a disparidade entre $I_{E}$ e $I_{D} e$, com isso, a profundidade do ponto tridimensional correspondente. 
Scharstein e Szeliski (2002) apresentam uma taxonomia de algoritmos existentes para esta finalidade. Um dos critérios de classificação divide os algoritmos em dois grandes grupos:

- Algoritmos locais, que analisam informações de uma vizinhança finita de cada ponto no par de imagens para calcular uma estimativa de similaridade entre eles;

- Algoritmos globais, que definem funções baseadas em critérios de continuidade (dos objetos visíveis na cena) e calculam os valores do mapa de profundidade como a solução de um problema de otimização destas funções.

Segundo aqueles autores, os algoritmos globais tendem a gerar mapas de profundidade de melhor qualidade. No entanto, eles possuem limitações como a dificuldade em se definir uma função adequada para otimização e a sensibilidade dos resultados aos parâmetros do algoritmo de otimização. Adicionalmente, o tempo de execução destes algoritmos é várias ordens de grandeza maior do que os algoritmos locais (SCHARSTEIN; SZELISKI, 2002).

Os algoritmos locais definem uma função de discrepância $F(a, b)$ e, para cada ponto $I_{E}$ da imagem $Q_{E}$, buscam o ponto $I_{D}$ da imagem $Q_{D}$ que minimiza o valor desta função. No caso de imagens retificadas, basta realizar esta busca sobre a linha da imagem $Q_{D}$ de mesma coordenada vertical que $I_{E}$.

$$
\begin{gathered}
S D\left(I_{E}, I_{D}\right)=\left(I_{E}-I_{D}\right)^{2} \\
A D\left(I_{E}, I_{D}\right)=\left|I_{E}-I_{D}\right|
\end{gathered}
$$

As funções mais freqüentemente utilizadas, segundo Scharstein e Szeliski (2002) são o quadrado da diferença (eq. 7) e a diferença absoluta (eq. 8) entre os pontos das duas imagens. No caso de imagens com vários canais de cor, o cálculo é realizado para cada canal e agregado para se obter o valor total da discrepância.

Para se obter maior robustez na estimativa dos pontos correspondentes, os algoritmos locais normalmente agregam a função de discrepância sobre uma janela retangular de tamanho pré-definido (SCHARSTEIN; SZELISKI, 2002). 
3.4.4 Limitações dos algoritmos de mapa de profundidade baseados em imageamento estéreo

Como os algoritmos baseados em imageamento estéreo dependem de se determinar pontos correspondentes nas duas imagens de um par estereoscópico, falhas neste processo levam à construção de um mapa incorreto. Conseqüentemente, existem duas condições que são particularmente desfavoráveis para estes algoritmos (KANADE et al., 1996; SCHARSTEIN; SZELISKI, 2002):

- Oclusão entre elementos da cena. Regiões que sejam obstruídas somente em uma das imagens do par estereoscópico resultam em pontos cuja correspondência não pode ser determinada;

- Regiões da imagem sem textura. Conjuntos de pontos da imagem apresentando aproximadamente a mesma cor produzem valores similares da função de discrepância. A utilização de janelas de avaliação reduz este problema, mas ele persiste no caso de imagens com regiões sem textura de dimensões maiores do que a janela de avaliação.

Adicionalmente, técnicas baseadas em imageamento estéreo utilizando somente duas câmeras produzem uma reconstrução parcial da cena que, na área de visão computacional, é comumente denominada representação 2,5D. Este termo se refere ao fato de que uma representação tridimensional completa da cena não é obtida.

\subsection{Representação Visual do Vídeo-Avatar}

Existem diferentes abordagens para a representação visual de um vídeo-avatar. $\mathrm{Na}$ literatura, várias dessas abordagens são baseadas em técnicas de reconstrução geométrica. No entanto, também existem soluções que utilizam uma representação bidimensional.

Reconstrução geométrica é o nome dado ao processo de sintetizar uma representação geométrica tridimensional correspondente a objetos presentes em uma ou mais imagens capturadas através de fotografia ou vídeo. Existem muitas técnicas diferentes que utilizam inteligência artificial, reconhecimento de padrões etc. 
(DEBEVEC; TAYLOR; MALIK, 1996; HOIEM; EFROS; HERBERT, 2005). Entretanto, somente um conjunto limitado delas é viável em aplicações interativas. Dentre estas técnicas, duas são freqüentemente encontradas na literatura como soluções para a geração de um modelo geométrico para vídeo-avatar: Stereo-Vision Reconstruction e Vision-Based Visual Hull, que serão explicadas a seguir. No final da seção, serão discutidas as técnicas de representação bidimensional.

\subsubsection{Stereo-Vision Reconstruction}

As técnicas de Stereo-Vision Reconstruction se baseiam na geração de uma representação geométrica a partir de um mapa de profundidade obtido previamente. Chen et al. (2002) geram uma malha de triângulos interconectados cujos vértices são calculados a partir de informações do mapa de profundidade e de características ópticas da câmera. Dado um ponto da imagem com coordenadas (i, j) e profundidade $\mathrm{d}_{\mathrm{ij}}$, o ponto tridimensional correspondente $\left(\mathrm{x}_{\mathrm{ij}}, \mathrm{y}_{\mathrm{ij}}, \mathrm{z}_{\mathrm{ij}}\right)$ é dado pelas eq.(9), eq.(10) e eq.(11). Nestas equações, $\alpha$ e $\beta$ correspondem à metade da abertura angular horizontal e vertical da câmera, respectivamente. W e H são as dimensões da imagem capturada pela câmera, em pixels. Uma vez que a malha triangular é sintetizada, a imagem original é mapeada como uma textura de forma que os pixels da imagem sejam aplicados nos vértices correspondentes. A Figura 16 ilustra este processo.

$$
\begin{gathered}
x_{i j}=d_{i j} \cdot \tan \alpha \cdot \frac{i-W / 2}{W / 2} \\
y_{i j}=d_{i j} \cdot \tan \beta \cdot \frac{H / 2-j}{H / 2} \\
z_{i j}=d_{i j}
\end{gathered}
$$




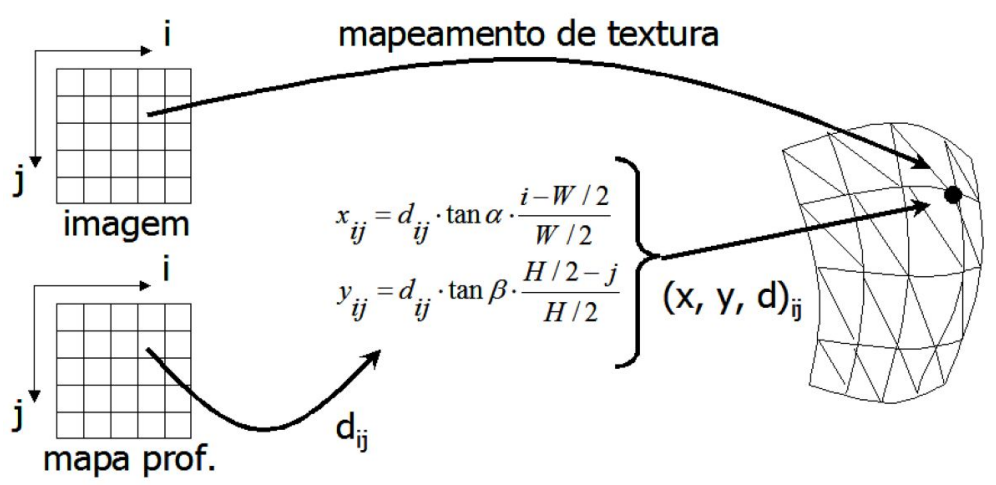

Figura 16 - Reconstrução a partir do mapa de profundidade

Como se pode esperar, a partir de um par de imagens de um objeto, somente é possível reconstruir uma malha geométrica parcial do mesmo. Tamagawa et al. (2001) utilizam uma abordagem que envolve múltiplos pares de câmeras distribuídos ao redor do objeto de interesse para que várias representações parciais do objeto sejam criadas. Durante a execução do sistema, a representação mais próxima do ponto de vista atual do usuário é selecionada.

\subsubsection{Vision-Based Visual Hull}

Outras técnicas de reconstrução geométrica se baseiam na geração de uma representação volumétrica aproximada dos objetos capturados em um conjunto de imagens, denominada visual hull. A definição formal e as propriedades dos visual hulls podem ser encontradas em Laurentini (1994).

Matusik et al. (2000) descrevem uma maneira de construir o visual hull de um objeto a partir de um conjunto de imagens do mesmo. Inicialmente, a silhueta do objeto de interesse precisa ser identificada em cada uma das imagens, o que requer técnicas de processamento de imagens apropriadas de acordo com a aplicação. As silhuetas resultantes são regiões fechadas contendo o contorno do objeto de interesse em cada imagem. A partir destas silhuetas, são gerados volumes cônicos com vértice na posição da câmera, como ilustrado na Figura 17. O visual hull é obtido a partir da interseção entre estes volumes, conforme a Figura 18. Magnor (2005) faz uma revisão de outras técnicas para a construção de vision-based visual hulls. 


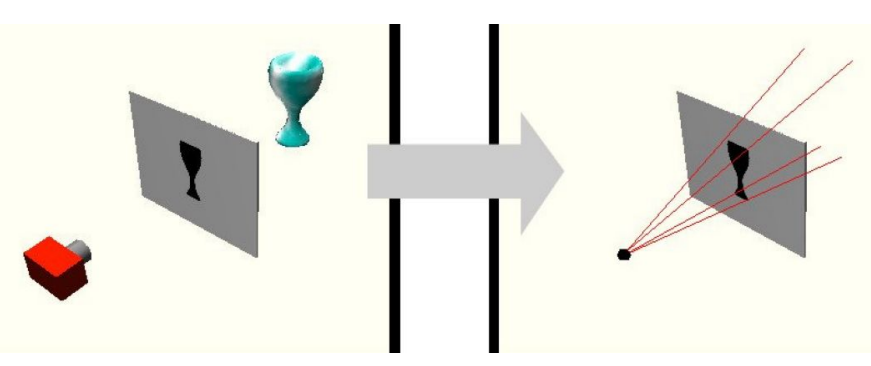

Figura 17 - Geração de um volume cônico a partir da silhueta

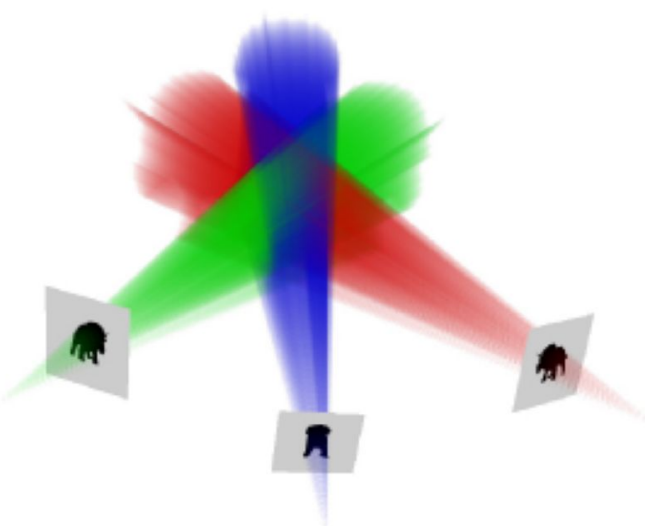

Figura 18 - Construção do visual hull (MATUSIK et al., 2000)

É importante notar que, depois que a representação volumétrica do visual hull foi obtida, em geral é preciso fazer a conversão para uma representação poligonal ou em forma de nuvem de pontos para permitir a sua renderização. Adicionalmente, a qualidade do visual hull depende da quantidade de câmeras utilizadas, o que por sua vez acrescenta um requisito estrito de sincronização entre as câmeras, pois a utilização de silhuetas obtidas em instantes de tempo muito diferentes resultará em perda de qualidade nos resultados. Por fim, o mapeamento das imagens capturadas sobre a representação geométrica construída é um problema que ainda tem levado a pesquisas por métodos mais eficientes (MATUSIK et al., 2000; PRINCE et al., 2002).

\subsubsection{Representações Bidimensionais do Vídeo-Avatar}

Uma alternativa às abordagens de reconstrução geométrica para visualização do vídeo-avatar consiste em utilizar uma representação bidimensional do mesmo através da técnica de Billboard. Em Computação Gráfica, a técnica de Billboard consiste em definir um modelo geométrico plano e aplicar a imagem de um objeto 
como textura sobre ele. A orientação do modelo é mantida de tal forma que o plano que o contém fique perpendicular à direção de visualização (MÖLLER; HAINES, 2002; WATT, 2000). Siscoutto (2003) emprega esta técnica em seu sistema de vídeo-avatar.

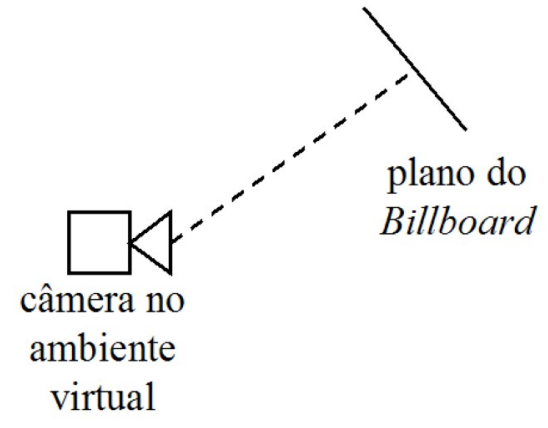

(a)

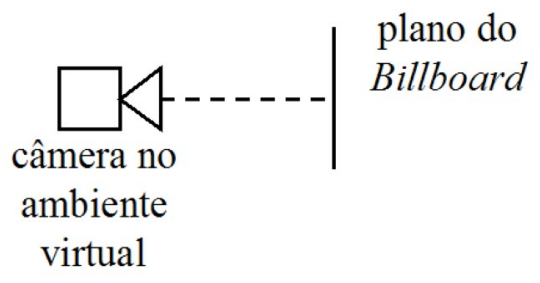

(b)

Figura 19 - Exemplos de configurações de billboard, em vista superior. (a) Configuração arbitrária, ilustrando a orientação do plano do billboard; (b) Configuração em que o plano do billboard fica paralelo ao plano de imagem.

Um caso particular da técnica de billboard consiste na situação em que o modelo geométrico é posicionado de forma a ficar paralelo ao plano de imagem. A Figura 19(a) ilustra uma configuração genérica de billboard e a Figura 19(b) ilustra este caso. Nesta situação, pode-se simplesmente renderizar a imagem do vídeo-avatar diretamente, sem a necessidade de projetá-la sobre um modelo geométrico. Em algumas aplicações, tais como jogos do EyeToy (EYETOY, 2008) a imagem do vídeo-avatar é renderizada com uma inversão no eixo vertical, de forma a simular um "espelho" para a interação do usuário.

\subsection{Detecção de Colisão em Ambientes Virtuais}

A necessidade de se detectar a ocorrência de uma colisão entre dois objetos ou modelos geométricos é comum a muitos projetos de jogos computacionais, realidade virtual e realidade aumentada. Os problemas de detecção de colisão podem ser divididos em duas categorias amplas: detectar a ocorrência de todas as colisões entre um conjunto de objetos e detectar a ocorrência de colisões entre dois objetos conhecidos. Cada uma destas categorias possui algoritmos apropriados para a sua solução (LIN; GOTTSCHALK, 1998). A interação de um vídeo-avatar em um 
ambiente virtual consiste em um problema do primeiro tipo. No restante desta seção, o termo "detecção de colisão" será usado para se referir a esse tipo de problema.

A abordagem trivial para a solução de problemas de detecção de colisão corresponde a fazer testes de interseção entre as representações geométricas dos objetos envolvidos. O número de testes necessários é proporcional ao quadrado do número de objetos a serem testados. Se os objetos forem representados por malhas poligonais, cada teste de interseção envolve comparações entre os polígonos dos dois objetos, aumentando a complexidade do algoritmo. Desta forma, essa abordagem resulta em algoritmos de, no mínimo, complexidade quadrática, ou $\mathrm{O}\left(\mathrm{N}^{2}\right)$ onde $\mathrm{N}$ é o número de objetos. Por estes motivos, existem muitas pesquisas que buscam obter soluções menos complexas para o problema.

Entre as técnicas propostas para a solução eficiente de problemas de detecção de colisão, pode-se citar a utilização da coerência espacial-temporal em simulações envolvendo vários objetos, para reduzir o número de cálculos realizados a cada passo da simulação; o particionamento do espaço de forma a eliminar testes entre objetos que estejam muito distantes e a utilização de modelos simplificados em lugar de objetos com geometria mais complexa para realizar testes rápidos de interseção. Se, por um lado, pesquisadores ligados às áreas de simulação e realidade virtual apresentam várias soluções completas e precisas para a detecção de colisão (COHEN et al., 1995; CHUNG; WANG, 1996), por outro lado os pesquisadores e desenvolvedores de jogos computacionais apresentam soluções aproximadas que reduzem a precisão dos resultados em troca de menor custo de processamento e maior velocidade (EBERLY, 2001; ERICSON, 2004).

Uma abordagem para a detecção aproximada de colisões entre objetos consiste no uso de octrees como modelo para representação de tais objetos (GARCIA; CORRE, 1989; HUBBARD, 1995; NASCIMENTO et al., 2000). Uma octree é uma estrutura de dados hierárquica que pode ser utilizada para construir uma representação volumétrica aproximada de objetos tridimensionais convexos (ERICSON, 2004). O nome desta estrutura se deve ao fato de que ela é organizada como uma árvore, onde cada nó possui oito filhos. A raiz da árvore representa um volume finito do espaço. Este volume é subdividido através de três planos perpendiculares, gerando oito novos volumes, que são representados por seus filhos. O processo continua recursivamente até uma profundidade máxima pré-determinada. A Figura 20 ilustra este processo. 


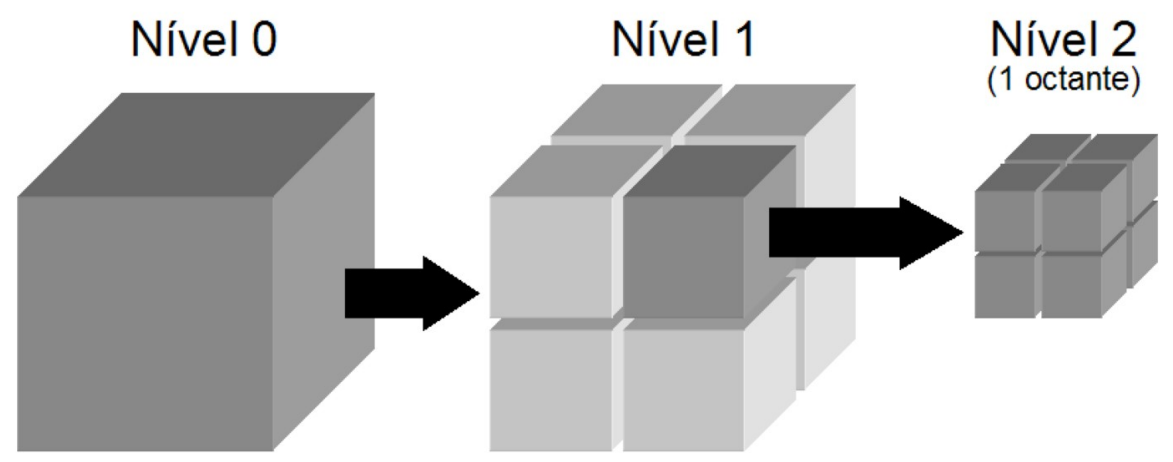

Figura 20 - Subdivisão do espaço através de uma octree.

Os nós terminais (folhas) de uma octree representam áreas do espaço totalmente preenchidas pelo objeto que está sendo representado. Nós internos (com filhos) representam regiões pelo menos parcialmente preenchidas pelo objeto.

A resolução do modelo de colisão gerado por uma octree depende diretamente de sua profundidade máxima. As folhas do nível mais profundo de uma octree de $\mathrm{N}$ níveis correspondem a volumes cujas dimensões são iguais a $1 /\left(2^{\mathrm{N}-1}\right)$ das dimensões do volume representado pela raiz da octree. Desta forma, um volume cúbico de lado $\mathrm{L}$ representado por uma octree de $\mathrm{N}$ níveis será particionado em volumes cúbicos de dimensões $L_{o}$ dadas pela eq.(12). No caso de um volume na forma de um paralelepípedo, esta equação também pode ser aplicada, para cada uma das suas dimensões (largura, altura e comprimento).

$$
L_{O}=\frac{L}{2^{N-1}}
$$

A detecção de colisão entre uma octree e um volume $V$ representando outro objeto do ambiente virtual é realizada testando-se recursivamente a interseção entre $V$ e os volumes de cada nível da octree, enquanto forem detectadas interseções. Se uma colisão for detectada com um nó terminal (folha), conclui-se que ocorreu uma colisão, dentro da resolução da octree. A Figura 21 ilustra dois testes de colisão. Neste caso, utiliza-se uma quadtree, que é uma estrutura de dados análoga para duas dimensões, para melhor visualização. No caso (a), uma colisão é detectada nos primeiros dois níveis da árvore, mas não nos nós terminais, de forma que nenhuma colisão é reportada. No caso (b), uma colisão é encontrada no último nível da árvore, indicando uma colisão entre os objetos. 


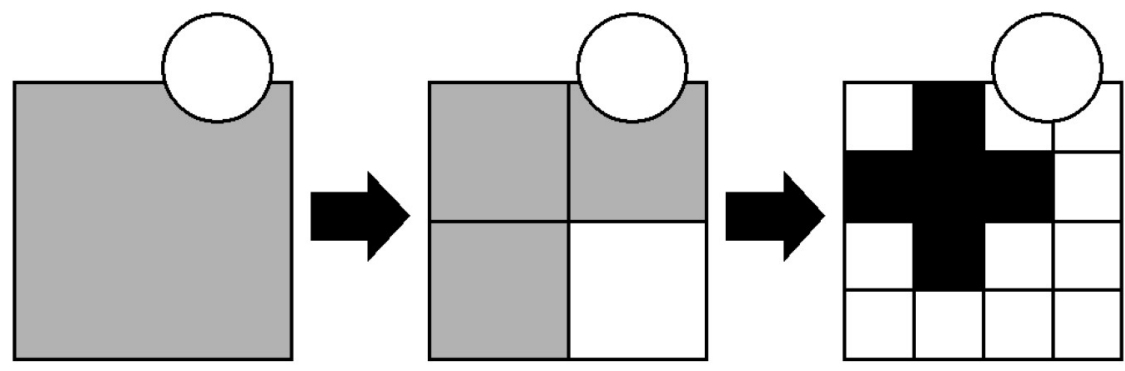

(a)
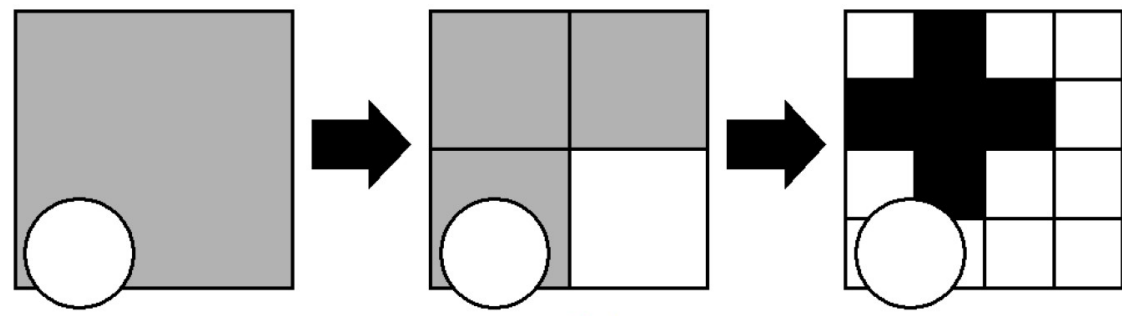

(b)

Figura 21 - Testes de colisão com uma quadtree. (a) Não ocorre colisão; (b) Colisão é detectada.

Pode-se utilizar esferas para representar o volume de cada nó da octree (NASCIMENTO et al., 2000). Neste caso, utilizam-se esferas de diâmetro igual à maior diagonal do paralelepípedo correspondente ao volume do nó. A vantagem de se utilizar esferas é que o teste de interseção com outros volumes é mais simples e computacionalmente menos custoso. Por outro lado, o volume ocupado pela esfera é maior do que o volume representado pelo nó da octree, o que pode levar a falsos resultados.

\subsection{Considerações Finais}

Neste capítulo foram apresentadas técnicas relacionadas ao projeto de sistemas de vídeo-avatar, incluindo a obtenção de um mapa de profundidade, métodos de exibição e detecção de colisão com o ambiente virtual.

$\mathrm{Na}$ proposta desta tese, a obtenção de um mapa de profundidade da imagem do vídeo-avatar é importante para permitir a detecção de colisão entre o vídeo-avatar e outros objetos do ambiente virtual.

As técnicas de reconstrução geométrica, que podem ser utilizadas para criar uma representação visual do vídeo-avatar, foram detalhadas. Embora a proposta desta 
tese utilize uma representação visual bidimensional, sua exposição é necessária para a análise e comparação com outros sistemas de vídeo-avatar no próximo capítulo. 


\section{Análise Comparativa de Sistemas de Vídeo-Avatar}

Neste capítulo são apresentados e discutidos trabalhos de pesquisa e projetos que se assemelham, ao menos em parte, à proposta desta tese. A análise se inicia com o sistema AVTC, que precede esta tese no mesmo grupo de pesquisa, passando aos sistemas de vídeo-avatar tridimensional e finalmente às outras soluções bidimensionais. No final do capítulo, uma análise comparativa desses trabalhos é apresentada, com relação aos requisitos deste projeto.

\subsection{AVTC - Ambiente Virtual para Teleconferência}

O projeto do Ambiente Virtual para Teleconferência (AVTC) teve como objetivo desenvolver uma arquitetura para teleconferência que incluía um vídeo-avatar estereoscópico dentro de um ambiente virtual (SISCOUTTO, 2003). No AVTC, duas câmeras de vídeo são utilizadas para se obter um par estereoscópico de imagens, que são utilizadas para a visualização do vídeo-avatar.

Inicialmente, o fundo das imagens capturadas é removido por meio de um algoritmo de chroma-key, o que requer o uso de um plano de fundo de cor uniforme e conhecida. A imagem resultante é mapeada como uma textura com fundo transparente sobre uma superfície retangular plana, que é renderizada dentro do ambiente virtual. O sistema AVTC permite a renderização de um par estereoscópico de imagens do ambiente virtual; neste caso, as texturas obtidas a partir das duas câmeras são utilizadas de forma síncrona com a geração das imagens.

Dado que o objetivo de Siscoutto (2003) era propor uma arquitetura completa para teleconferência, uma parte significativa de seu trabalho foi dedicada a analisar aspectos de interface de usuário e comunicação em rede. Isto incluiu a proposta de dispositivos para permitir a locomoção do usuário no ambiente virtual e o estudo de protocolos de transmissão de vídeo.

O vídeo-avatar proposto naquele trabalho empregou de forma inovadora o efeito estereoscópico para aumentar a sensação de profundidade e volume do vídeoavatar, sem a necessidade de técnicas de reconstrução geométrica. Por outro lado, 
a interação do vídeo-avatar com o ambiente virtual se limitava à detecção de colisão de um volume envoltório com outros objetos, para permitir a movimentação pelo ambiente.

\subsection{D-Live}

O projeto 3D-Live, descrito por Prince et al. (2002) é um sistema de videoconferência utilizando realidade aumentada. Neste sistema são utilizadas 14 câmeras de vídeo digitais distribuídas ao redor do usuário, além de uma posicionada acima dele. Três computadores dual Pentium III de $1 \mathrm{GHz}$ são utilizados para processar as imagens capturadas pelas câmeras e gerar um vídeo-avatar através de técnicas de visionbased visual hull.

O vídeo-avatar obtido é visualizado por outros usuários através de HMDs (HeadMounted Displays) opacos, apresentado sobre marcadores fiduciais existentes no ambiente. Tais marcadores podem ser manipulados e o sistema é capaz de sintetizar a imagem do vídeo-avatar sob pontos de vista diferentes em tempo real, combinando informações das imagens de vídeo. A Figura 22 apresenta um exemplo de execução deste sistema.

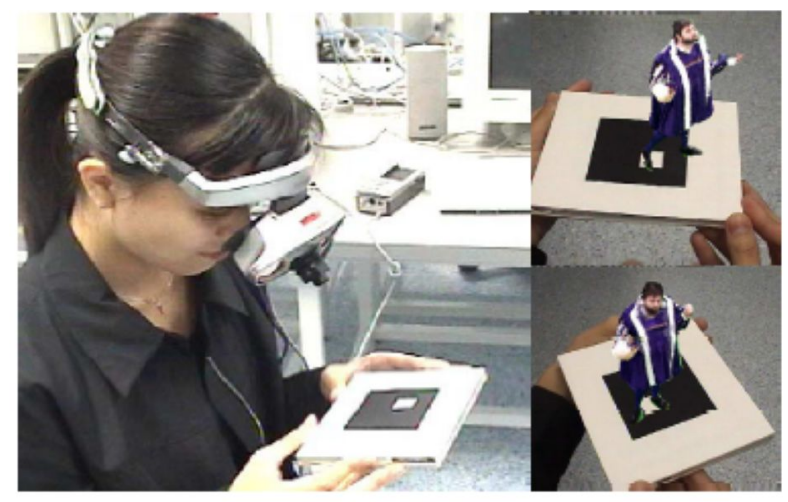

Figura 22 - Vídeo-avatar do sistema 3D-Live (PRINCE et al., 2002)

O sistema 3D-Live produz um vídeo-avatar de alta qualidade e este projeto, assim como o sistema MXRToolkit (NGUYEN et al., 2005) que evoluiu a partir dele, podem ser considerados exemplos do estado da arte atual na geração de vídeo-avatares. 


\subsection{Blue-C}

O sistema Blue-C descrito por Naef, Staadt e Gross (2004) consiste em um conjunto de bibliotecas de programação, além de uma plataforma de hardware específica para otimizar processos de aquisição de vídeo para a geração de vídeo-avatares. O objetivo do Blue-C é oferecer uma plataforma integrada para o desenvolvimento de aplicações envolvendo realidade virtual, realidade aumentada e multimídia.

Da mesma forma que o sistema 3D-Live analisado anteriormente, o Blue-C também constrói vídeo-avatares através de técnicas de vision-based visual hull, o que implica na utilização de grande quantidade de câmeras. No caso do Blue-C, um vídeoavatar é armazenado como uma nuvem de pontos no espaço. A sua renderização é feita através de uma técnica denominada "splat rendering", em que cada ponto da nuvem é representado por um quadrilátero de tamanho variável com uma textura elíptica de cor determinada pelas imagens capturadas do vídeo (NAEF; STAADT; GROSS, 2004).

\subsection{ITS - Immersive Telecommunication System}

Da mesma forma que o 3D-Live e o Blue-C, o sistema proposto por Lee et al. (2005) utiliza técnicas de vision-based visual hull para construir um vídeo-avatar de alta qualidade visual. Neste caso, o objetivo é desenvolver um sistema de teleconferência integrando ambientes de CAVE (Cave Automatic Virtual Environment). Um diferencial deste projeto é que as imagens utilizadas para construção do visual hull são capturadas com filtros de infravermelho e a utilização de fontes de iluminação apropriadas.

O sistema ITS também prevê a interação tridimensional do vídeo-avatar através de uma composição de diferentes técnicas. O modelo tridimensional baseado em visual hull é processado para se obter a posição relativa dos braços e demais partes do corpo do usuário. Estas informações são utilizadas para a realização de comandos de interação. Ao mesmo tempo, uma malha poligonal é construída a partir do visual hull para a detecção de colisão com outros objetos. 


\subsection{AR-Soccer}

Paelke, Reiman e Stichling (2004) propõem o jogo AR-Soccer mostrado na Figura 23, envolvendo a aplicação de Realidade Aumentada em um dispositivo móvel, como por exemplo um computador de mão, com uma câmera de vídeo acoplada.

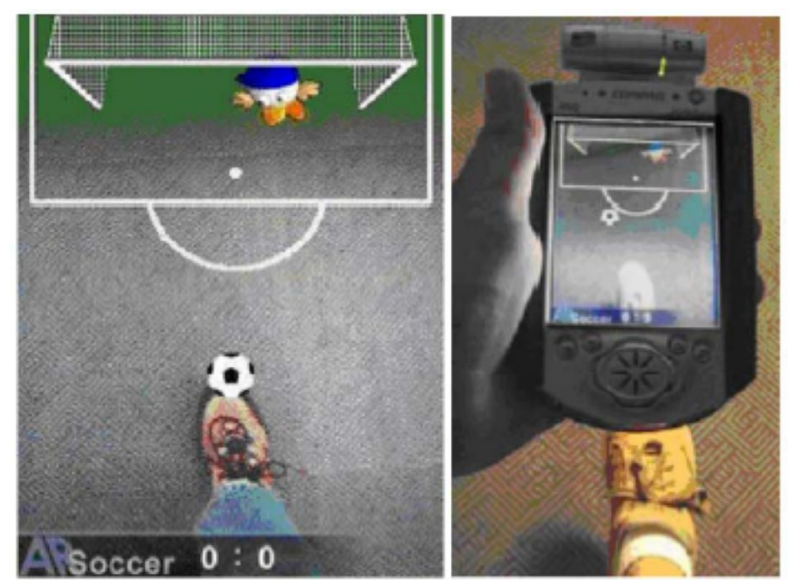

Figura 23 - O jogo AR-Soccer (PAELKE; REIMAN; STICHLING, 2004)

No AR-Soccer, o vídeo-avatar consiste na imagem do pé do usuário, que deve chutar uma bola virtual. Como os objetos virtuais são renderizados sobre a imagem do mundo real, não é preciso reconstruir o vídeo-avatar. Para realizar a interação entre o pé e os elementos virtuais, são utilizadas técnicas de processamento de imagens para a detecção do contorno do pé na imagem digitalizada.

\subsection{EyeToy}

O EyeToy (EYETOY, 2008) é um produto desenvolvido pela empresa Sony para utilização com o console de jogos Playstation 2. Ele consiste em uma câmera de vídeo digital similar às webcams utilizadas para videoconferência em computadores pessoais, conectada ao console através de uma porta USB. A câmera é colocada sobre o aparelho televisor ao qual o console está conectado e o jogador se posiciona à frente deste arranjo. 

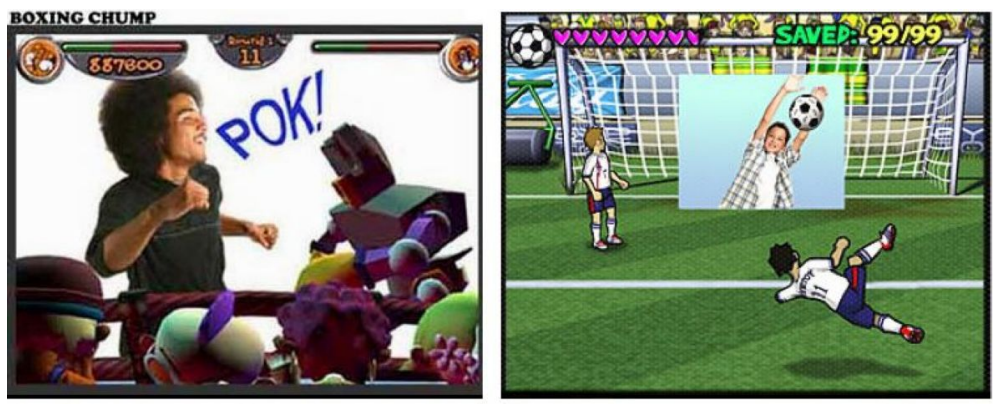

Figura 24 - Jogos do EyeToy (EYETOY, 2008)

Desenvolvedores de jogos para o console têm acesso a uma biblioteca proprietária de programação, que fornece recursos para comunicação com a câmera e algoritmos de processamento de imagens para a criação de jogos que utilizem a imagem do jogador capturada em vídeo. A Figura 24 apresenta imagens de dois jogos que utilizam este dispositivo.

\subsection{Kick-Ass Kung Fu}

O projeto Kick-Ass Kung Fu descrito por Hämäläinen et al. (2005) consiste em uma plataforma de realidade aumentada que serve tanto para entretenimento como ferramenta de treinamento para artes marciais.

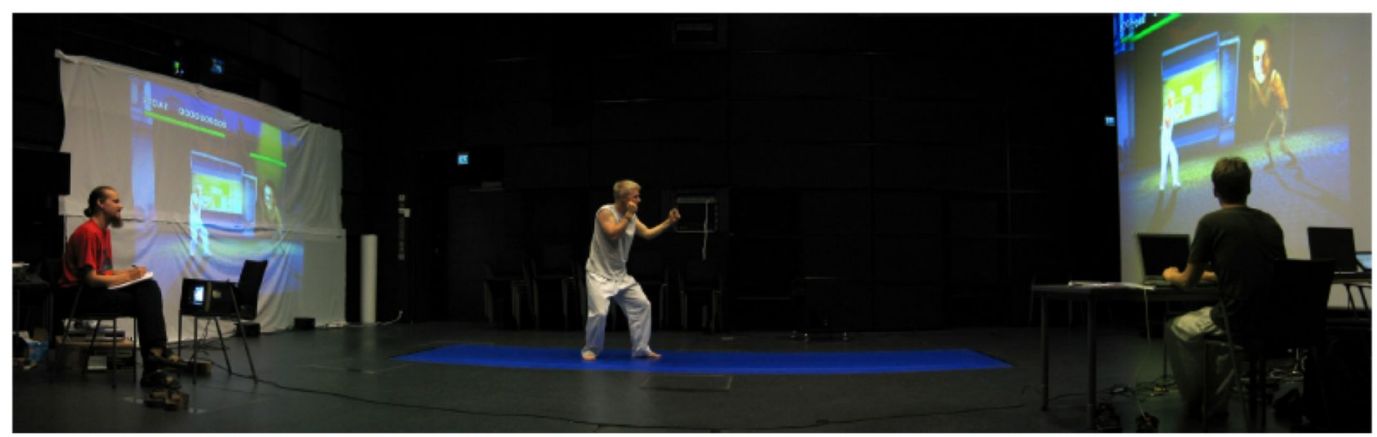

Figura 25 - Arranjo do projeto Kick-Ass Kung Fu (HÄMÄLÄINEN et al., 2005)

Neste caso, a pesquisa parece voltada mais para o estudo da interface homemcomputador envolvida neste tipo de aplicação. Ainda assim, é possível analisar a tecnologia de vídeo-avatar adotada. Como no EyeToy, o vídeo-avatar utilizado neste projeto é bidimensional, obtido a partir da segmentação da imagem do usuário capturada por uma única câmera digital de vídeo. Diferentemente do EyeToy, neste caso são utilizadas duas telas de projeção, na frente e atrás do usuário e a câmera é colocada em uma orientação perpendicular a estas telas. Desta forma, o usuário 
pode ver a sua imagem de perfil enquanto pratica seus movimentos em um cenário virtual, conforme a Figura 25.

\subsection{Z-Cam}

No momento da escrita desta tese, o sistema Z-Cam está em desenvolvimento pela empresa 3DV Systems (3DV SYSTEMS, 2008). A proposta desse produto é similar à desta tese: prover um sistema de vídeo-avatar com interação tridimensional, para uso doméstico, em aplicações de entretenimento.

A solução adotada neste caso envolve uma técnica baseada na emissão de pulsos controlados de luz e medição da quantidade de luz refletida pelos objetos da cena em um curto intervalo de tempo (da ordem de nanossegundos). Neste caso, a quantidade de luz captada pela câmera é inversamente proporcional à distância dos objetos (GVILI et al., 2003).

O Z-Cam utiliza uma fonte de luz infravermelha para emitir os pulsos de luz, de forma a reduzir a interferência da luz ambiente. Adicionalmente, a implementação desta técnica requer uma câmera digital com sensor de alta sensibilidade, e um sistema obturador capaz de atuar com a velocidade requerida para a amostragem dos pulsos de luz. Um protótipo deste dispositivo, fornecido pelo fabricante, era capaz de produzir mapas de profundidade em resolução de 160×120 pixels a taxas de 60 quadros por segundo e 320x240 pixels a 30 quadros por segundo.

\subsection{Considerações Finais}

Neste capítulo foram apresentados projetos que representam o estado da arte na geração de vídeo-avatares para aplicações de Realidade Aumentada, bem como outros projetos que possuem alguma relação com a proposta desta tese. A Tabela 1 contém um quadro comparativo dos trabalhos apresentados neste capítulo, quanto a diferentes aspectos, baseados nos requisitos do projeto desta tese. Não foi possível 
analisar a taxa de atualização dos vídeo-avatares, pois esta informação não foi encontrada nas referências existentes.

Tabela 1 - Comparação de trabalhos relacionados.

\begin{tabular}{|c|r|r|c|c|c|}
\hline Sistema & $\begin{array}{c}\text { Número } \\
\text { de } \\
\text { câmeras }\end{array}$ & $\begin{array}{c}\text { Número de } \\
\text { computadores }\end{array}$ & $\begin{array}{c}\text { Arranjo } \\
\text { portátil }\end{array}$ & $\begin{array}{c}\text { Modelo visual } \\
\text { do vídeo- } \\
\text { avatar }\end{array}$ & $\begin{array}{c}\text { Tipo de } \\
\text { Interação }\end{array}$ \\
\hline AVTC & 2 & 1 & $\operatorname{sim}$ & $2 \mathrm{D}$ & $\begin{array}{c}\text { colisão 3D com o } \\
\text { ambiente virtual }\end{array}$ \\
\hline 3D-Live & 14 & 3 & não & 3D & N/A \\
\hline Blue-C & 3 ou mais & 1 ou mais & não & 3D & N/A \\
\hline ITS & 3 ou mais & 4 & não & 3D & 3D \\
\hline AR Soccer & 1 & 1 & sim & 2D & 2D \\
\hline EyeToy & 1 & 1 & sim & 2D & 2D \\
\hline $\begin{array}{c}\text { Kick-Ass } \\
\text { Kung-fu }\end{array}$ & 1 & 1 & não & 2D & 2D \\
\hline Z-Cam & 2 & 1 & sim & 2D & 3D \\
\hline
\end{tabular}

Como se pode observar, poucos sistemas podem ser facilmente transportados e permitem interação tridimensional com objetos do ambiente virtual. Adicionalmente, os sistemas que produzem um vídeo-avatar tridimensional necessitam de múltiplas câmeras e computadores.

Pode-se dizer que esta tese busca um aprimoramento das técnicas de vídeo-avatar propostas por Siscoutto (2003) no sistema AVTC. Da mesma forma que aquele trabalho, procura-se seguir na busca de soluções com menores requisitos de hardware e processamento. No entanto, em vez de utilizar as técnicas de estereoscopia, neste trabalho pretende-se explorar a construção de um vídeo-avatar utilizando técnicas de mapeamento de profundidade.

Comparado com a proposta e os objetivos desta tese, o sistema 3D-Live apresenta requisitos de hardware e processamento elevados para uma implementação de baixo custo monetário. Da mesma forma, a necessidade de uma montagem envolvendo grande número de câmeras ao redor do usuário torna a utilização de um sistema como este inviável em ambientes domésticos. O escopo do sistema Blue-C é notavelmente maior do que o desta tese. Enquanto o foco deste trabalho é a inclusão de um vídeo-avatar de baixo custo em ambientes virtuais, o Blue-C procura fornecer uma solução completa para o desenvolvimento de aplicações envolvendo vídeo-avatares e outros recursos.

Os objetivos deste trabalho se assemelham aos dos sistemas EyeToy e Kick Ass Kung Fu, com relação à busca de uma solução de baixo custo para incorporar vídeoavatares a jogos computacionais. Da mesma forma que o EyeToy, este trabalho 
também assume a hipótese que o vídeo-avatar será visualizado somente do mesmo ponto de vista da câmera. Entretanto, enquanto o vídeo-avatar gerado pelo EyeToy e pelo Kick Ass Kung Fu é bidimensional, a proposta desta tese é de incorporar informações de profundidade à imagem capturada, para que se obtenha um vídeoavatar tridimensional.

Por fim, o projeto Z-Cam se assemelha, em seus objetivos, à proposta deste trabalho e a solução empregada naquele projeto é a que melhor satisfaz os requisitos propostos, entre os sistemas analisados. No entanto, tal solução depende, inerentemente, de um equipamento específico e de tecnologia proprietária, o que impede a sua utilização com equipamentos domésticos. 


\section{Inovações Tecnológicas Propostas para Vídeo-Avatar de Baixo Custo}

Este capítulo apresenta as técnicas propostas para viabilizar um sistema de vídeoavatar que atenda aos requisitos de projeto discutidos na seção 1.3 e que são contribuições desta tese. Para permitir a interação em três dimensões, é preciso recuperar informações de profundidade relativas à imagem do vídeo-avatar - ou seja, calcular seu mapa de profundidade. Nesta tese, propõe-se o uso de um algoritmo baseado em imageamento estéreo que é detalhado na primeira seção deste capítulo. A partir destas informações, é preciso estabelecer um modelo de colisão para o vídeo-avatar que possa ser utilizado em tempo real. Propõe-se a utilização de um modelo baseado em octree, que é descrito em seguida. Por fim, os resultados de testes realizados para avaliar o desempenho das técnicas propostas também são apresentados neste capítulo.

\subsection{Proposta do Vídeo-Avatar}

O vídeo-avatar proposto utiliza a mesma abordagem de visualização apresentada por Siscoutto (2003). Aquele autor já demonstrou a viabilidade de um vídeo-avatar com representação bidimensional e visualização estereoscópica utilizando-se um computador pessoal e duas câmeras de vídeo domésticas. No entanto, o presente trabalho se propõe a expandir a funcionalidade daquele vídeo-avatar, acrescentando a capacidade de interação em três dimensões, dentro dos requisitos de projeto apresentados no capítulo 1.

Da mesma forma que o sistema apresentado por Siscoutto (2003), o vídeo-avatar aqui proposto pressupõe uma configuração de câmeras de vídeo previamente calibrada e que permanece fixa durante a utilização do sistema. Um exemplo de arranjo para a utilização de um sistema com o vídeo-avatar proposto é apresentado na Figura 26 em vista superior. 


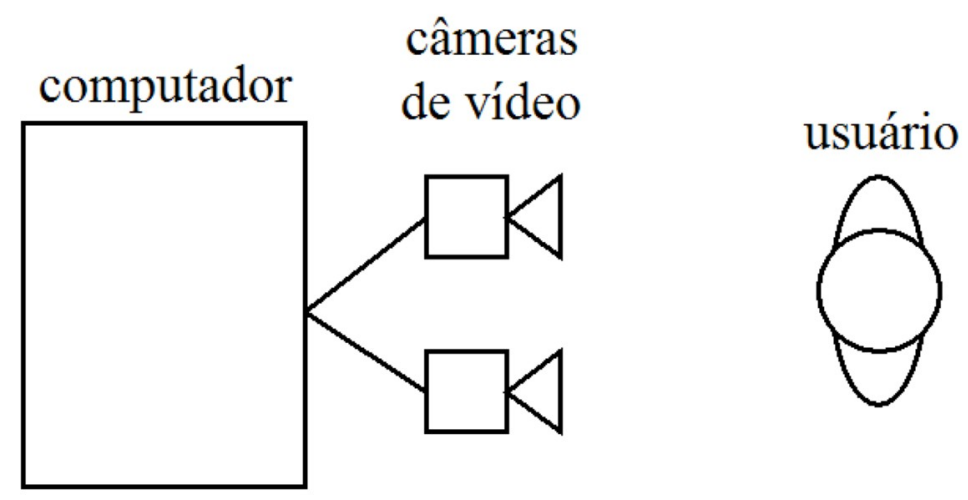

Figura 26 - Diagrama ilustrando a configuração de equipamentos para utilização do vídeo-avatar proposto neste trabalho

Uma conseqüência da utilização do arranjo apresentado na Figura 26 é o fato de que o vídeo-avatar somente contém informação sobre a vista frontal do usuário. Aplicações deste vídeo-avatar podem empregar as técnicas de câmera e navegação propostas por Siscoutto (2003) para a inserção do vídeo-avatar em um ambiente virtual. Considerando-se a utilização do presente sistema em aplicações domésticas, em que sistemas de visualização estereoscópica ainda não são comuns, o vídeoavatar desta tese pode ser apresentado tanto em visão monoscópica como estereoscópica.

Uma alternativa não explorada por Siscoutto (2003), mas observada em outros sistemas como o EyeToy (2008) consiste na exibição da imagem do vídeo-avatar com uma transformação geométrica de espelhamento horizontal. Dada uma imagem Q, sua imagem Q' com espelhamento horizontal é dada pela aplicação da eq.(13) sobre os pontos de $\mathrm{Q}$, onde $\mathrm{W}$ é a largura da imagem $\mathrm{Q}$ em pixels.

$$
Q^{\prime}(x, y)=Q(W-1-x, y)
$$

Como o nome implica, a imagem da câmera apresentada sob esta transformação permite que o usuário se observe como se estivesse diante de um espelho. Este recurso pode ser empregado para a construção de interfaces intuitivas para jogos computacionais e outras aplicações. 


\subsection{Mapa de Profundidade}

Em função dos requisitos estabelecidos para o projeto desta tese, o mapa de profundidade do vídeo-avatar é calculado utilizando-se um algoritmo baseado em imageamento estéreo. Como discutido anteriormente, outras técnicas necessitam de câmeras com características especiais, condições específicas de iluminação, fontes de iluminação controladas ou procedimentos de calibração complexos. No caso do imageamento estéreo, é desejável que as imagens estejam retificadas (conforme discutido na seção 3.4.2).

Como o mapa de profundidade só é necessário para a interação do vídeo-avatar, propõe-se que as imagens sejam previamente segmentadas, com a remoção do fundo por algum algoritmo apropriado. Desta forma, o processamento do mapa de profundidade pode ser realizado somente sobre a região de interesse. O diagrama de blocos da Figura 27 representa os processos que devem ser realizados sobre os quadros de vídeo capturados, para que o cálculo do mapa de profundidade seja possa ser efetuado.

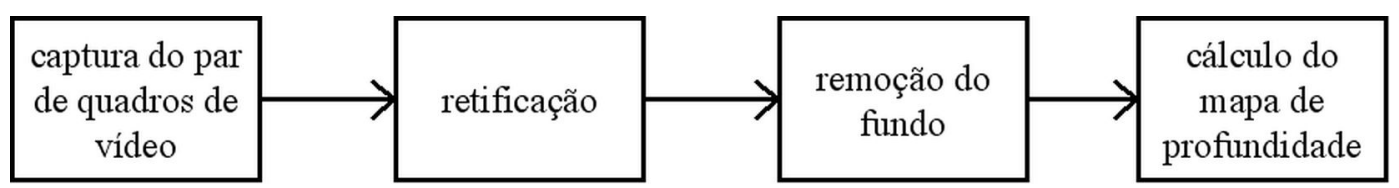

Figura 27 - Diagrama de blocos do processamento dos quadros de vídeo para a produção do mapa de profundidade

Levando-se em consideração a diferença apontada por Scharstein e Szeliski (2002) entre o custo computacional dos algoritmos locais e globais de imageamento estéreo, propõe-se a utilização de um algoritmo local. A função de discrepância adotada é a soma do quadrado das diferenças entre pixels das duas imagens do par estéreo. Esta função pode ser calculada tanto sobre os três canais de cor $(R, G, B)$ de uma imagem colorida como também sobre uma imagem em escala de cinza correspondente à luminância dos pixels da imagem original.

O cálculo da função de discrepância é realizado sobre uma janela de avaliação quadrada de tamanho fixo, cujas dimensões podem ser definidas em tempo de execução. Desta forma, a estimativa de discrepância $E$ entre um ponto $I_{E}$ de coordenadas $(r, s)$ pertencente ao quadro esquerdo e um ponto $I_{D}$ de coordenadas $(\mathrm{t}, \mathrm{u})$ pertencente ao quadro direito de um par estereoscópico é dada pela eq.(14). Deve-se observar que, para imagens retificadas, $s=u$, ou seja, são considerados os 
pixels na mesma linha das duas imagens. $Q_{E}(r, s, i)$ corresponde ao i-ésimo canal de cor de um pixel da imagem esquerda e $Q_{D}(t, u, i)$ corresponde ao i-ésimo canal de cor de um ponto da imagem direita. C é o número de canais de cor da imagem (1 para imagens em escala de cinza, 3 para imagens coloridas usando representação RGB). $\mathrm{N}$ é o tamanho da janela de avaliação.

$$
E\left(I_{E}, I_{D}\right)=E(r, s, t, u)=\sum_{i=-N / 2}^{N / 2} \sum_{j=-N / 2}^{N / 2} \sum_{k=1}^{C}\left[Q_{E}(r+j, s+i, k)-Q_{D}(t+j, u+i, k)\right]^{2}
$$

Uma conseqüência de se utilizar esta função de agregação baseada em uma janela é que o mapa de profundidade não pode ser calculado para uma região na borda da imagem, com largura igual a N/2 pixels, sendo $\mathrm{N}$ o tamanho da janela de avaliação. Isto se deve ao fato de que nesta região não é possível agregar o valor da função de discrepância sobre toda a janela. Como as estimativas são comparadas entre si, adotar estimativas parciais pode levar a resultados incorretos.

Assumindo-se que o par de imagens se encontra retificado (conforme discutido na seção 3.4.2), para cada ponto $I_{E}$ da imagem esquerda com coordenadas ( $\left.x, y\right)$, a estimativa de discrepância é calculada para todos os pontos da imagem direita com coordenadas $(\mathrm{z}, \mathrm{w})$ tais que $\mathrm{N} / 2 \leq \mathrm{z}<\mathrm{x}$ e $\mathrm{w}=\mathrm{y}$. $\mathrm{N}$ é o tamanho da janela de avaliação. Esta limitação no espaço de busca na linha se deve ao fato de que, com a paralaxe existente entre as duas imagens, o ponto correspondente da imagem da direita só pode se encontrar em uma coordenada horizontal igual ou menor à do ponto da imagem da esquerda.

O ponto correspondente é determinado como aquele que resulta no menor valor da estimativa de discrepância. A disparidade entre os pontos é calculada como a diferença entre as coordenadas horizontais dos dois pontos. A Figura 28 apresenta 0 algoritmo para o cálculo da disparidade de um ponto de coordenadas ( $x, y)$ em pseudo-código.

Dado que as imagens utilizadas para o vídeo-avatar foram previamente segmentadas de acordo com a proposta desta tese, pode-se excluir automaticamente do cálculo do mapa de profundidade todos os pontos marcados com uma intensidade ou cor previamente definida. Se a imagem do vídeo-avatar ocupar, por exemplo, $50 \%$ da área total da imagem, esta medida permite uma redução de $50 \%$ nos cálculos de mapa de profundidade. 


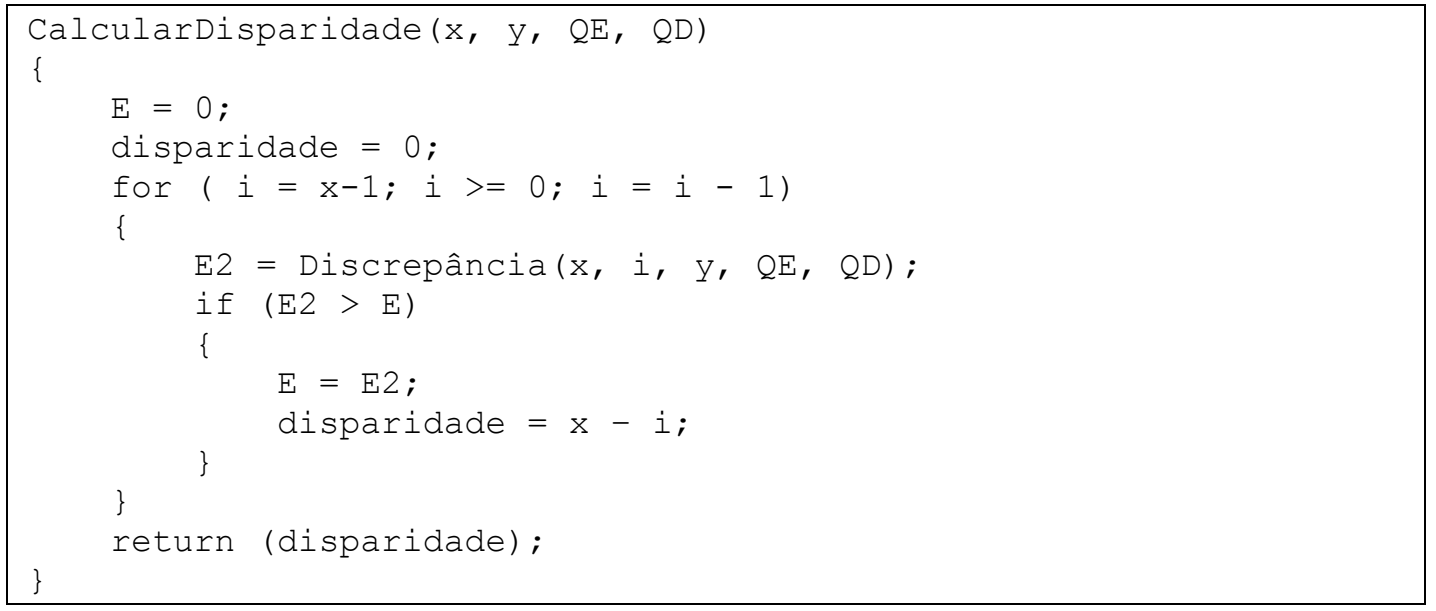

Figura 28 - Pseudo-código para o cálculo de disparidades

Deve-se observar que em um algoritmo local de mapa de profundidade como o proposto nesta tese, o valor de profundidade de cada ponto é calculado de forma independente dos demais. Por este motivo, sua implementação permite o uso de técnicas de processamento paralelo de forma relativamente simples. Idealmente, todos os pontos do mapa de profundidade poderiam ser calculados simultaneamente. No entanto, isso não é factível nos computadores pessoais existentes atualmente. Desta forma, propõe-se que a implementação divida a imagem em faixas horizontais, que podem ser processadas em paralelo pelo algoritmo, conforme ilustrado na Figura 29.

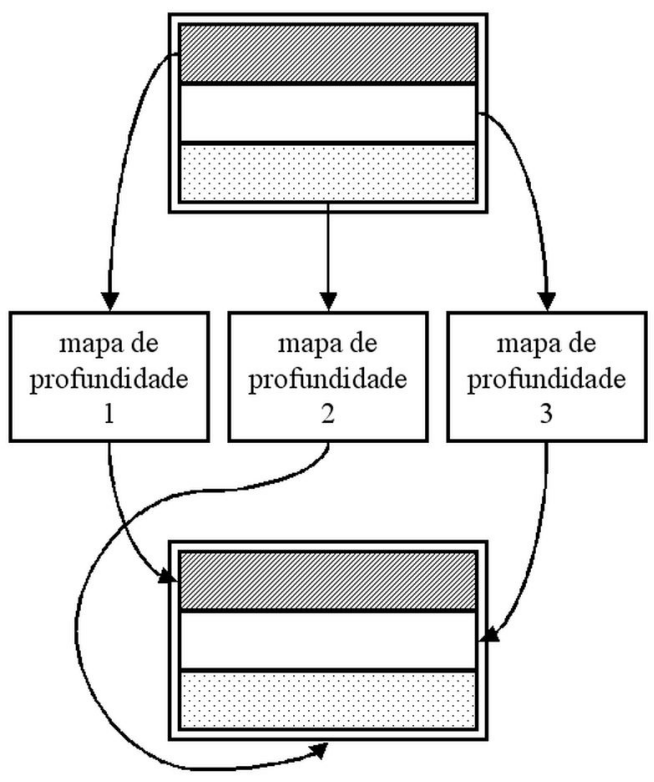

Quadros de vídeo

Processos com execução paralela

Mapa de profundidade

Figura 29 - Diagrama ilustrativo da execução paralela do cálculo do mapa de profundidade em regiões distintas da imagem 
Erros devidos à oclusão entre elementos da cena e falta de textura na imagem podem gerar estimativas incorretas de profundidade, que resultam em descontinuidades no mapa de profundidade. Scharstein e Szeliski (2002) observam que algumas técnicas locais aplicam critérios de consistência baseados em características da cena para reduzir estes erros. Nesta tese, propõe-se a aplicação de um filtro de mediana sobre o mapa de profundidade calculado, como forma de aplicar um critério simples de continuidade dos elementos da cena. Uma característica do filtro mediana é que ele promove a suavização da imagem, removendo ruído e ao mesmo tempo preservando a agudeza das bordas (GONZALES; WOODS, 2000). No caso do mapa de profundidade, este é o comportamento desejado para eliminar pontos de ruído correspondentes a estimativas incorretas de profundidade.

\subsection{Detecção de Colisão para Interação no Ambiente Virtual}

A partir de um mapa de profundidade contendo a informação de profundidade para cada pixel da imagem, como por exemplo o mapa obtido com a técnica descrita na seção anterior, é possível construir um modelo para realizar interação e detecção de colisão do vídeo-avatar com o ambiente virtual. Propõe-se a utilização de uma representação em forma de octree para o vídeo-avatar e volumes envoltórios para os demais objetos do ambiente virtual.

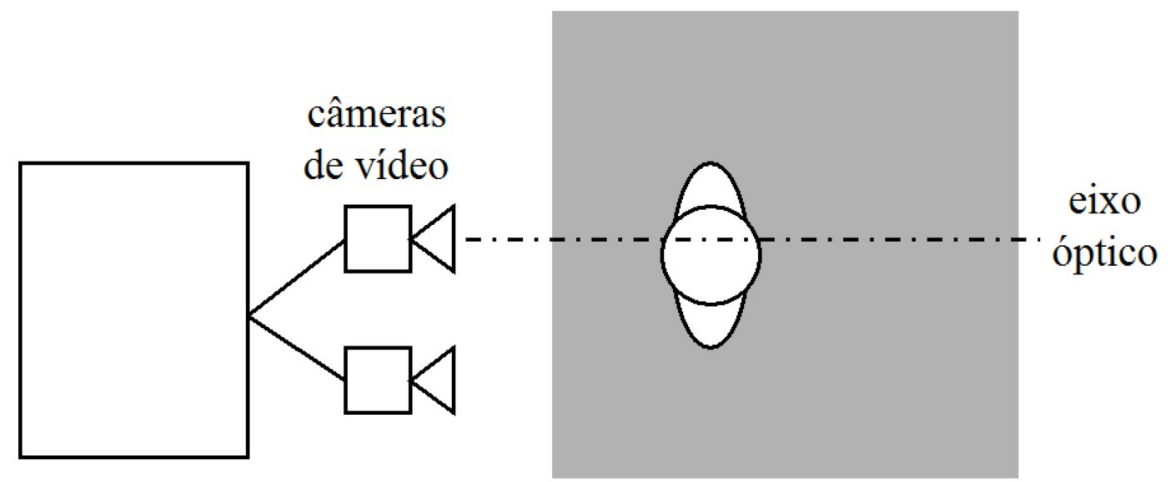

Figura 30 - Volume envolvido pela octree para detecção de colisão do vídeo-avatar.

Dado o arranjo de câmeras fixo descrito no início deste capítulo, a octree é utilizada para mapear um volume de dimensões conhecidas, na forma de um paralelepípedo 
com faces alinhadas aos eixos do sistema de coordenadas das câmeras e posicionado de forma que suas dimensões sejam simétricas em relação ao eixo óptico da câmera tomada como referência para a construção do mapa de profundidade. Na Figura 30, a área marcada em cinza corresponde à região do espaço que é mapeada pela octree. As dimensões do paralelepípedo utilizado pela octree podem ser definidas pelo usuário. Juntamente com o nível máximo de profundidade da octree, estes parâmetros definirão a resolução do modelo de colisão, de acordo com a eq.(15), na qual $\mathrm{N}$ é o número máximo de níveis da octree e L é uma das dimensões do paralelepípedo. Por exemplo, no caso de uma octree com cinco níveis envolvendo o volume de um cubo com dois metros de lado, a resolução será de $12,5 \mathrm{~cm}$.

$$
R=\frac{L}{2^{N-1}}
$$

Os volumes envoltórios utilizados para representar os outros objetos podem ser paralelepípedos com faces paralelas ao sistema de coordenadas da câmera ou esferas. Como será visto na seção 5.3.1, os testes de colisão de uma octree com esses volumes podem ser realizados de maneira muito eficiente.

As próximas duas seções apresentam, primeiramente, os detalhes da técnica para construção eficiente da octree a partir do mapa de profundidade e, em seguida, a técnica de detecção de colisão adotada.

\subsubsection{Construção da Octree}

O processo de construção da octree se inicia com a conversão dos pontos do mapa de profundidade para coordenadas tridimensionais, utilizando-se as eq.(9) a (11). Esses pontos devem, então ser classificados dentro dos volumes representados pelos nós da octree para que, ao final do processo, tenha-se uma octree correspondente ao vídeo-avatar.

O processo intuitivo de construção de uma octree consiste na geração recursiva de uma estrutura de árvore utilizando-se alocação dinâmica de memória. Esta representação é bastante eficiente em termos de ocupação de memória. No entanto, este processo pode se tornar lento devido ao custo de alocar e liberar memória a 
cada vez que a octree precisa ser reconstruída. Uma alternativa poderia ser alocar previamente toda a memória necessária para os nós e gerenciar esta memória conforme a árvore é construída ou modificada. Entretanto, esta abordagem anula a vantagem da eficiência no uso de memória sem trazer outros benefícios.

Por este motivo, propõe-se a utilização de uma representação de octree baseada em um vetor. Neste caso, todos os nós de todos os níveis da octree são armazenados permanentemente na estrutura de dados. Para uma octree de profundidade $D, 0$ número de nós é dado pela eq.(16).

$$
N=\sum_{i=0}^{D} 8^{i}
$$

Como se pode observar, o número de nós aumenta exponencialmente com a profundidade da árvore. O tamanho do vetor a ser alocado é igual a este número multiplicado pelo tamanho do tipo de dado utilizado para armazenar as informações da octree. Por exemplo, utilizando-se um byte por nó, uma octree de sete níveis requer cerca de $293 \mathrm{kB}$ de memória. Por motivos de otimização de velocidade de acesso à memória, no entanto, é desejável alocar cada nó com o tamanho de uma palavra de máquina do processador utilizado. Neste caso, em processadores de 32 bits, portanto, uma octree de sete níveis requer cerca de $1,17 \mathrm{MB}$ de memória. Uma octree desta profundidade ainda permite uma resolução de $62,5 \mathrm{~mm}$ para o modelo de colisão, considerando-se um volume cúbico de dois metros de lado e aplicandose a eq.(15).

A Figura 31 apresenta um exemplo de como os nós da octree são armazenados no vetor. Para maior clareza da figura, foi utilizada uma árvore com somente quatro filhos por nó; no entanto o mesmo princípio se aplica para a octree. Se um nó ocupa a posição $\mathrm{P}$ do vetor, seus filhos ocuparão as posições $8 \mathrm{P}+1$ a $8 \mathrm{P}+8$. Utilizando-se esta relação, é possível iterar recursivamente sobre os nós da octree representada como vetor.

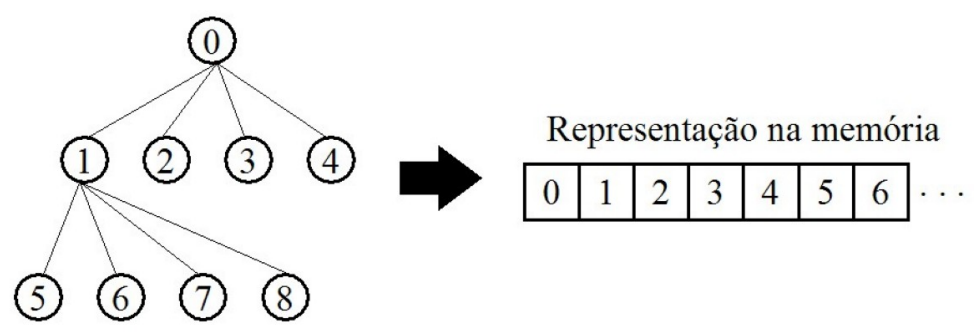

Figura 31 - Representação de uma árvore utilizando-se um vetor em memória 
Adicionalmente, as folhas da octree representada como vetor podem ser acessadas diretamente utilizando-se uma técnica conhecida como Códigos de Posição de Morton (ERICSON, 2005). Esta técnica converte as coordenadas ( $x, y, z)$ de um ponto no espaço tridimensional compreendido pela octree em um índice do vetor que armazena a folha da octree correspondente, desde que os filhos de cada nó sejam armazenados em uma ordem coerente com a forma como o código é obtido.

Os códigos de posição de Morton podem ser calculados de acordo com as eq.(17) a (20). Os valores $(x, y, z)_{\min }$ e $(x, y, z)_{\max }$ correspondem aos limites do volume do espaço tridimensional representado na octree. $\mathrm{N}$ é um número inteiro igual ou maior à profundidade da árvore. A função trunc(x) retorna um número inteiro correspondente a $\mathrm{x}$ sem qualquer parte fracionária.

$$
\begin{aligned}
& M_{x}=\operatorname{trunc}\left(\frac{x-x_{\min }}{x_{\max }-x_{\min }} \cdot 2^{N}\right) \\
& M_{y}=\operatorname{trunc}\left(\frac{y-y_{\min }}{y_{\max }-y_{\min }} \cdot 2^{N}\right) \\
& M_{z}=\operatorname{trunc}\left(\frac{z-z_{\min }}{z_{\max }-z_{\min }} \cdot 2^{N}\right) \\
& M=\text { Intercalar }\left(M_{x}, M_{y}, M_{z}\right)
\end{aligned}
$$

A função Intercalar(A,B,C) retorna um número obtido pela composição dos bits de $A$, $B$ e $C$ intercalados sucessivamente. Isto é, se $A=\left(a_{1} a_{2} a_{3} \ldots\right)_{2}, B=\left(b_{1} b_{2} b_{3} \ldots\right)_{2}$ e $C=$ $\left(c_{1} c_{2} c_{3} \ldots\right)_{2}$, então o retorno desta função será $\left(a_{1} b_{1} c_{1} a_{2} b_{2} c_{2} a_{3} b_{3} c_{3} \ldots\right)_{2}$. Ericson (2005) apresenta uma implementação eficiente desta função. Uma conseqüência da forma como os códigos de Morton são calculados é que eles necessitam de uma representação com número de bits igual a três vezes a profundidade da octree. Por exemplo, uma variável de 32 bits só pode ser usada para armazenar códigos de Morton para octrees de profundidade menor ou igual a 10.

A utilização dos códigos de posição de Morton permite que a classificação dos pontos do vídeo-avatar na estrutura da octree seja feita da seguinte forma: primeiramente, calcula-se o código de Morton correspondente à posição de um ponto do vídeo-avatar. Em seguida, altera-se o valor da folha indexada por aquele código, indicando que aquele volume do espaço está preenchido pelo vídeo-avatar. Depois que todos os pontos foram classificados, a informação presente nas folhas deve ser propagada recursivamente para os demais nós da árvore. O número de 
operações necessário para construir a octree segundo esta abordagem é dado pela eq.(21). P é o número de pontos a serem classificados. A segunda parcela da equação corresponde ao número de nós da árvore, que precisam ser acessados para propagar a informação recursivamente.

$$
N_{O P}=P+\sum_{i=0}^{D} 8^{i}
$$

A abordagem usual para classificar os pontos em uma octree consiste em testar recursivamente se o ponto está contido no volume representado em cada nó, até atingir uma folha. Neste caso, a classificação de cada ponto requer D operações, onde $\mathrm{D}$ é a profundidade da árvore. Portanto, o número de operações para classificar pela abordagem recursiva um conjunto de $\mathrm{P}$ pontos será dado pela eq.(22).

$$
N^{\prime}{ }_{O P}=P \cdot D
$$

A Tabela 2 traz os valores comparativos entre as abordagens recursiva e Morton, para dois tamanhos do conjunto de pontos a serem classificados. Experimentalmente, verificou-se que o mapa de profundidade do vídeo avatar produz conjuntos de pontos com tamanho da ordem de $10^{4}$. Esta tabela torna evidente a vantagem de se utilizar uma abordagem baseada nos códigos de posição de Morton para octrees de até sete níveis (ou seja, profundidade máxima igual a seis).

Tabela 2 - Comparação do número de operações para construção de octree

\begin{tabular}{|c|r|r|r|r|}
\cline { 2 - 5 } \multicolumn{1}{c|}{} & \multicolumn{4}{c|}{ Técnica de classificação (Número de pontos) } \\
\hline $\begin{array}{c}\text { Profundidade } \\
\text { da árvore }\end{array}$ & $\begin{array}{c}\text { Códigos de } \\
\text { Morton } \\
(10000)\end{array}$ & $\begin{array}{c}\text { Testes } \\
\text { Recursivos } \\
(10000)\end{array}$ & $\begin{array}{c}\text { Códigos de } \\
\text { Morton } \\
(20000)\end{array}$ & $\begin{array}{c}\text { Testes } \\
\text { Recursivos } \\
(20000)\end{array}$ \\
\hline 1 & 10001 & 10000 & 20001 & 20000 \\
\hline 2 & 10009 & 20000 & 20009 & 40000 \\
\hline 3 & 10073 & 30000 & 20073 & 60000 \\
\hline 4 & 10585 & 40000 & 20585 & 80000 \\
\hline 5 & 14681 & 50000 & 24681 & 100000 \\
\hline 6 & $\mathbf{4 7 4 4 9}$ & $\mathbf{6 0 0 0 0}$ & $\mathbf{5 7 4 4 9}$ & $\mathbf{1 2 0 0 0 0}$ \\
\hline 7 & 309593 & 70000 & 319593 & 140000 \\
\hline
\end{tabular}


Deve-se observar ainda que a operação de marcar as folhas da octree baseando-se nos códigos de Morton envolve somente um acesso de leitura ao mapa de profundidade e uma escrita (na folha da octree) de um valor constante. Desta forma, a classificação de cada ponto é independente dos demais e pode ser implementada utilizando-se técnicas de processamento paralelo. A segunda fase da construção da octree, que envolve a propagação recursiva das informações, também pode ser implementada de forma paralela, mas pode necessitar de procedimentos de sincronização, pois o estado final de cada nó depende dos valores de seus oito filhos, que podem estar sendo processados simultaneamente.

\subsubsection{Detecção de Colisão com Objetos do Ambiente Virtual.}

$\mathrm{Na}$ proposta de vídeo-avatar desta tese, cada elemento do ambiente virtual que pode colidir com o vídeo-avatar é representado por um volume envoltório com uma de duas formas possíveis: uma esfera de raio arbitrário ou um paralelepípedo com arestas alinhadas ao sistema de coordenadas da octree.

A detecção de colisão entre uma octree e um volume envoltório é realizada recursivamente, da maneira que descrita na seção 3.6. Os testes de colisão entre um paralelepípedo correspondente a um nó da octree e um volume envoltório são baseados nas formulações dadas por Ericson (2005).

\subsection{Ferramenta Configurável de Testes}

Para se realizar os testes das técnicas propostas nas seções anteriores, foi desenvolvida uma ferramenta configurável de testes, utilizando-se a linguagem $\mathrm{C}++$, as bibliotecas OpenCV (OPENCV, 2008) e OpenGL (OPENGL, 2008) e o OpenGL Framework GLFW (GLFW, 2008). Nesta ferramenta, existem implementações das técnicas descritas nesta tese e uma interface de usuário para visualização interativa dos resultados. Através da ferramenta é possível visualizar a operação dos algoritmos sobre quadros estáticos ou seqüências de vídeo, tanto sintéticas como capturadas por câmeras. Adicionalmente, vários parâmetros dos algoritmos e dos 
testes podem ser definidos em um arquivo de configuração que utiliza o formato XML (Extensible Markup Language). Uma descrição detalhada deste arquivo de configuração pode ser encontrada no Apêndice A.

A Figura 32 apresenta uma visão da interface da ferramenta configurável de testes em execução. Ela consiste em quatro janelas: as duas janelas superiores apresentam as imagens capturadas pelas câmeras de vídeo e segmentadas; a janela inferior direita apresenta o mapa de profundidade na forma de uma imagem em escala de cinza, onde tons mais claros indicam maior proximidade da câmera e tons mais escuros indicam pontos mais distantes. Por fim, a janela inferior direita apresenta uma visualização do modelo de colisão do vídeo-avatar. Esta janela pode exibir tanto a nuvem de pontos tridimensionais calculados a partir do mapa de profundidade, como a octree construída a partir deles.

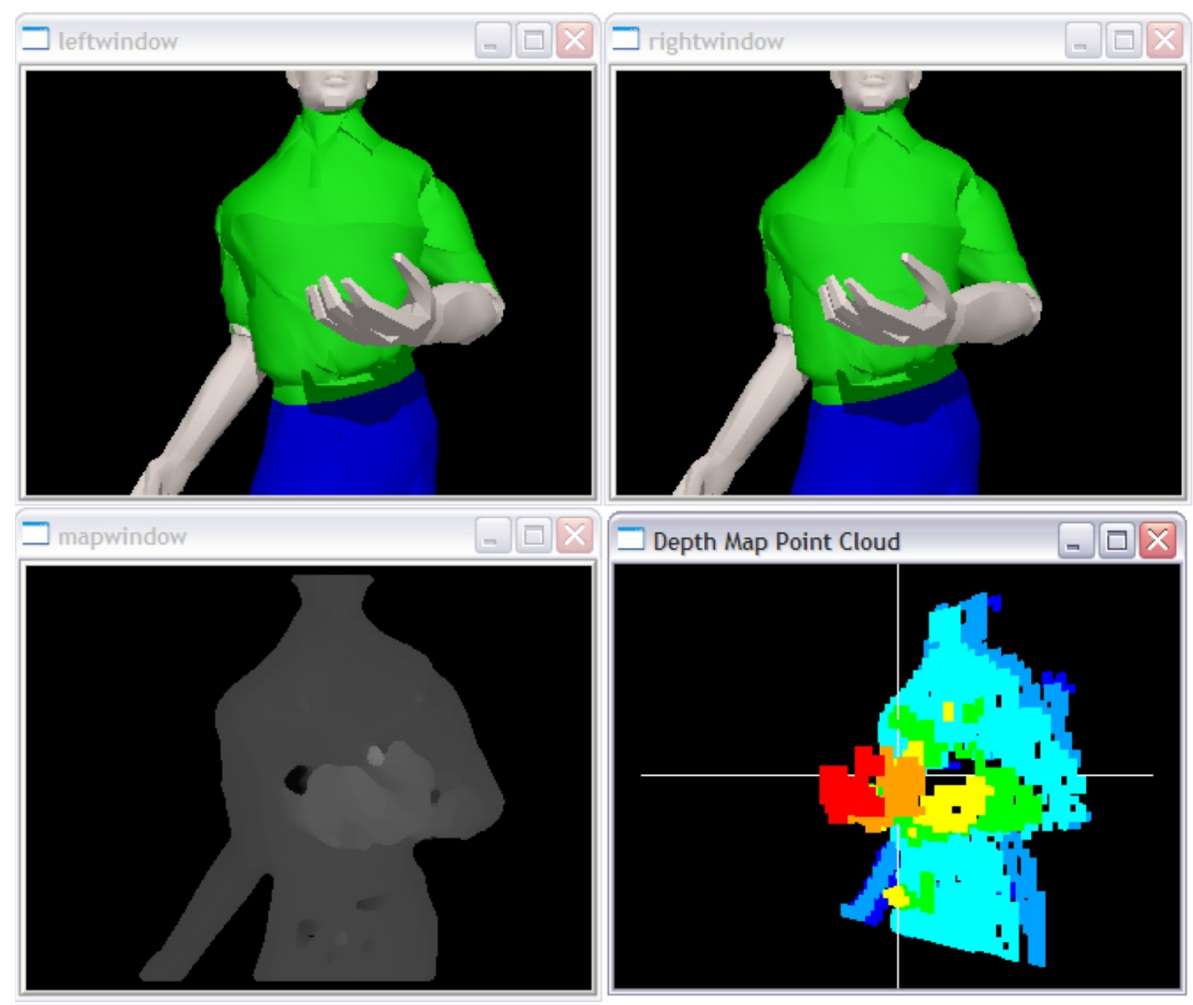

Figura 32 - Visualização da ferramenta configurável de testes

A ferramenta configurável de testes pode ser utilizada tanto com conjuntos de quadros capturados a partir de uma câmera como também com imagens previamente retificadas e segmentadas. Ela foi utilizada para realizar avaliações qualitativas do modelo de colisão gerado pelas técnicas propostas e também para alguns dos testes apresentados na próxima seção. 


\subsection{Resultados}

Esta seção apresenta os resultados de diferentes testes qualitativos realizados utilizando-se a ferramenta configurável de testes descrita anteriormente. Para a realização das medidas de tempo de execução dos algoritmos, foi necessário alterar a ferramenta, adicionando-se chamadas da função GetTickCount da biblioteca OpenCV antes e depois da operação dos algoritmos. Esta função retorna uma medida de tempo baseada no relógio do processador, que pode ser convertida em uma medida de tempo com precisão de microssegundos. Calculando-se a diferença entre os valores registrados, obtém-se o tempo de execução do algoritmo.

\subsubsection{Qualidade do Subsistema de Mapa de Profundidade}

Scharstein e Szeliski (2002) disponibilizam um conjunto de imagens de referência que utilizaram em seu trabalho para comparar diferentes algoritmos de geração de mapa de profundidade baseados em imageamento estéreo. Estas imagens correspondem a pares estereoscópicos devidamente retificados e o mapa de disparidades correspondente. Um mapa de disparidades é uma imagem em escala de cinza em que cada ponto contém a distância horizontal que separa os pontos correspondentes nas duas imagens do par estéreo. Aqueles autores também definem duas métricas de qualidade para avaliar os algoritmos. A primeira é chamada "percentual de pixels ruins" e definida da seguinte forma: um "pixel ruim" (bad pixel) é um ponto do mapa de disparidade gerado por um dado algoritmo cujo valor difere por mais de uma unidade do valor do mapa de disparidade de referência. Desta forma, o percentual de pixels ruins é o número de pixels ruins produzidos por um algoritmo, dividido pelo total de pixels do mapa de disparidade. A segunda é o "percentual de pixels pretos". Por convenção, os algoritmos marcam os pontos em que não foi possível estimar a disparidade correspondente com o valor zero, que em uma imagem de escala de cinza corresponde à cor preta. O percentual de pixels pretos é o número de pixels pretos dividido pelo total de pixels do mapa, e é uma 
medida do número de pontos que não puderam ser determinados devido à oclusão, falta de textura ou outras limitações do algoritmo.

O seguinte teste foi realizado com o propósito de determinar a qualidade dos mapas de profundidade gerados pelo algoritmo proposto: uma implementação do algoritmo foi criada para gerar mapas de disparidade. Utilizando-se as imagens "venus" (434×383 pixels) e "sawtooth" (434×380 pixels) disponibilizadas por Scharstein e Szeliksi (2002), foram gerados os mapas variando-se o tamanho da janela de avaliação entre $3 \times 3$ pixels e $15 \times 15$ pixels. Foram então calculadas os valores de percentual de pixels pretos e percentual de pixels ruins. A Figura 33 apresenta a imagem "sawtooth" e o mapa de disparidades de referência, onde se verifica que o melhor resultado obtido com a implementação do algoritmo proposto foi utilizando-se uma janela de avaliação de 9x9 pixels.

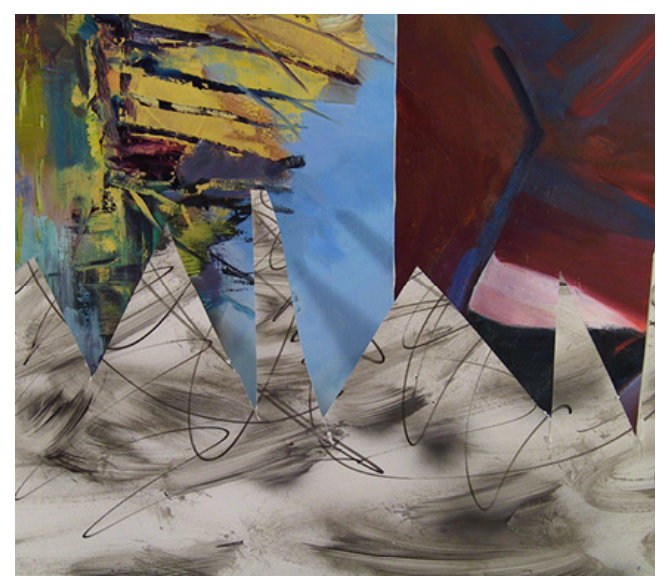

(a)

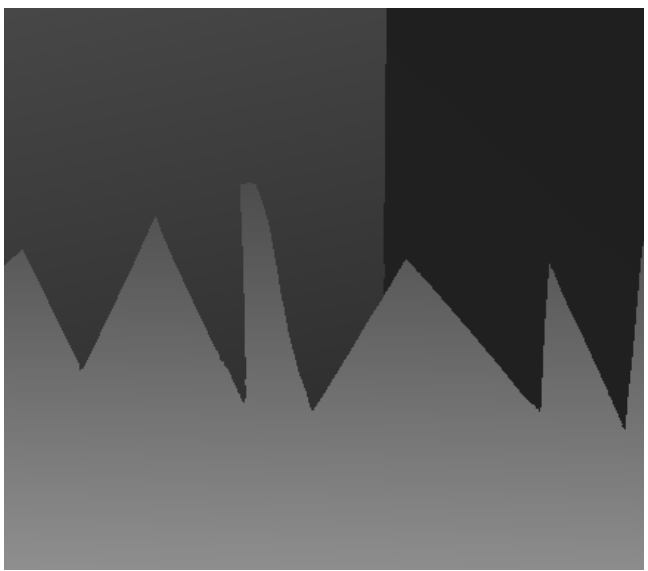

(b)

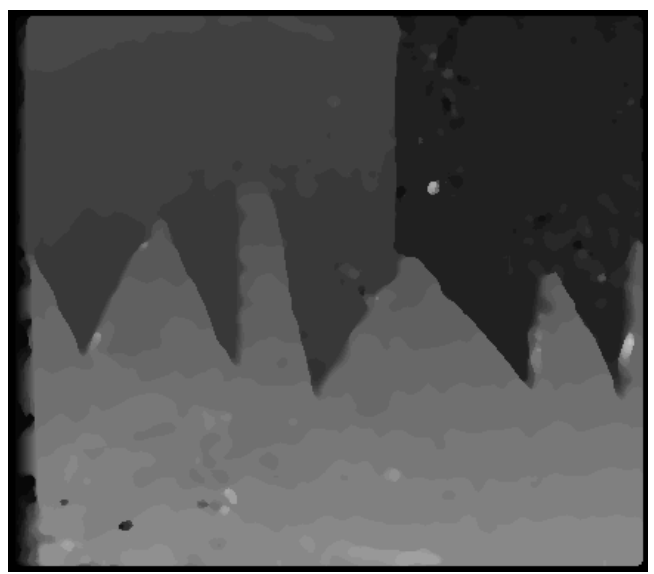

(c)

Figura 33 - Resultado do teste com a figura de referência "Sawtooth" (SCHARSTEIN; SZELIKSI, 2002). (a) Uma das imagens de referência; (b) mapa de disparidades de referência; (c) mapa de disparidades com uma janela $9 \times 9$. 
Da mesma forma, a Figura 34 apresenta a imagem de referência "venus", o mapa de disparidades de referência correspondente e o melhor resultado obtido com a implementação do algoritmo proposto, neste caso utilizando-se uma janela de avaliação de $15 \times 15$ pixels.

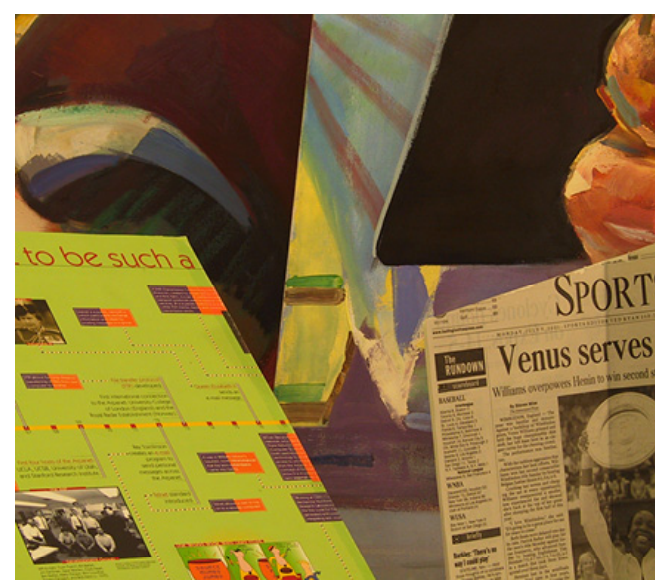

(a)

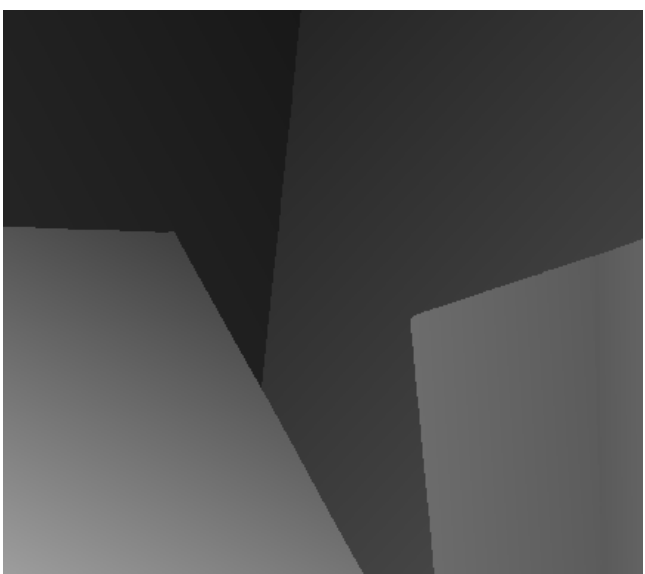

(b)

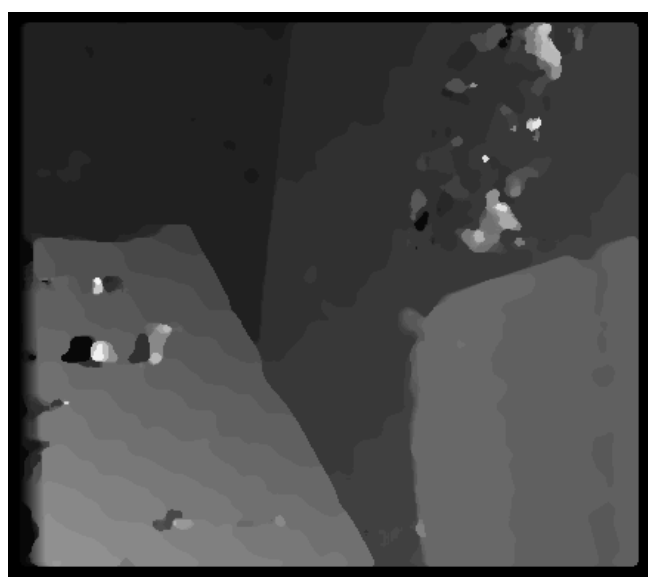

(c)

Figura 34 - Resultado do teste com a figura de referência "Venus" (SCHARSTEIN; SZELIKSI, 2002).

(a) Uma das imagens de referência; (b) mapa de disparidades de referência; (c) mapa de disparidades com uma janela $15 \times 15$.

A Tabela 3 traz todos os resultados do teste para a imagem "Sawtooth" e a Tabela 4 traz os resultados para a imagem "Venus". Os tempos de processamento foram obtidos na execução em um único thread em um computador com processador AMD $643200+$ com freqüência de $2 \mathrm{GHz}$ e $1 \mathrm{~GB}$ de memória.

Tabela 3 - Resultados dos testes com a imagem "Sawtooth" (434×380 pixels)

\begin{tabular}{|l|l|l|l|}
\hline JANELA & tempo(s) & \%black pixels & \%bad pixels \\
\hline $3 \times 3$ & 0,223 & 1,226 & 16,42 \\
\hline $5 \times 5$ & 0,5859 & 2,204 & 11,29 \\
\hline $7 \times 7$ & 1,176 & 3,178 & 9,672 \\
\hline $9 \times 9$ & 1,884 & 4,147 & 9,163 \\
\hline $11 \times 11$ & 2,827 & 5,111 & 9,217 \\
\hline
\end{tabular}




\begin{tabular}{|l|l|l|l|}
\hline $13 \times 13$ & 3,887 & 6,07 & 9,551 \\
\hline $15 \times 15$ & 5,158 & 7,025 & 9,953 \\
\hline
\end{tabular}

Tabela 4 - Resultados dos testes com a imagem "Venus" (434×383 pixels)

\begin{tabular}{|l|l|l|l|}
\hline JANELA & tempo(s) & $\begin{array}{l}\text { percentual de pixels } \\
\text { pretos }\end{array}$ & $\begin{array}{l}\text { percentual de pixels } \\
\text { ruins }\end{array}$ \\
\hline $3 \times 3$ & 0,2324 & 1,221 & 31,96 \\
\hline $5 \times 5$ & 0,5876 & 2,196 & 22,63 \\
\hline $7 \times 7$ & 1,212 & 3,166 & 18,08 \\
\hline $9 \times 9$ & 1,939 & 4,131 & 15,22 \\
\hline $11 \times 11$ & 2,856 & 5,091 & 13,38 \\
\hline $13 \times 13$ & 3,882 & 6,046 & 11,92 \\
\hline $15 \times 15$ & 5,417 & 6,997 & 10,89 \\
\hline
\end{tabular}

A partir dos dados coletados, foi possível comparar o ganho de qualidade com o aumento do custo computacional, com o aumento do tamanho da janela de avaliação, apresentados na Figura 35 e Figura 36. A medida de processamento relativo é feita de acordo com a eq.(23), onde $T_{i}$ é o tempo de processamento para um dado tamanho de janela e $\mathrm{T}_{\text {ref }}$ é o tempo de processamento para uma janela de avaliação de tamanho $3 \times 3$.

$$
\mathrm{T}_{\text {rel }}=\mathrm{T}_{\mathrm{i}} / \mathrm{T}_{\text {ref }}
$$

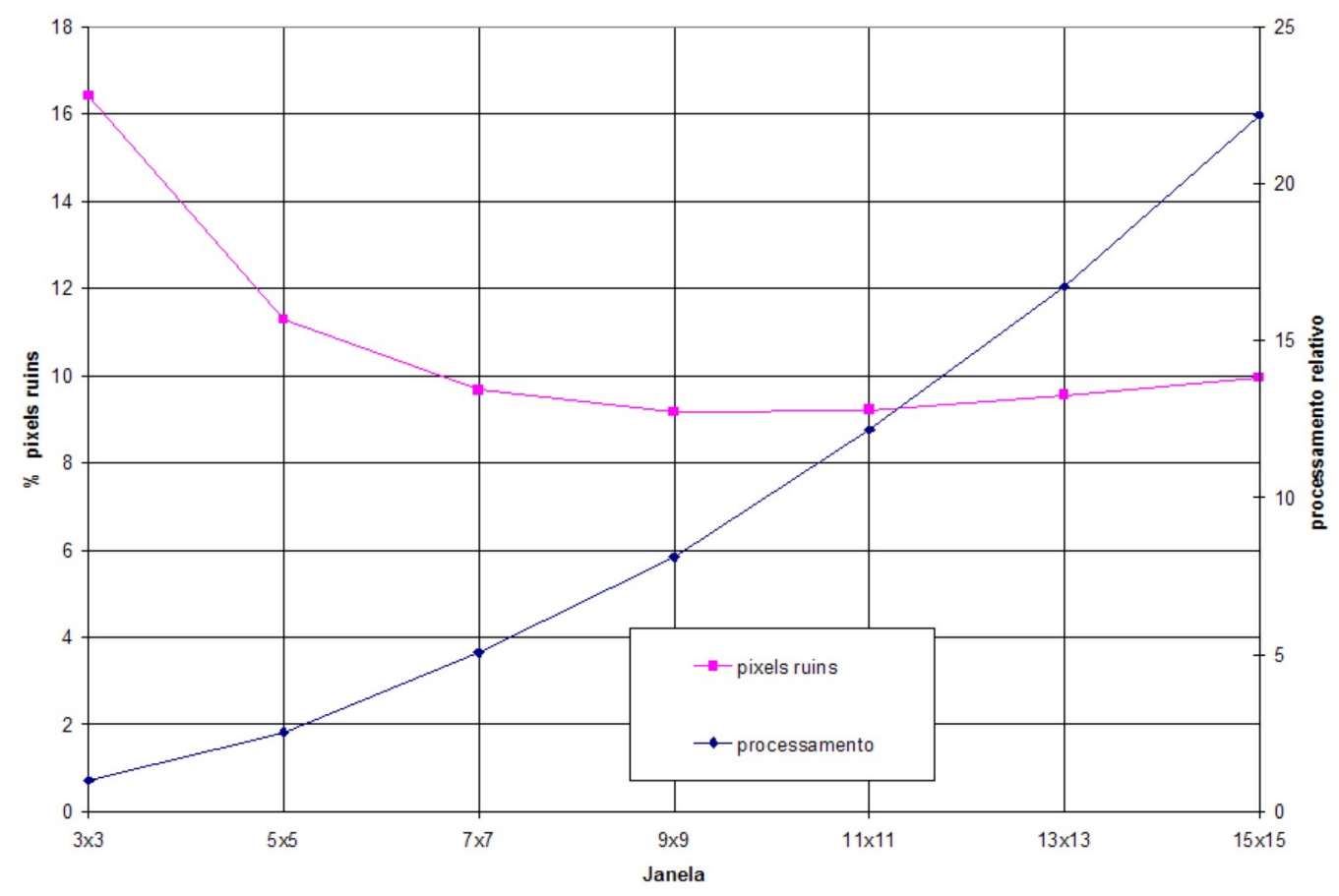

Figura 35 - Ganho de qualidade $\mathrm{x}$ aumento do processamento com diferentes tamanhos de janela de avaliação, considerando-se a figura de referência "Sawtooth". 


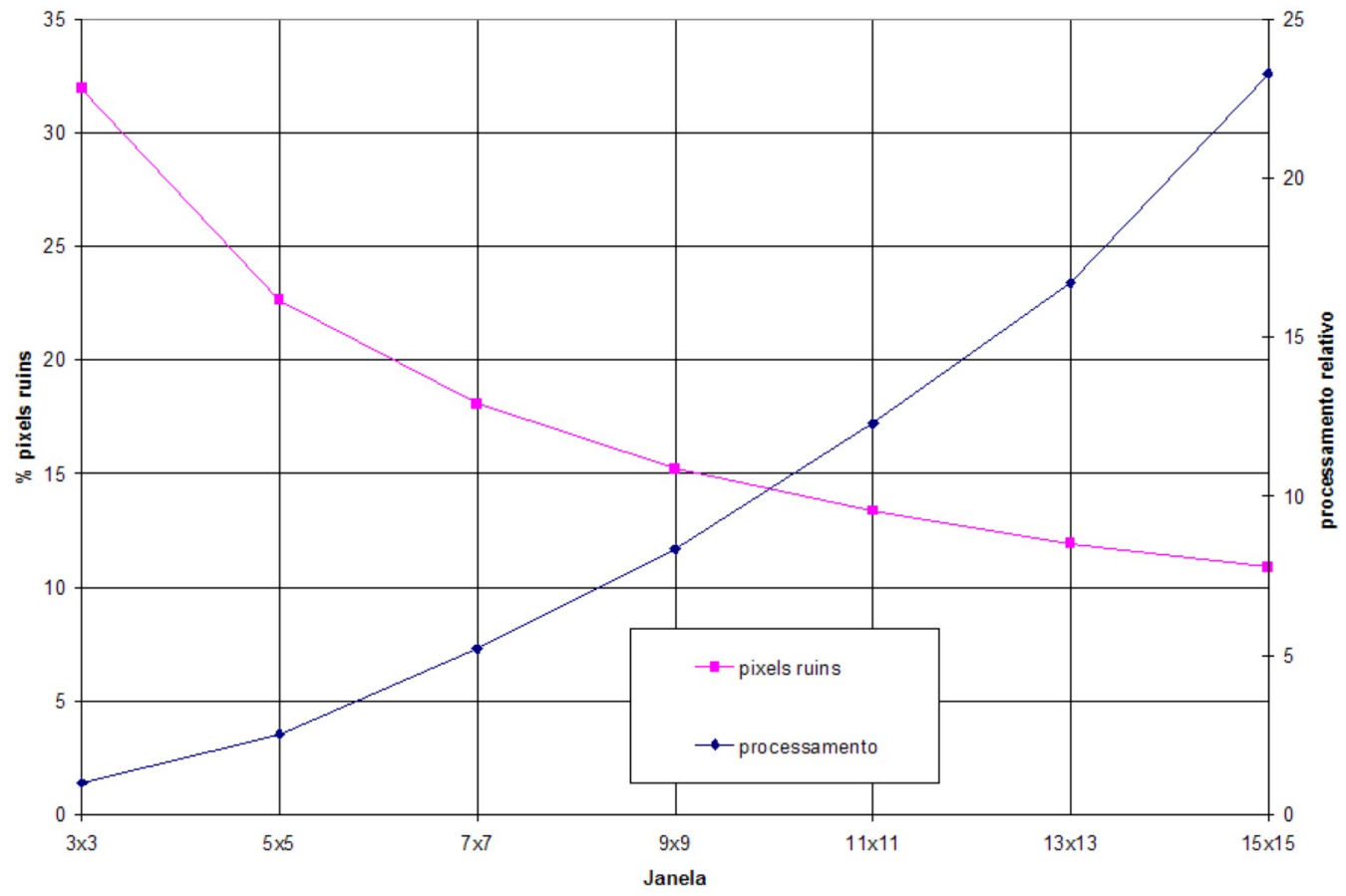

Figura 36 - Ganho de qualidade $\mathrm{x}$ aumento do processamento com diferentes tamanhos de janela de avaliação, considerando-se a figura de referência "Sawtooth".

Observando-se os gráficos da Figura 35 e Figura 36, pode-se concluir que, para o algoritmo de mapa de profundidade proposto nesta tese, janelas de avaliação de dimensões entre $5 \times 5$ e 9x9 pixels apresentam a melhor relação entre aumento da qualidade do mapa de profundidade e aumento do processamento necessário. No caso da imagem de referência "Sawtooth", nota-se uma queda na qualidade do mapa de profundidade quando uma janela maior do que 9x9 é utilizada. Isso se deve ao fato de que os contornos e bordas do mapa são suavizados com o uso de janelas de avaliação maiores. Uma janela muito grande pode fazer com que contornos próximos se misturem, elevando a taxa de erros.

\subsubsection{Desempenho do Subsistema de Mapa de Profundidade}

Dado que os tamanhos de janela de avaliação de $5 \times 5,7 \times 7$ e $9 \times 9$ pixels foram os que apresentaram melhor relação entre desempenho e qualidade, foi realizado um teste comparando-se o desempenho entre estas três alternativas. Adicionalmente, foram medidos os tempos de execução utilizando-se o algoritmo com uma a quatro threads, em um computador Intel Core 2 Quad Q6600 de 2.4GHz, com 4GB de 
RAM. Os resultados deste teste são apresentados na Figura 37. Os valores apresentados correspondem à média do tempo de execução do algoritmo de cálculo do mapa de profundidade sobre 100 pares estereoscópicos de imagens, convertidas para escala de cinza.

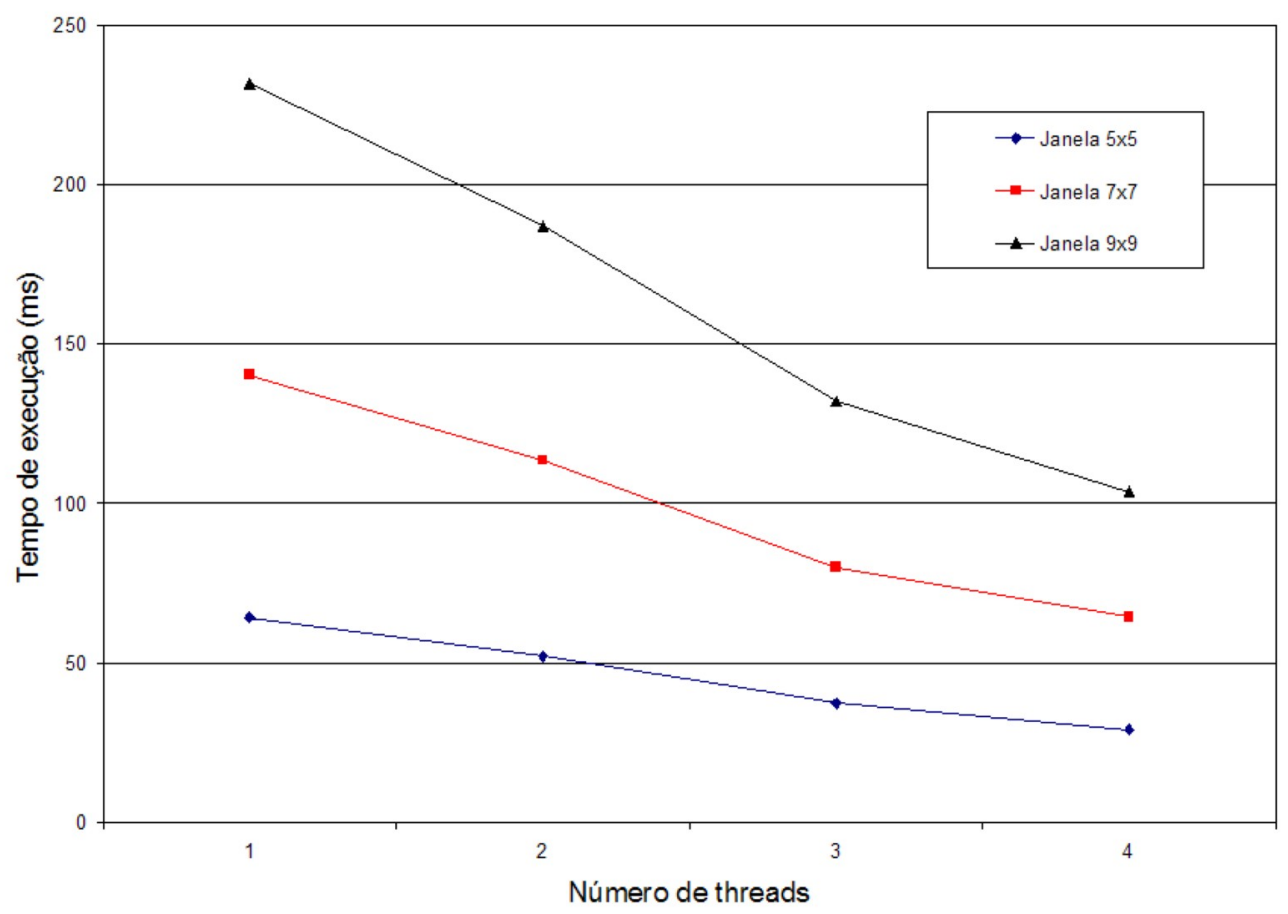

Figura 37 - Resultados do teste de desempenho do algoritmo de mapa de profundidade

Em todos os casos, aplica-se o filtro de mediana com uma janela $7 \times 7$ para suavizar o mapa de profundidade. O tamanho da janela deste filtro foi definido a partir de observações qualitativas da sua influência sobre o mapa de profundidade gerado. Janelas de dimensões inferiores não causavam efeitos significativos quanto à redução de descontinuidades causadas por erros; janelas de dimensões superiores à selecionada passavam a suavizar excessivamente os contornos do vídeo-avatar.

\subsubsection{Desempenho da Construção da Octree}

Para a avaliação do desempenho do algoritmo de construção da octree, foi implementado um protótipo no qual um mapa de profundidade é calculado e usado como entrada para o algoritmo a ser testado. A implementação deste algoritmo, no protótipo, permite a execução paralela da etapa de classificação dos pontos, através 
do uso de múltiplas threads. A etapa de propagação recursiva das informações na octree é realizada de forma seqüencial.

Os tempos médios de execução foram calculados, tendo-se como base um conjunto de oitenta pares estereoscópicos de imagens capturados a partir de câmeras de vídeo calibradas. Os testes foram executados em um computador Intel Core 2 Quad Q6600 2.4GHz com 4GB de RAM. Em função da disponibilidade de quatro núcleos de processamento, foram medidos os tempos de execução para o algoritmo com uma a quatro threads paralelas. Também foram medidos os tempos de execução variando-se entre quatro e sete níveis.

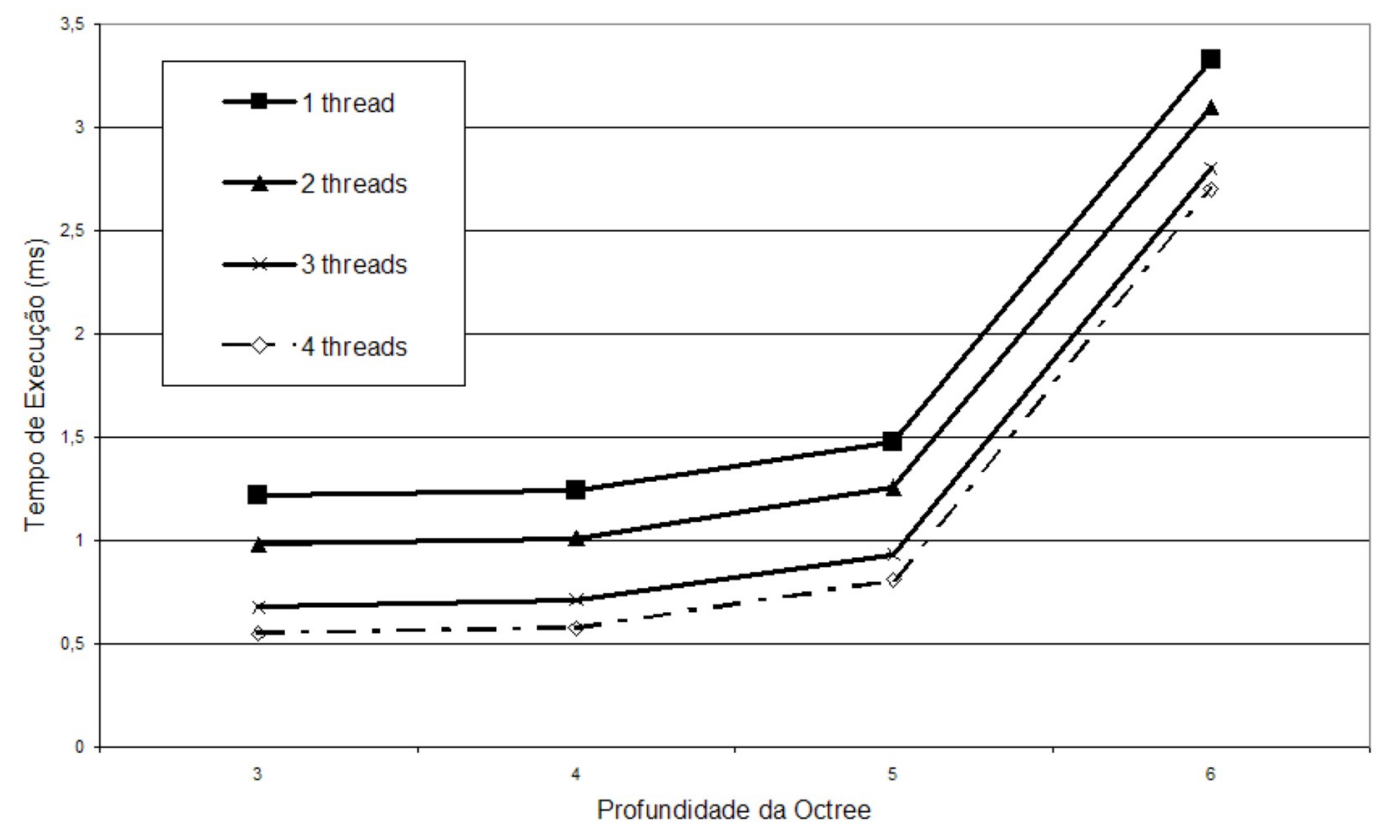

Figura 38 - Tempos médios de execução do algoritmo de construção da octree

Os resultados são apresentados na Figura 38. Como se pode observar, o comportamento do tempo de execução do algoritmo é exponencial com a profundidade da octree. No entanto, considerando-se a faixa de valores possíveis para este parâmetro, o algoritmo ainda apresenta um desempenho bastante aceitável, mesmo utilizando-se somente uma thread de execução.

A Figura 39 mostra um gráfico com o ganho de desempenho relativo com a execução paralela do algoritmo. Este gráfico permite observar um aspecto interessante desta implementação. Torna-se evidente que a execução paralela somente da classificação dos pontos resulta em menor ganho de desempenho conforme aumenta a profundidade da octree. Isto se deve ao fato de que, com o aumento da profundidade, o número de nós cresce exponencialmente e a etapa de 
propagação recursiva das informações se torna dominante em termos de tempo de execução.

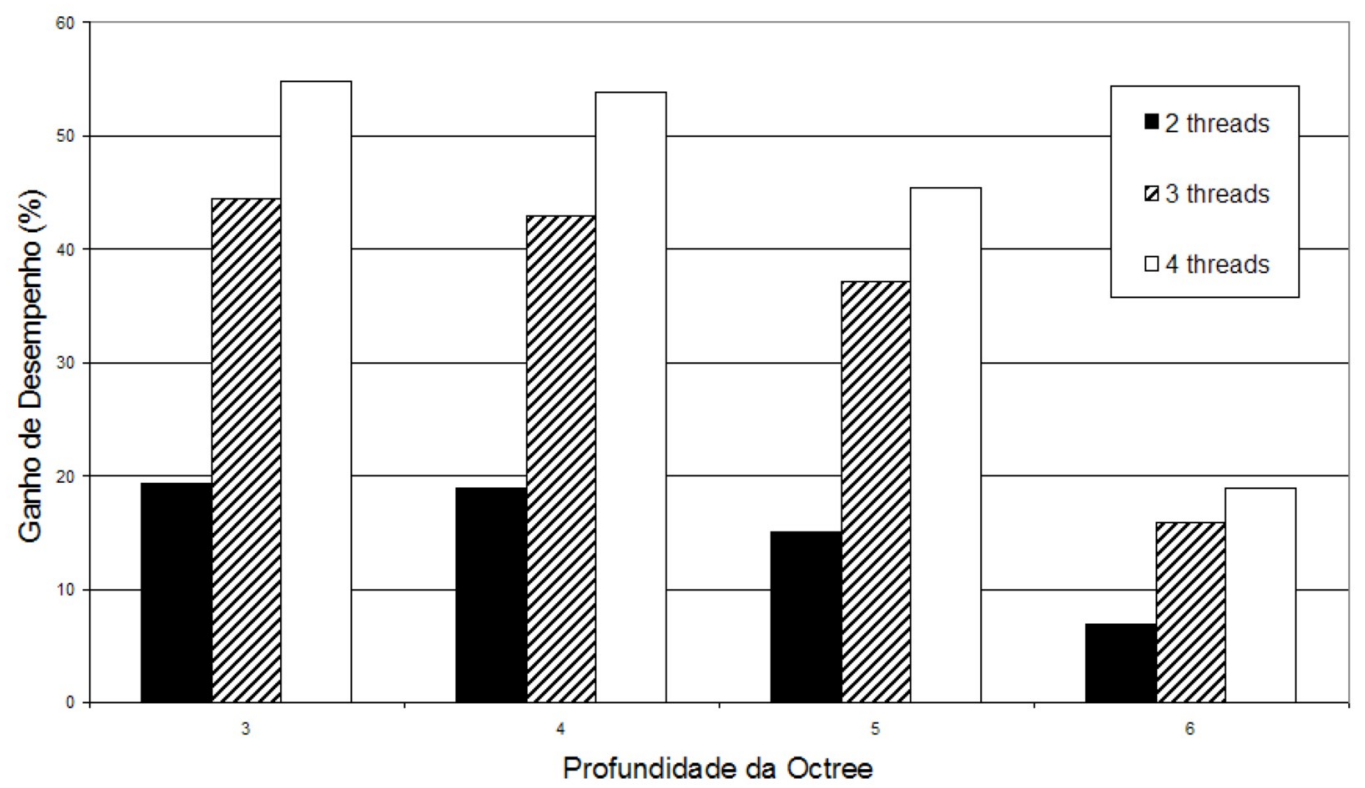

Figura 39 - Ganho de desempenho relativo com a execução do algoritmo com múltiplas threads

\subsubsection{Desempenho dos Testes de Deteç̧ão de Colisão}

Para verificar o desempenho do algoritmo de teste de colisão entre o vídeo-avatar e outros objetos, foi implementado um protótipo que fornecia um conjunto de pontos para o algoritmo de construção da octree de forma a produzir uma configuração alternada de regiões ocupadas e vazias no espaço. Esta configuração, ilustrada na Figura 40, faz com que todos os nós internos da octree sejam marcados como "parcialmente preenchidos" e, conseqüentemente, todo teste de colisão tenha que ser avaliado até atingir a profundidade máxima da octree. Esta configuração, que pode ser considerada um exemplo de pior caso para o algoritmo, é uma boa medida para o limite inferior de desempenho do mesmo. 


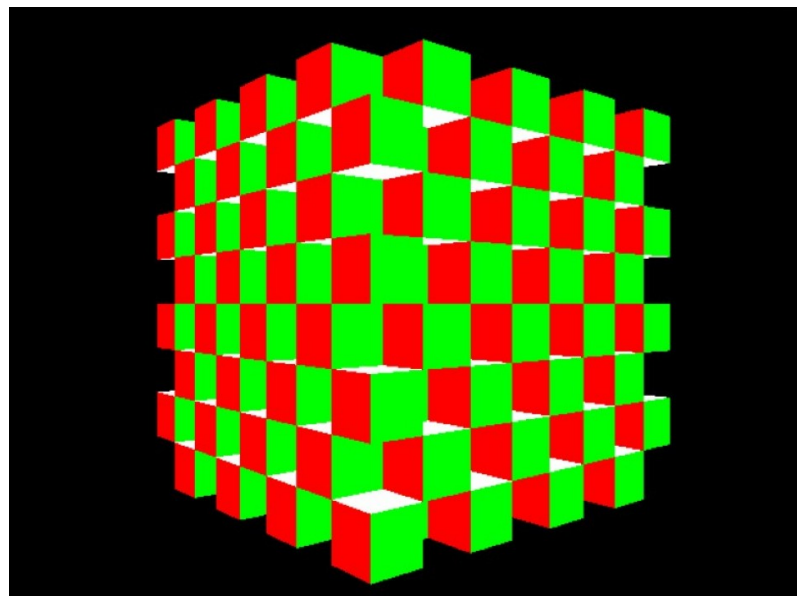

Figura 40 - Visualização da configuração da octree para avaliação de desempenho do algoritmo de teste de colisão

A octree foi configurada para envolver uma região cúbica com 2 unidades de lado. Um conjunto de mil volumes envoltórios foi gerado dentro de um volume cúbico de 2,4 unidades de lado. Desta forma, alguns dos volumes poderiam ser gerados fora da região compreendida pela octree.

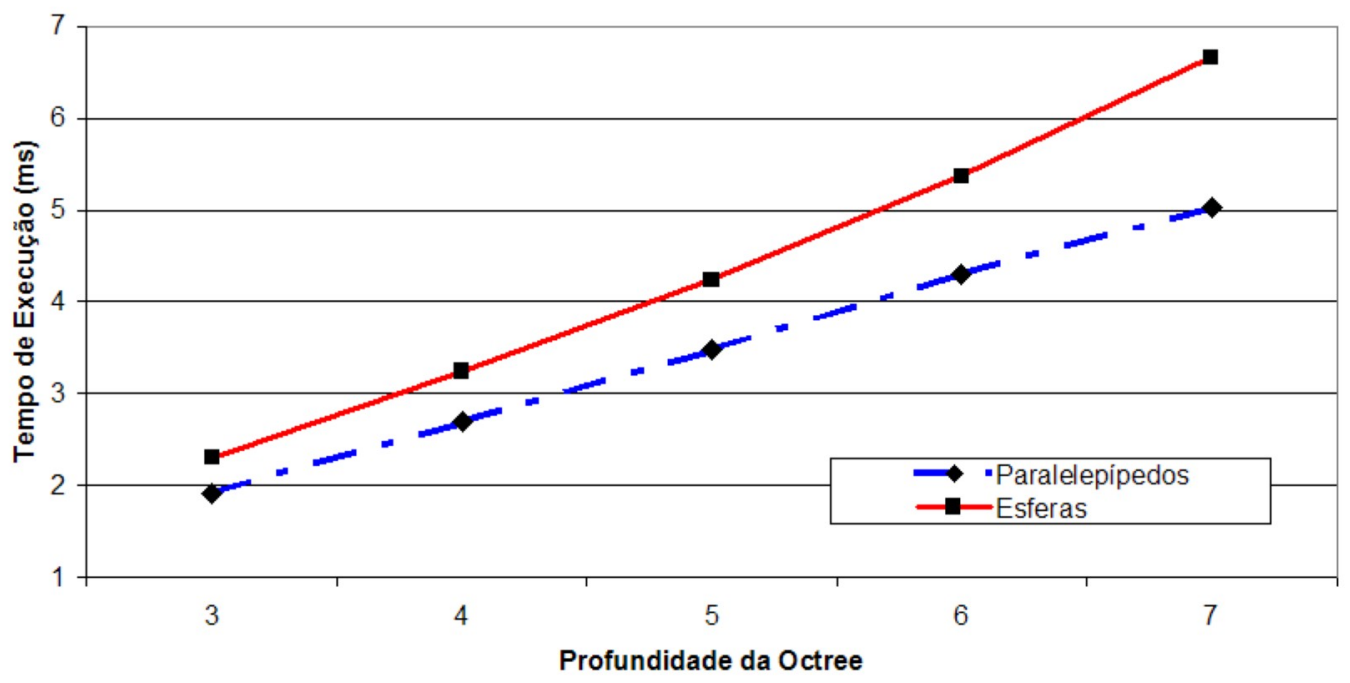

Figura 41 - Tempos médios de execução dos testes de colisão do video-avatar com mil objetos

Foram realizados testes separados nos quais os volumes eram cubos com 0,2 unidades de lado e outros testes empregando esferas de 0,2 unidades de diâmetro. Cada um dos testes foi repetido cem vezes para cada conjunto de volumes e os tempos de execução foram medidos, para octrees de diferentes profundidades. Durante os testes, foram verificadas grandes flutuações nas medições realizadas ao se utilizar o computador Intel Core 2 Quad. Tais variações foram atribuídas a limitações de precisão das funções de medição de tempo utilizadas. Por este motivo, o teste foi repetido utilizando-se uma versão executável não otimizada em um 
computador com menor capacidade de processamento: um AMD 64 3200+ com $1 G B$ de RAM. Os resultados dos testes realizados nesta plataforma são apresentados na Figura 41. Os tempos de execução indicados se referem à realização dos testes de colisão contra mil volumes.

\subsection{Considerações Finais}

Este capítulo apresentou as técnicas propostas para o sistema de vídeo-avatar com interação 3D para uso em equipamentos domésticos, bem como os resultados de testes realizados com implementações de tais técnicas.

Os mapas de disparidade produzidos pelo algoritmo proposto nesta tese tiveram percentual de pixels ruins variando entre $9,953 \%$ e $16,42 \%$ para a imagem de referência "Sawtooth" e entre 10,89\% e $31,96 \%$ para a imagem de referência "Venus". Os resultados de Scharstein e Szeliski (2002) para algoritmos semelhantes mostram medidas de porcentagem de pixels ruins entre $5 \%$ e $15 \%$ para a imagem "Sawtooth" e entre 10\% e 30\% para a imagem "Venus". Desta forma, pode-se concluir que o algoritmo de mapa de profundidade proposto é praticamente equivalente a outros algoritmos baseados em métodos locais de imageamento estéreo encontrados na literatura, em termos da qualidade do mapa de profundidade. Ao mesmo tempo, o desempenho do protótipo de mapa de profundidade se mostrou satisfatório quando se utilizou uma janela de avaliação de $5 \times 5$ pixels. Neste caso, o tempo de execução foi significativamente inferior a $100 \mathrm{~ms}$ mesmo sem a execução paralelizada do algoritmo. Deve-se observar, no entanto, que esta implementação foi desenvolvida de forma a permitir flexibilidade nos parâmetros do algoritmo. Portanto, implementações mais otimizadas devem existir.

Por fim, o desempenho dos protótipos implementados dos algoritmos de construção da octree e detecção de colisão se mostrou adequado para a utilização em tempo real em um computador pessoal.

Para se ter maior controle sobre a repetibilidade dos testes e permitir isolar as características dos algoritmos, foram utilizadas imagens controladas, como as do repositório de imagens estereoscópicas de Middlebury, ou imagens sintéticas, nas quais os parâmetros das câmeras eram conhecidos. 
É interessante observar que os tempos de execução dos algoritmos de mapa de profundidade e detecção de colisão, quando somados, se mantêm abaixo de 100ms, ao menos em algumas configurações. Conseqüentemente, isto demonstra que as técnicas propostas conseguem satisfazer o requisito de taxa de atualização do vídeo-avatar. 


\section{AVMix: Sistema de Vídeo-AvataR}

Com base nos resultados apresentados no capítulo 5, torna-se possível especificar um sistema de vídeo-avatar integrando as técnicas propostas. Este capítulo apresenta a especificação do AVMix, uma proposta de tal sistema. Inicialmente, é apresentada uma visão geral e um detalhamento de seus componentes. Em seguida, são mostrados resultados qualitativos de um protótipo implementado.

\subsection{Visão Geral do sistema AVMix}

O AVMix é um sistema de software para a geração de vídeo-avatar com interação 3D a partir da captura da imagem do usuário através de duas câmeras de vídeo. $\mathrm{O}$ objetivo deste sistema é fornecer a infra-estrutura de geração deste vídeo-avatar para aplicações de Realidade Aumentada voltadas para equipamentos domésticos, como computadores pessoais e webcams. Desta forma, a especificação do sistema AVMix busca atingir os objetivos propostos para esta tese.

Considerando-se a independência de algumas operações necessárias para a criação do vídeo-avatar, a arquitetura do sistema AVMix foi dividida em cinco subsistemas: Aquisição, Segmentação, Mapa de Profundidade, Composição e Interação, conforme ilustrado na Figura 42 seguindo a notação da UML 2.0 (FOWLER, 2005).

Para maior clareza na visualização do diagrama, os nomes das interfaces entre os subsistemas foram omitidos. O componente denominado "Câmeras" inclui as câmeras digitais, os drivers de dispositivo das mesmas e as bibliotecas de software externas, utilizadas para acessar os quadros por elas capturados. Esta divisão permite uma maior flexibilidade da implementação do sistema AVMix, pois, uma vez que as interfaces entre os subsistemas sejam bem definidas, é possível fazer alterações na implementação de cada um deles. 


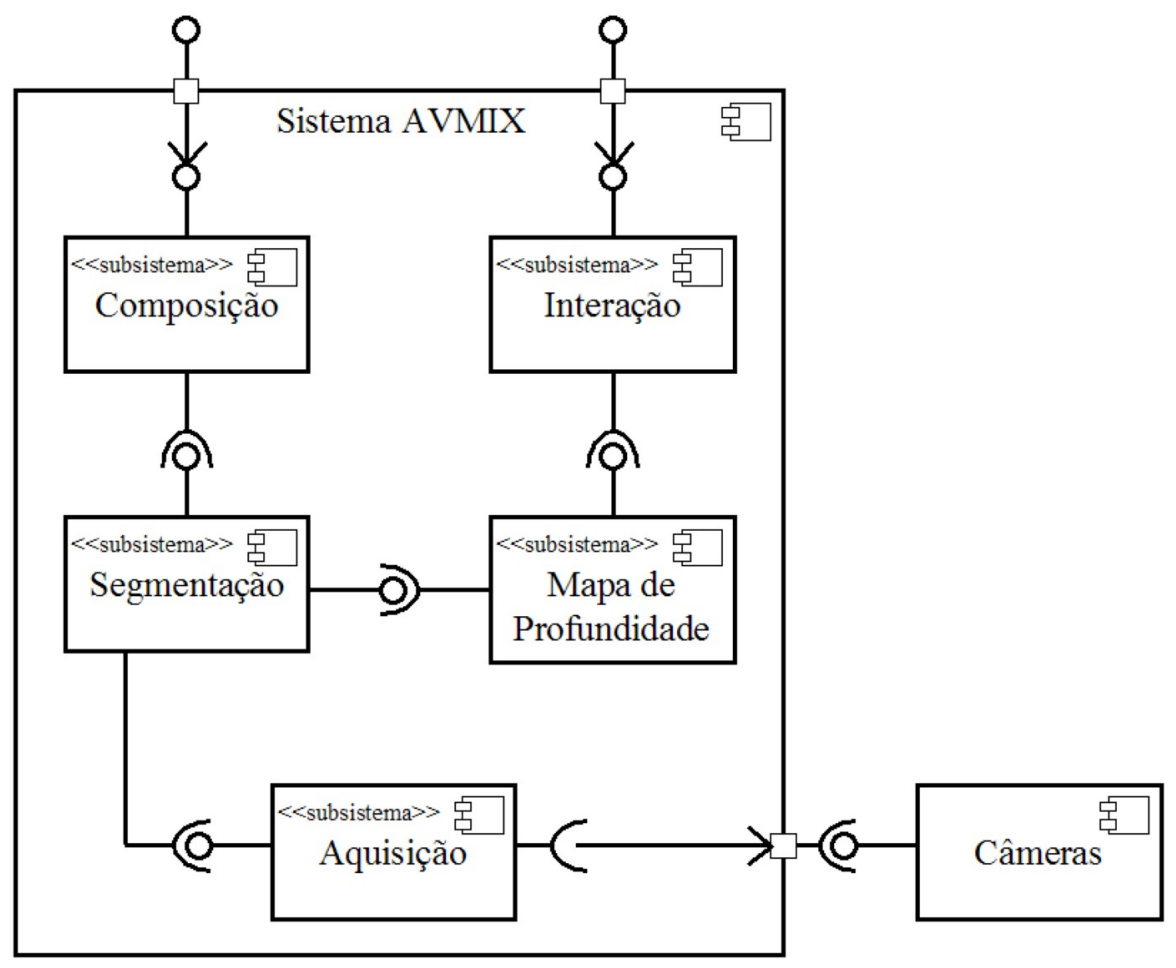

Figura 42 - Subsistemas da arquitetura do sistema AVMIX.

Os subsistemas do sistema AVMix serão discutidos nas próximas seções. Os diagramas de classes do projeto podem ser encontrados no Apêndice $B$, juntamente com diagramas de seqüência ilustrando padrões de utilização do sistema.

\subsection{Subsistema de Aquisição}

O subsistema de Aquisição é responsável pela obtenção dos quadros de vídeo que serão processados pelo restante do sistema. Desta forma, este subsistema faz a interface com as câmeras de vídeo digitais. A motivação para a existência deste componente é permitir o desacoplamento do restante do sistema de tecnologias específicas de aquisição de vídeo, tanto em software como hardware. Opcionalmente, esse subsistema pode realizar a sincronização da captura dos quadros de vídeo das câmeras, para garantir um limite máximo de atraso entre os instantes em que os quadros foram capturados.

O principal serviço fornecido pelo subsistema de Aquisição é a produção de pares de quadros de vídeo no formato de bitmaps não compactados, com resolução especificada pelos outros subsistemas, a partir de uma fonte de vídeo previamente 
configurada. Conseqüentemente, o subsistema é responsável pelas eventuais conversões de formato e de resolução necessárias entre a imagem capturada e aquela que deve ser fornecida. Para atingir este objetivo, foi especificada uma interface denominada IStereoPair, que representa uma fonte de pares de quadros de vídeo estereoscópicos. Diferentes implementações desta interface podem existir, de acordo com as tecnologias utilizadas.

$\mathrm{Na}$ implementação do sistema AVMix, existem três classes concretas correspondentes a esta interface: CameraPairOpenCV, e CameraPairDSVL que se utilizam de duas bibliotecas de captura de vídeo e VideoPair, que se utiliza de quadros de vídeo gravados como imagens previamente. O subsistema de Aquisição também é responsável pela calibração das câmeras e pela realização da operação de retificação sobre as imagens capturadas, de forma que o par de quadros possa ser tratado como o caso ideal de imageamento estéreo. Na implementação do protótipo do subsistema de aquisição, não foi incluído nenhum recurso para a sincronização explícita da aquisição das imagens provenientes das duas câmeras de vídeo.

\subsubsection{Calibração}

A calibração do par de câmeras utilizadas para o vídeo-avatar consiste em estabelecer seus parâmetros intrínsecos e extrínsecos. Os parâmetros intrínsecos da câmera são relacionados às características ópticas da lente e da câmera: distância focal, distorção radial da lente e posição do centro da imagem (intersecção do eixo óptico com o plano da imagem). Os parâmetros extrínsecos da câmera se referem à posição e orientação de cada câmera em relação a um sistema de coordenadas previamente definido.

O sistema AVMix utiliza o método de calibração proposto por Zhang (2000), no qual um conjunto de pontos com uma configuração geométrica conhecida é detectado em uma série de imagens. A transformação de homografia é calculada entre estas imagens e o erro de projeção é minimizado, para se obter os parâmetros intrínsecos e extrínsecos das câmeras. No protótipo, utiliza-se a implementação deste algoritmo existente na biblioteca de processamento de imagens OpenCV (OPENCV, 2008). 
Primeiramente, devem ser capturados pares de imagens, correspondentes à observação simultânea pelas duas câmeras do objeto de calibração - no caso, um padrão quadriculado retangular, como mostrado na Figura 43.

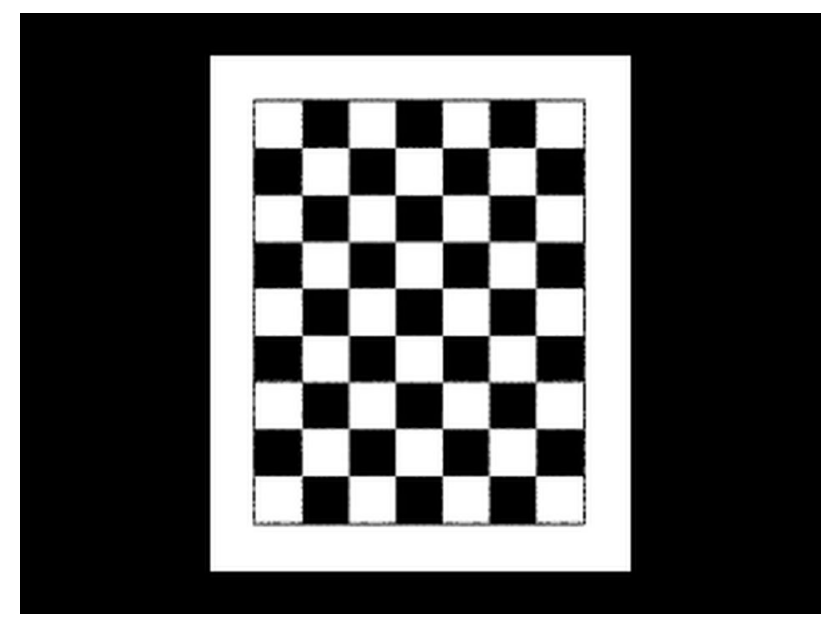

Figura 43 - Objeto de calibração utilizado na calibração das câmeras

Embora o algoritmo de Zhang (2000) permita a calibração de uma câmera a partir de apenas duas imagens de configurações distintas do objeto de calibração, observouse experimentalmente que os melhores resultados são obtidos utilizando-se três imagens com configurações bastante distintas do objeto de calibração, cobrindo diferentes áreas do plano de imagem. A Figura 44 mostra um conjunto de configurações do objeto de calibração que atendem a estes requisitos e podem ser facilmente reproduzidas por um usuário doméstico.
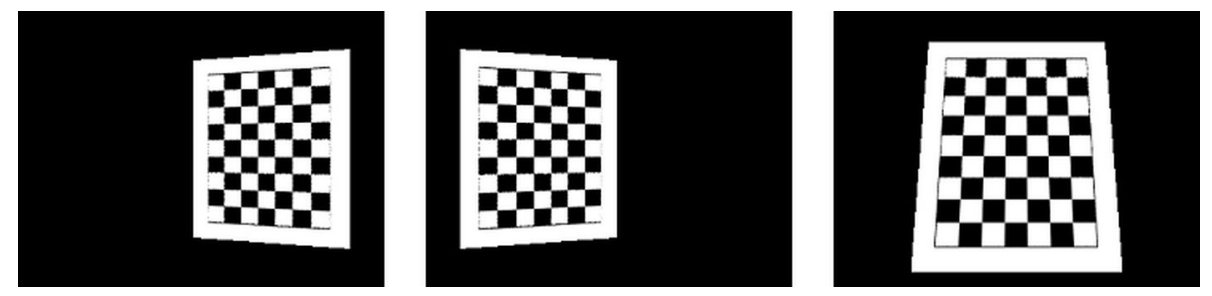

Figura 44 - Exemplo de configurações do objeto de calibração que levam a um bom desempenho do algoritmo de Zhang (2000)

$\mathrm{Na}$ implementação do sistema AVMix, a classe CameraParams armazena os parâmetros intrínsecos e extrínsecos de uma câmera e também implementa a execução do algoritmo de calibração. Adicionalmente, a classe CalibrationTool pode ser utilizada para simplificar a tarefa de calibração simultânea de um par de câmeras para visão estereoscópica. 


\subsubsection{Retificação}

O processo de retificação de um par estereoscópico de imagens foi explicado na seção 3.4.2. No sistema AVMix, a retificação das imagens é feita de acordo com o algoritmo proposto por Fusiello, Trucco e Verri (2000). Este algoritmo define um novo sistema de coordenadas que corresponderia à orientação do par de câmeras paralelas, da seguinte forma:

- $O$ eixo $X$ do novo sistema é tomado como paralelo ao vetor que une os centros ópticos das câmeras (linha de base);

- O eixo $\mathrm{Y}$ do novo sistema é definido como perpendicular ao eixo $\mathrm{X}$ e perpendicular ao eixo óptico de uma das câmeras;

- $O$ eixo $Z$ do novo sistema é definido como perpendicular aos eixos $X$ e $Y$ calculados anteriormente.

As matrizes de transformação de cada câmera para este novo sistema são calculadas e, a partir delas, as matrizes de projeção são determinadas. Estas matrizes de projeção, quando aplicadas sobre as imagens provenientes das câmeras, resultam nas imagens retificadas.

A implementação desta técnica é realizada na classe RectificationParams, que também armazena as matrizes de transformação para retificação das imagens.

\subsection{Subsistema de Segmentação}

O subsistema de Segmentação é responsável pelo processamento de imagens obtidas a partir do subsistema de Aquisição, produzindo novas imagens que contenham somente o usuário sobre um fundo de cor uniforme. Estas imagens podem ser utilizadas tanto para a geração mais eficiente de mapas de profundidade como também para a composição do vídeo-avatar com o ambiente virtual. 


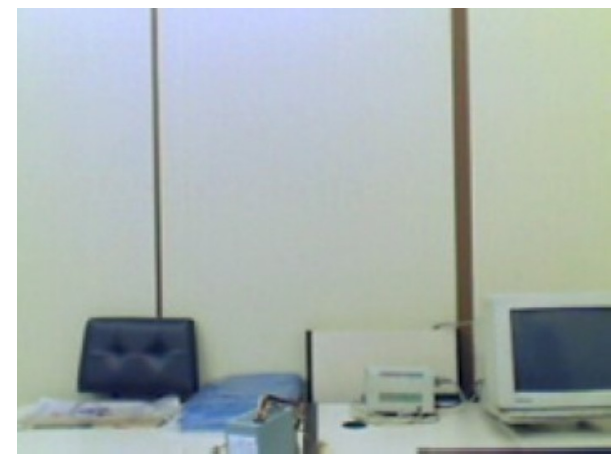

(a)

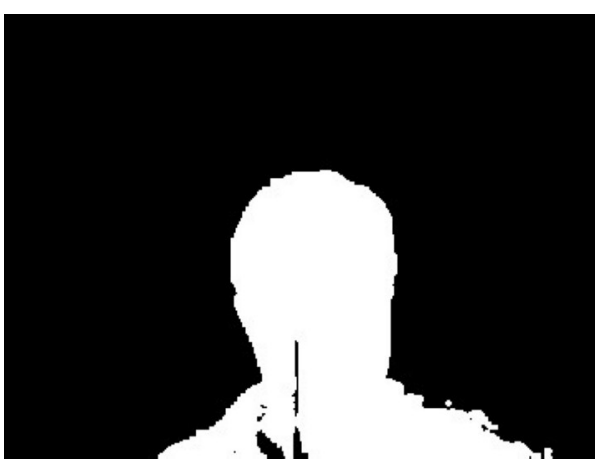

(c)

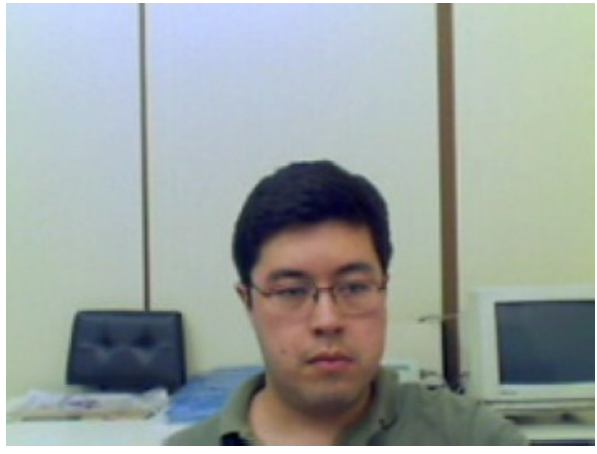

(b)

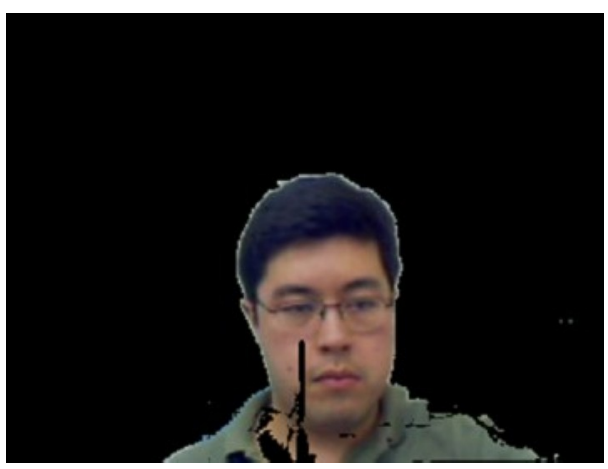

(d)

Figura 45 - Exemplo do algoritmo de segmentação: (a) imagem de referência; (b) quadro capturado; (c) máscara obtida por subtração e limiarização; (d) imagem segmentada resultante.

Atualmente, o subsistema de Segmentação utiliza a técnica de subtração de fundo estático para realizar a remoção do fundo das imagens. Para isso, uma imagem de referência da cena de fundo vista através de cada uma das câmeras é armazenada. Posteriormente, a subtração pixel a pixel entre os quadros capturados e as imagens de referência é realizada. Uma operação de limiarização é realizada sobre a imagem resultante, obtendo-se uma máscara que pode ser utilizada para segmentar o fundo da imagem. Para remover ruídos provenientes do processo de subtração, é realizada uma operação de dilatação e erosão sobre a máscara, antes da sua aplicação na imagem. A Figura 45 ilustra a aplicação do algoritmo descrito, mostrando um quadro de referência, um novo quadro capturado pela câmera, a máscara de segmentação obtida pela subtração entre imagens e limiarização e a imagem segmentada.

Uma das vantagens do algoritmo adotado é que sua execução é rápida e não requer preparação especial do fundo da cena. No entanto, como se pode observar, a segmentação pode apresentar falhas quando existe similaridade de cor entre a imagem de referência e os quadros capturados posteriormente. 
Uma alternativa para a segmentação é a técnica de chroma-key, utilizada em Siscoutto (2003). De forma simplificada, essa técnica identifica o fundo por uma tonalidade de cor previamente definida. Sanches (2007) apresenta uma explicação detalhada desta técnica e suas variações. Esta técnica não foi adotada no protótipo do sistema AVMix por necessitar de um fundo com cor definida e conhecida.

Para permitir flexibilidade na escolha do algoritmo de segmentação, foi especificada uma interface IBackgroundRemover e implementada uma classe BGSubtractor para o algoritmo de subtração de fundo estático.

O subsistema de Segmentação também utiliza os serviços do subsistema de Aquisição para realizar a retificação das imagens segmentadas, que serão fornecidas para o subsistema de Mapa de Profundidade.

\subsection{Subsistema de Mapa de Profundidade}

O subsistema de Mapa de Profundidade é responsável pela geração de um mapa de profundidade de um par estereoscópico de imagens obtido a partir do subsistema de Segmentação. O algoritmo utilizado foi detalhado no capítulo 5.

A especificação do sistema AVMix define uma interface IDepthMapper, responsável pelo processamento de um par estéreo de imagens segmentado e retificado. Também é definida a classe concreta DMFlex, que é uma implementação parametrizável do algoritmo de mapa de profundidade, para a qual o usuário pode selecionar:

- Tamanho da janela de avaliação;

- Valor máximo de disparidade a ser considerado entre as imagens;

- Se as imagens devem ser processadas em formato colorido (RGB) ou somente no canal de luminância (escala de cinza);

- Número de threads para execução paralelizada do algoritmo. 


\subsection{Subsistema de Composição}

O subsistema de Composição utiliza as imagens provenientes do subsistema de Segmentação para construir uma representação visual do vídeo-avatar, que é fornecida para aplicações usuárias do sistema AVMix.

A interface IVideoAvatar é definida para permitir diferentes implementações dessa representação visual. Na implementação do sistema AVMix desenvolvida durante esta tese, a abordagem adotada para a representação visual é a mesma de Siscoutto (2003) e consiste em se utilizar um modelo geométrico plano com a imagem segmentada do vídeo-avatar aplicada como textura sobre o mesmo. A vantagem desta representação é que não há necessidade de ser realizar nenhum tipo de reconstrução geométrica e o processamento de renderização pode ser realizado inteiramente em uma placa aceleradora gráfica, reduzindo-se o custo de processamento. A desvantagem desta técnica é que, por se tratar de uma representação bidimensional, ela se torna inadequada caso seja preciso rotacionar o ponto de vista.

Adicionalmente, o protótipo do sistema AVMix também permite a visualização da imagem do vídeo-avatar com uma transformação geométrica de espelhamento, que já foi discutida anteriormente.

\subsection{Subsistema de Interação}

O subsistema de Interação fornece os serviços de detecção de colisão entre o modelo do vídeo-avatar e outros objetos do ambiente virtual no qual ele está inserido. Este sistema também é responsável pela construção e atualização do modelo de colisão baseado em octree utilizado pelo vídeo-avatar. Os algoritmos utilizados neste subsistema foram detalhados no capítulo 5 .

Assim como nos outros subsistemas, define-se primeiramente uma interface, que neste caso é denominada ICollisionModel e, em seguida, uma implementação concreta da mesma, correspondente às técnicas propostas nesta tese. Desta forma, o sistema AVMix define a classe Octree, responsável pela implementação dos 
algoritmos de construção da árvore e detecção de colisão e a classe OctreeCollisionModel, que realiza a conversão do mapa de profundidade em pontos do espaço tridimensional que serão processados pela octree. As classes BoundingBox e BoundingSphere são utilizadas para representar volumes envoltórios dos objetos virtuais.

\subsection{Resultados}

Um protótipo do sistema AVMix foi implementado na linguagem $\mathrm{C}++$, utilizando-se as bibliotecas OpenCV (OPENCV, 2008) e OpenGL (OPENGL, 2008). Utilizando-se este protótipo, foi desenvolvida uma aplicação de teste que consiste em um ambiente virtual contendo um único objeto de cor branca posicionado à frente da região que pode ser ocupada pelo vídeo-avatar. Quando uma colisão é detectada entre o objeto e o vídeo-avatar, a cor do objeto é alterada para magenta.

A aplicação de teste foi executada em uma plataforma de hardware consistindo em um computador com processador Intel Core 2 Quad Q6600, com 2GB de memória e placa de vídeo GeForce $8600 \mathrm{GT}$, com sistema operacional Windows XP. Foram utilizadas duas webcams Upson modelo CC-883, com conexão USB 2.0, configuradas para aquisição de imagens na resolução de $320 \times 240$ pixels, formato de cores RGB com 24 bits/pixel a 15 quadros por segundo. Outros modelos de câmeras com características técnicas semelhantes podem ser utilizados, mas é recomendável que os seus drivers permitam um controle manual de brilho, contraste e ajuste de branco (white balance). A Figura 46 mostra uma imagem da execução do sistema, com cinco janelas. Em sentido horário, a partir do canto superior esquerdo, tem-se: a janela principal, que exibe o ambiente de realidade aumentada, contendo o objeto virtual e o vídeo-avatar; a janela que exibe o mapa de profundidade que está sendo gerado; a janela de console, que exibe informações sobre os comandos que podem ser dados para a aplicação e, por último, duas janelas que exibem as imagens capturadas das câmeras, retificadas, segmentadas e convertidas para escala de cinza. Desta forma, é possível observar não somente o resultado final (exibido na primeira janela), mas também os resultados intermediários gerados durante 0 
processamento do sistema. A partir desta interface, é possível realizar uma avaliação qualitativa dos resultados do sistema AVMix.

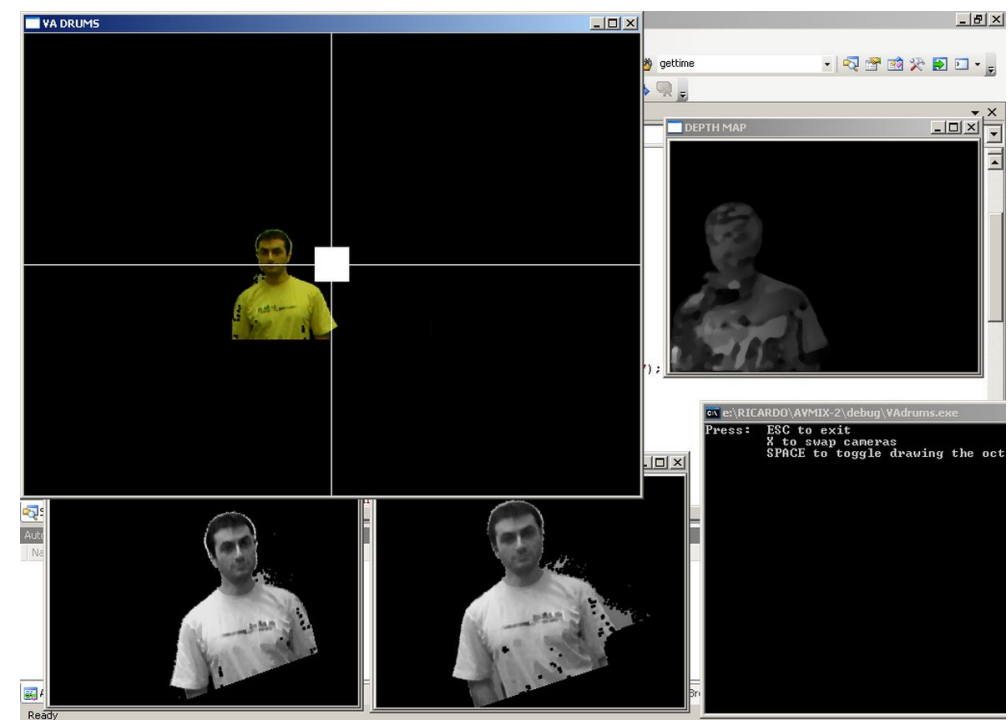

Figura 46 - A aplicação de teste do sistema AVMix

A Figura 47 apresenta outra imagem da aplicação de testes do sistema AVMix. Nesse caso, a janela principal exibe uma representação da octree utilizada para detecção de colisão no espaço sobre a imagem do vídeo-avatar. Cada bloco colorido corresponde a um nó da octree, utilizando uma codificação em cores que representa a distância entre aquele nó e a câmera. Adicionalmente, observa-se que o objeto virtual é desenhado na cor magenta, para indicar que foi detectada uma colisão entre o vídeo-avatar e aquele objeto.

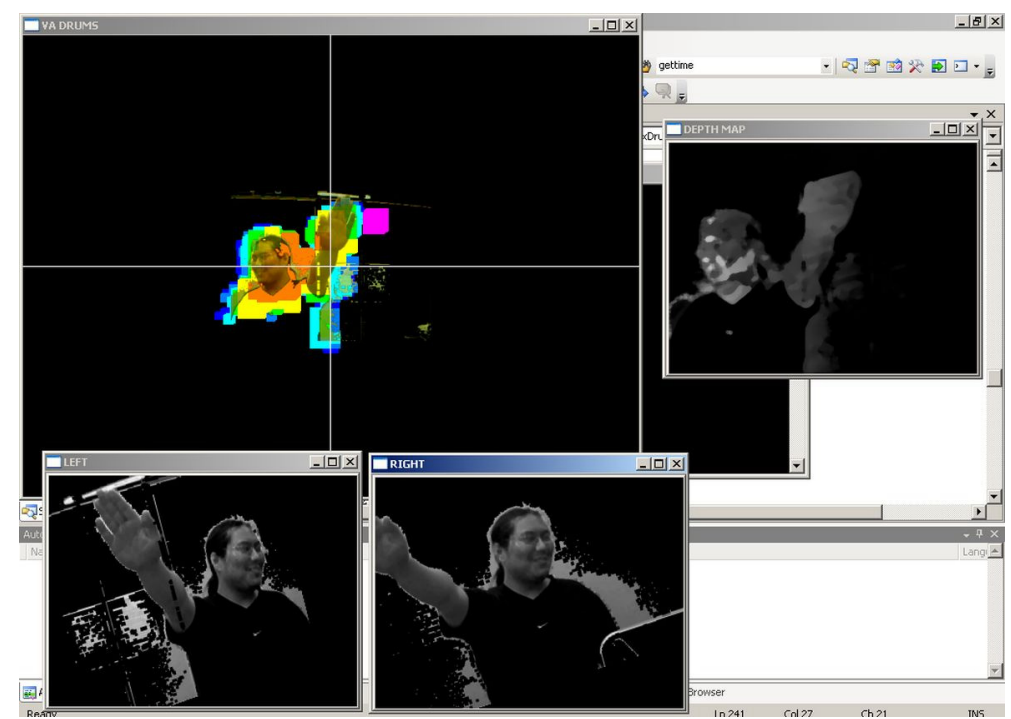

Figura 47 - Exibição da octree utilizada para colisão na aplicação de teste do sistema AVMix Além da avaliação qualitativa, na qual procurou-se determinar a qualidade visual do vídeo-avatar e a detecção de colisões entre o vídeo-avatar e objetos virtuais, 
também foi realizada uma medição de desempenho da aplicação. Para isso, o código da aplicação foi modificado para calcular o intervalo de tempo transcorrido durante o processamento de um par de quadros de vídeo obtidos das câmeras, utilizando-se a função GetTickCount da biblioteca OpenCV. Os valores foram gravados em arquivo e posteriormente, o tempo médio de execução foi calculado como a média aritmética desses valores. A taxa de quadros por segundo da aplicação foi calculada como o inverso deste valor.

Tabela 5 - Tempo de processamento por quadro da aplicação de teste do sistema AVMix, em função do número de threads

\begin{tabular}{|c|r|r|}
\hline Número de Threads & Tempo de processamento $(\mathrm{ms})$ & Taxa de quadros/segundo \\
\hline 1 & 94,62 & 10,57 \\
\hline 2 & 62,83 & 15,92 \\
\hline 3 & 43,52 & 22,98 \\
\hline 4 & 38,08 & 26,30 \\
\hline
\end{tabular}

A Tabela 5 apresenta os tempos médios de processamento e taxas de quadros por segundo, variando-se o número de threads para o algoritmo de cálculo do mapa de profundidade. Os parâmetros do sistema foram: imagens de 320x240 pixels, janela de avaliação $5 \times 5$, cálculo do mapa utilizando-se imagens em escala de cinza (somente um canal, de luminância), suavização do mapa de profundidade com filtro de mediana $7 \times 7$ e uma octree com sete níveis (profundidade máxima seis).

\subsection{Considerações Finais}

Neste capítulo foi apresentada a arquitetura do sistema AVMix, definida a partir das técnicas propostas no capítulo 5. Os subsistemas que compõem o sistema AVMix foram descritos, incluindo suas responsabilidades e interfaces. Este capítulo também apresentou uma aplicação de teste, desenvolvida a partir de uma implementação do sistema AVMix. Esta aplicação foi utilizada para uma avaliação qualitativa e quantitativa do sistema, permitindo verificar a viabilidade da proposta da tese. 


\section{CONCLUSÃo}

As principais contribuições desta tese são as técnicas propostas para o cálculo do mapa de profundidade, construção de um modelo de colisão baseado em octree e detecção de colisão com objetos do ambiente virtual, representados por volumes envoltórios simplificados. A partir da integração destas técnicas, é possível obter-se um vídeo-avatar capaz de interagir em tempo real, em três dimensões, com objetos de um ambiente virtual.

Os resultados de testes realizados com protótipos das técnicas propostas demonstram a viabilidade de se utilizar esse vídeo-avatar em um sistema composto de um computador pessoal e duas câmeras digitais domésticas.

\subsection{Trabalhos Futuros}

Trabalhos que podem continuar o desenvolvimento do sistema AVMix incluem a investigação de algoritmos alternativos de calibração das câmeras, retificação e segmentação das imagens. Também é possível citar como trabalhos derivados desta tese o desenvolvimento de novas aplicações de Realidade Aumentada que utilizem o sistema AVMix ou as técnicas propostas de mapa de profundidade e interação como parte de sua infra-estrutura.

\subsubsection{Calibração dinâmica de cores das webcams}

Durante os testes qualitativos do sistema AVMix, observou-se que os resultados obtidos eram sensíveis aos parâmetros de configuração das câmeras. Ocorre que muitos modelos de webcams fazem ajustes automáticos de brilho e contraste, que não podem ser desativados. Para aumentar a robustez do sistema, pode-se propor um algoritmo capaz de, adaptativamente, compensar os ajustes automáticos das câmeras durante a execução do software. 


\subsubsection{Estereoscopia}

Um dos possíveis desenvolvimentos para a continuidade do projeto apresentado nesta tese consiste na expansão do sistema AVMix para permitir a exibição de vídeo-avatares estereoscópicos, de maneira semelhante ao trabalho de Siscoutto (2003). Como os objetivos desta tese se encontravam em propor técnicas para viabilizar um vídeo-avatar com interação tridimensional em sistemas de baixo custo, esta funcionalidade não foi abordada. Adicionalmente, as técnicas propostas e o sistema AVMix permitem a variação da distância de linha de base entre as câmeras para que se possa ajustar a resolução do mapa de profundidade. No entanto, a princípio, a captura de imagens para exibição estereoscópica deveria ser realizada com uma distância de linha de base igual à separação interocular humana. $O$ estudo de como conciliar estes requisitos, bem como a análise de técnicas de exibição de imagens esteroscópicas sem a necessidade de dispositivos de custo elevado, poderiam ser abordados em trabalhos futuros.

\subsubsection{Reconstrução Parcial do Vídeo-Avatar}

Atualmente, o sistema AVMix utiliza uma representação visual bidimensional para o vídeo-avatar, o que implica na adoção de um ponto de vista fixo para a câmera no ambiente virtual. Esta representação visual poderia ser modificada para um modelo tridimensional, poligonal ou volumétrico. Tal modelo ainda seria uma reconstrução parcial do usuário devido à utilização de somente duas câmeras, mas poderia permitir alguma variação no ponto de vista da câmera virtual. Um dos motivos para se adotar a representação bidimensional no sistema AVMix é o maior custo computacional dos algoritmos de reconstrução. A busca de algoritmos de reconstrução que possam ser executados em tempo real em um computador pessoal poderia ser o tema de uma nova pesquisa. 
7.1.4 Integração com o enJine

O enJine (ENJINE, 2008) é um projeto do INTERLAB visando o desenvolvimento de um engine para jogos didático e expansível. Um engine para jogos pode ser definido como um conjunto de componentes integrados e reutilizáveis que facilitam 0 desenvolvimento de jogos de computador (NAKAMURA, 2003). A integração entre uma implementação do sistema AVMix com o enJine permitiria a sua utilização para o desenvolvimento de projetos de jogos envolvendo vídeo-avatar. Dado que o enJine é escrito na linguagem Java com a biblioteca Java 3D (JAVA MEDIA 3D, 2008), uma possível abordagem seria a integração do código do protótipo do sistema AVMix, através da tecnologia Java Native Interface (JNI).

\subsubsection{Implementações Paralelizadas e Utilização de GPGPU}

Atualmente, as implementações propostas para os algoritmos de mapa de profundidade e detecção de colisão já utilizam recursos de paralelismo. No entanto, diferentes implementações poderiam ser propostas, notavelmente para a consolidação da octree. Da mesma forma, trabalhos futuros poderiam explorar a viabilidade de se implementar estes algoritmos através de técnicas de GPGPU (General Programming on the GPU), passando parte do custo de processamento para a placa aceleradora de vídeo. 


\section{REFERÊNCIAS*}

3DV SYSTEMS. Contém informações sobre o sistema Z-Cam. Disponível em: <http://www.3dvsystems.com/>. Acesso em: 21 jan. 2008.

AZUMA, R. T. A Survey of Augmented Reality. Presence: Teleoperators and Virtual Environments, [S.I.], v.6, n.4, p. 355-385, ago. 1997.

BASRI, R.; JACOBS, D. Photometric stereo with general, unknown lighting. International Journal of Computer Vision. EUA, v. 72, n. 3, p. 239-357, maio 2007.

BIANCHINI, R. C. Uma Arquitetura BDI para Comportamentos Interativos de Agentes em Jogos Computacionais. 2005. 215 f. Tese (Doutorado em Engenharia Elétrica) - Escola Politécnica, Universidade de São Paulo, São Paulo, 2005.

BILLINGHURST, M.; GRASSET, R.; LOOSER, J. Designing Augmented Reality Interfaces. Computer Graphics, New York, EUA, v. 39, n. 1, p. 17-22, fev. 2005.

BILLINGHURST, M.; KATO, H. Collaborative Mixed Reality. In: INTERNATIONAL SYMPOSIUM ON MIXED REALITY, 1., 1999, Yokohama, Japão. Anais... Berlim, Alemanha: Springer-Verlag, 1999. p. 261-284.

BLOW, J. Game Development: Harder Than You Think. ACM Queue, New York, EUA, v.1, n.10, p. 28-37, fev. 2004.

CHEN, L.; TIAN, M.; CHEN, G.; CHEN, C. Using Stereo Camera to Realize Realistic Video Avatar in Virtual Environment. In: INTERNATIONAL CONFERENCE ON SIGNAL PROCESSING, 6., 2002, Beijing, China. Anais... New York, EUA: IEEE, 2002. p. 707-710.

CHEOK, A. D.; GOH, K. H.; LIU, W.; FARBIZ, F.; TEO, S. L.; LEE, S. P.; LI, Y.; FONG, S. W.; YANG, X. Human Pacman: A mobile wide-area entertainment system based on physical, social, and ubiquitous computing. In: ACM SIGCHI INTERNATIONAL CONFERENCE ON ADVANCES IN COMPUTER ENTERTAINMENT TECHNOLOGY, 2004, Singapura. Anais... New York, EUA: ACM Press, 2004. p. 360-361.

"De acordo com:

ASSOCIAÇÃO BRASILEIRA DE NORMAS TÉCNICAS. NBR 6023: informação e documentação: referências: elaboração. Rio de Janeiro, 2002. 
CHUNG, K.; WANG, W. Quick collision detection of polytopes in virtual environments. In: SYMPOSIUM ON VIRTUAL REALITY SOFTWARE AND TECHNOLOGY, 1996, Hong Kong, China. Anais... New York, EUA: ACM Press, 1996. p. 125-131.

COHEN, J. D.; LIN, M. C.; MANOCHA, D.; PONAMGI, M. K. I-COLLIDE: an interactive and exact collision detection system for large-scale environments. In: SYMPOSIUM ON INTERACTIVE 3D GRAPHICS, 1995, Monterey, EUA. Anais... New York, EUA: ACM Press, 1995. p. 189-197.

DEBEVEC, P; TAYLOR, C. J.; MALIK, J. Modeling and Rendering Architecture from Photographs: A hybrid geometry- and image-based approach. In: INTERNATIONAL CONFERENCE ON COMPUTER GRAPHICS AND INTERACTIVE TECHNIQUES, 23, 1996, New Orleans, EUA. Anais... New York, EUA: ACM Press, 1996. p. 11-20.

DIOT, C.; GAUTIER, L. A distributed architecture for multiplayer interactive applicationson the Internet. IEEE Network, EUA, v. 13, n. 4, p. 6-15, jul. 1999.

EBERLY, D. H. 3D Game Engine Design. San Francisco, EUA: Morgan-Kaufmann, 2001. 561p.

ENJINE: Engine for Games in Java. Disponível em: <https://enjine.dev.java.net/>. Acesso em: 21 jan. 2008.

ERICSON, C. Real-Time Collision Detection. San Francisco, EUA: MorganKaufmann, 2004. 593p.

EYETOY. Contém informações sobre o produto EyeToy, empregado em jogos nos quais o jogador interage através de sua imagem em vídeo. Disponível em: <http://www.eyetoy.com/>. Acesso em: 21 jan. 2008.

FAUGERAS, O. Three-dimensional Computer Vision. Cambridge, EUA: MIT Press, 1993. $695 \mathrm{p}$.

FOWLER, M. UML Essencial. 3. ed. Tradução de João Tortello. Porto Alegre: Bookman, 2005. 160 p.

FRAUNHOFER FIT: Outdoor Augmented Reality Game. Disponível em: $<$ http://www.fit.fraunhofer.de/projekte/netattack/index_en.xml>. Acesso em: 23 maio 2006. 
FUSIELLO, A.; TRUCCO, E.; VERRI, A. A compact algorithm for rectification of stereo pairs. Machine Vision and Applications, EUA, v. 12, n. 1, p. 16-22, 2000.

GARCIA, G.; CORRE, J. F. A New Collision Detection Algorithm Using Octree Models. In: IEEE INTERNATIONAL WORKSHOP ON INTELLIGENT ROBOTS AND SYSTEMS, 1989, EUA. Anais... IEEE Computer Society, 1989. p. 93-98.

GLFW: An OpenGL Framework. Disponível em: <http://glfw.sourceforge.net>. Acesso em: 21 jan. 2008.

GONZALES, R. C., WOODS, R. E. Processamento de Imagens Digitais. São Paulo: Edgard Blücher, 2000. 509 p.

GOVIL, A.; YOU, S.; NEUMANN, U. A Video-Based Augmented Reality Golf Simulator. In: ACM INTERNATIONAL CONFERENCE ON MULTIMEDIA, 8., 2000, Los Angeles, EUA. Anais... New York, EUA: ACM Press, 2000. p. 489-490.

GVILI R.; KAPLAN, A.; OFEK, E.; YAHAV, G. Depth Key. In: SPIE ELECTRONIC IMAGING CONFERENCE, 2003, Santa Clara, EUA. Anais... [S.I. : s.n.], 2003.

HÄMÄLÄINEN, P.; ILMONEN, T.; HOYSNIEMI, J.; LINDHOLM, M.; NYKANEN, A. Martial Arts in Artificial Reality. In: SIGCHI CONFERENCE ON HUMAN FACTORS IN COMPUTING SYSTEMS, 2005, Portland, EUA. Anais... New York, EUA: ACM Press, 2005. p. 781-790.

HISTORY OF VIDEOGAMES. California, EUA: CNET Networks, 2006. Apresenta um histórico dos jogos computacionais. Disponível em: <http://www.gamespot.com/gamespot/features/video/hov/>. Acesso em: 21 jan. 2008.

HOIEM, D.; EFROS, A. A.; HERBERT, M. Automatic Photo Pop-up. ACM Transactions on Graphics, New York, EUA, v. 24, n. 3, p. 577-584, jul. 2005.

HOSHNIO, J. Building Virtual Human Body from Video. In: IEEE VIRTUAL REALITY, 2002, Orlando, EUA. Anais... Washington DC, EUA: IEEE Computer Society, 2002. p. 265-266.

HUBBARD, P. M. Collision Detection for Interactive Graphics Applications, IEEE Transactions on Visualization and Graphics, Washington, DC, EUA, v. 1, n. 3, p. 218-230, 1995. 
ID SOFTWARE. Contém informações sobre o jogo Quake. Disponível em: <http://www.idsoftware.com>. Acesso em: 21 jan. 2008.

JACOBER, E. C. Proposta e Implementação de uma Interface para Motores de Jogos Interativa e Centrada no Usuário. 2007. 176 f. Dissertação (Mestrado em Engenharia Elétrica) - Escola Politécnica, Universidade de São Paulo, São Paulo, 2007.

JAVA MEDIA 3D APIS. Contém a especificação da biblioteca Java 3D. Disponível em: <http://java.sun.com/products/java-media/3D/reference/api/index.html>. Acesso em: 21 jan. 2008.

KANADE, T.; YOSHIDA, A.; ODA, K.; KANO, H.; TANAKA, M. A Stereo Machine for Video-rate Dense Depth Mapping and Its New Applications. In: COMPUTER VISION AND PATTERN RECOGNITION, 1996, San Francisco, EUA. Anais... Washington DC, EUA: IEEE Computer Society, 1996. p. 196-202.

KATO, H.; BILLINGHURST, M. Marker Tracking and HMD Calibration for a Videobased Augmented Reality Conferencing System. In: IEEE AND ACM INTERNATIONAL WORKSHOP ON AUGMENTED REALITY, 2., 1999, San Francisco, EUA. Anais... Washington DC, EUA: IEEE Computer Society, 1999. p. 85-94.

KIRNER, T. G.; KIRNER, C.; KAWAMOTO, A. L. S.; CANTÃO, J.; PINTO, A.; WAZLAWICK, R. S. Development of a Collaborative Virtual Environment for Educational Applications. In: ACM ANNUAL WEB3D SYMPOSIUM, 6., 2001, Paderborn, Alemanha. Anais... New York, EUA: ACM Press, 2001. p. 61-68.

LAURENTINI, A. The Visual Hull Concept for Silhouette-Based Image Understanding. IEEE Transactions on Pattern Analysis and Machine Intelligence, v. 16, n. 2, p. 150-162, fev. 1994.

LEE, S. Y.; KIM, I.; AHN, S. C.; LIM, M.; KIM, H. Toward Immersive Telecommunication: 3D Video Avatar with Physical Interaction. In: INTERNATIONAL CONFERENCE ON ARTIFICIAL REALITY AND TELEXISTENCE, 2005, Christchurch, Nova Zelândia. Anais... [S.I. : s.n], 2005. p. 56-61.

LEWIS, M.; JACOBSON, J. Game Engines in Scientific Research. Communications of the ACM, New York, v. 45, n. 1, p. 27-31, jan. 2002.

LIAO, M.; WANG, L.; YANG, R.; GONG, M. Light Fall-off Stereo. In: IEEE CONFERENCE ON COMPUTER VISION AND PATTERN RECOGNITION, 2007, Minneapolis, EUA. Anais... EUA: IEEE Computer Society, 2007. p. 1-8. 
LIN, M.; GOTTSCHALK, S. Collision Detection Between Geometric Models: a Survey. In: IMA CONFERENCE ON MATHEMATICS OF SURFACES, 1998, Birmingham, Reino Unido. Anais... Winchester, Reino Unido: Information Geometers, 1998. p. 37-56.

MAGERKURTH, C.; ENGELKE, T.; MEMISOGLU, M. Augmenting the Physical Domain with Physical and Social Elements. In: ACM SIGCHI INTERNATIONAL CONFERENCE ON ADVANCES IN COMPUTER ENTERTAINMENT TECHNOLOGY, 2004, Singapura. Anais... New York, EUA: ACM Press, 2004. p. 163-172.

MAGNOR, M. A. Video-Based Rendering. Wellesley, EUA: A K Peters, 2005. 224p.

MATUSIK, W.; BUEHLER, C.; RASKAR, R.; GORTLER, S.; MCMILLAN, L. Imagebased visual hulls. In: INTERNATIONAL CONFERENCE ON COMPUTER GRAPHICS AND INTERACTIVE TECHNIQUES, 27., 2000, New Orleans, EUA. Anais... New York, EUA: ACM Press/Addison-Wesley Publishing, 2000. p. 369-374.

MATYSCZOK, C.; RADKOWSKI, R.; BERSSENBRUEGGE, J. AR-Bowling: Immersive and Realistic Game Play in Real Environments Using Augmented Reality. In: ACM SIGCHI INTERNATIONAL CONFERENCE ON ADVANCES IN COMPUTER ENTERTAINMENT TECHNOLOGY, 2004, Singapura. Anais... New York, EUA: ACM Press, 2004. p. 269-274.

MILGRAM, P; KISHINO, F. A Taxonomy of Mixed Reality Visual Displays. IEICE Transactions on Information Systems, [S.I.], v.E77-D, dez. 1994.

MÖLLER, T. A.; HAINES, E. Real-Time Rendering. 2. Natick, EUA: AK Peters, 2002. 835p.

MUELLER, F.; AGAMANOLIS, S. Sports Over a Distance. ACM Computers in Entertainment, New York, EUA, v. 3, n. 3, p. 4E, jul. 2005.

NAEF, M.; STAADT, O.; GROSS, M. blue-c API: A Multimedia and 3D Video Enhanced Toolkit for Collaborative VR and Telepresence. In: ACM SIGGRAPH INTERNATIONAL CONFERENCE ON VIRTUAL REALITY CONTINUUM AND ITS APPLICATIONS IN INDUSTRY, 2004, Singapura. Anais... New York, EUA: ACM Press, 2004. p. 11-18.

NAKAMURA, R.; TORI, R.; JACOBER, E.; BIANCHINI, R.; BERNARDES JR, J. L. Development of a Game Engine Using Java. In: GAMES AND DIGITAL ENTERTAINMENT WORKSHOP, 2., 2003, Salvador, BA. Anais... [S.I.]:SBC, 2003. 1 CD-ROM. 
NASCIMENTO, H. P.; PELLEGRINO, S. R. Sistema de Detecção de Colisão usando Octrees Esféricas. In: WORKSHOP BRASILEIRO DE REALIDADE VIRTUAL, 3., 2000, Gramado, RS. Anais... [S.I.]:SBC, 2000. p. 271-272.

NGUYEN, T.; QUI, T. C. T.; XU, K.; CHEOK, A. D.; TEO, S. L.; ZHOU, Z.; MALLAWAARACHCHI, A.; LEE, S. P.; LIU, W.; TEO, H. S.; THANG, L. N.; LI, Y.; KATO, H. Real-Time 3D Human Capture System for Mixed-Reality Art and Entertainment. IEEE Transactions on Visualization and Computer Graphics, Piscataway, EUA, v. 11, n. 6, p. 706-721, 2005.

NIJHOLT, A.; TRAUM, D. The Virtuality Continuum Revisited. In: CONFERENCE ON HUMAN FACTORS IN COMPUTING SYSTEMS, 2005, Portland, EUA. Resumos... New York, EUA: ACM Press, 2005. p. 2132-2133.

NPD GROUP. 2006 U.S. Video Game and PC Game Retail sales reach \$13.5 billion exceeding previous record set in 2002 by over $\$ 1.7$ billion. Disponível em: < http://www.npd.com/press/releases/press_070119.html>. Acesso em: 21 jan. 2008.

OPENGL: The Industry Standard for High-Performance Graphics. Contém informações sobre o padrão OpenGL. Disponível em: <http://www.opengl.org>. Acesso em: 21 jan. 2008.

OPENCV: Open Source Computer Vision Library. Contém informações, documentação e o software da biblioteca OpenCV. Disponível em: < http://www.intel.com/technology/computing/opencv/>. Acesso em 21 jan. 2008.

PAELKE, V.; REIMANN, C; STICHLING, D. Foot-based mobile Interaction with Games. In: ACM SIGCHI INTERNATIONAL CONFERENCE ON ADVANCES IN COMPUTER ENTERTAINMENT TECHNOLOGY, 2004, Singapura. Anais... New York, EUA: ACM Press, 2004. p. 321-324.

PIEKARSKI, W; THOMAS, B. ARQuake: the Outdoor Augmented Reality Gaming System. Communications of the ACM, New York, EUA, v. 45, n. 1, p. 36-38, jan. 2002.

PRINCE, S.; CHEOK, A. D.; FARBIZ, F.; WILLIAMSON, T.; JOHNSON, N.; BILLINGHURST, M.; KATO, H. 3D-Live: Real Time Interaction for Mixed Reality. In: ACM CONFERENCE ON COMPUTER SUPPORTED COOPERATIVE WORK, 2002, New Orleans, EUA. Anais... New York, EUA: ACM Press, 2002. p. 364-371.

RASKAR, R; LOW, K. Interacting with Spatially Augmented Reality. In: INTERNATIONAL CONFERENCE ON COMPUTER GRAPHICS, VIRTUAL REALITY AND VISUALISATION, 1., 2001, Cape Town, África do Sul. Anais... New York, EUA: ACM Press, 2001. p. 101-108. 
RHYNE, T. M. Computer Games and Scientific Visualization. Communications of the ACM, New York, EUA, v. 45, n. 7, p. 40-44, jul. 2002.

SANCHES, S. R. R. A Utilização da Técnica de Chromakey para Composição de Cenas em Ambientes de Realidade Misturada. 2007. 152 f. Dissertação (Mestrado em Ciência da Computação) - Centro Universitário Eurípides de Marília, Marília, 2007.

SCHARSTEIN, D.; SZELISKI, R. A taxonomy and evaluation of dense two-frame stereo correspondence algorithms. International Journal of Computer Vision, EUA, v.47, n.1, p. 7-42, 2002.

SINGHAL, S.; ZYDA, M. Networked Virtual Environments: Design and Implementation. Nova York, EUA: ACM Press, 1999. 331p.

SISCOUTTO, R. A. Proposta de Arquitetura para Teleconferência Baseada na Integração de Vídeo-Avatar Estereoscópico em Ambiente Virtual Tridimensional. 2003. 192 f. Tese (Doutorado em Engenharia Elétrica) - Escola Politécnica, Universidade de São Paulo, São Paulo, 2003.

SUBBARAO, M.; SURYA, G. Depth from defocus: A spatial domain approach. International Journal of Computer Vision, EUA, v. 13, n. 3, p. 271-294, dez. 1994.

SWARTOUT, W.; VAN LENT, M. Making a Game of System Design. Communications of the ACM, New York, EUA, v. 46, n. 7, p. 32-39, jul. 2003.

TAMAGAWA, K.; YAMADA, T.; OGI, T.; HIROSE, M. Developing a 2.5-D Video Avatar. IEEE Signal Processing Magazine, [S.I.], v. 18, n. 3, p. 35-42, maio 2001.

THOMAS, B.; CLOSE, B.; DONOGHUE, J.; SQUIRES, J.; DE BONDI, P.; PIEKARSKI, W. First Person Indoor/Outdoor Augmented Reality Application: ARQuake. Personal and Ubiquitous Computing, Londres, Inglaterra, v. 6, n. 1, p. 75-86, fev. 2002.

WATT, A. 3D Computer Graphics. 3. EUA: Pearson Education, 2000. 570p.

ZHANG, Z. A flexible new technique for camera calibration. Transactions on Pattern Analysis and Machine Intelligence, EUA, v. 22, n. 11, p. 1330-1334, nov. 2000.

ZHANG, L.; NAYAR, S. K. Projection defocus analysis for scene capture and image display. In: INTERNATIONAL CONFERENCE ON COMPUTER GRAPHICS AND 
INTERACTIVE TECHNIQUES, 33., 2006, Boston, EUA. Anais... New York, EUA: ACM Press/Addison-Wesley Publishing, 2006. p. 907-915. 


\section{GLOSSÁRIO}

Avatar: Um avatar é uma representação, humanóide ou não, de um usuário dentro do ambiente virtual (KIRNER, 2001). Em geral, o avatar é utilizado para permitir que os usuários possam observar a posição e orientação uns dos outros, aumentando a sensação de presença no ambiente virtual.

Disparidade: Neste trabalho, este termo se refere à diferença entre os valores da coordenada horizontal de dois pixels correspondentes em um par de imagens estereoscópicas. A partir da disparidade, é possível calcular a profundidade do pixel, ou seja, a distância que se encontrava o ponto do espaço tridimensional originalmente projetado naquele ponto da imagem.

Engine: $O$ termo engine é utilizado em diferentes contextos nas áreas de computação. Neste trabalho, refere-se aos engines para jogos, que podem ser definidos como um conjunto de componentes integrados e reutilizáveis que facilitam o desenvolvimento de jogos de computador (NAKAMURA, 2003).

Pixel: Termo que significa picture element. Corresponde a um elemento discreto que compõe uma imagem bidimensional. Em geral, um pixel possui propriedades de posição, correspondente às coordenadas que este ocupa na matriz da imagem, e de cor, através de algum modelo de representação de cores.

Pixel Shader: Termo utilizado para um programa responsável pela geração de informações de cor de um fragmento a ser renderizado em um hardware de processamento gráfico programável.

Realidade Aumentada: Neste trabalho, define-se Realidade Aumentada como parte da área de pesquisa da Realidade Virtual que trata da integração de objetos reais e virtuais em um mesmo ambiente. Desta forma, abrange tanto a inclusão de objetos virtuais em um ambiente real como a representação de objetos reais em ambientes virtuais.

Realidade Virtual: Este termo é usado para designar o campo de pesquisa e desenvolvimento, envolvendo diferentes áreas de conhecimento como a computação gráfica, simulação e sistemas de tempo real com o objetivo de criar ambientes sintéticos tridimensionais. Estes ambientes podem ser reproduções de espaços físicos existentes ou construções baseadas em conjuntos de dados abstratos. 
Registro: $\mathrm{Na}$ área de Realidade Aumentada, este termo se refere ao alinhamento visual entre objetos reais e virtuais visíveis na mesma cena. Obter um registro preciso é um desafio sempre presente em aplicações de Realidade Aumentada.

Renderização: Este termo, em computação gráfica, se refere ao processo de gerar uma imagem sintética de um objeto ou cena, a partir de uma descrição geométrica dos mesmos.

Tempo real: Neste trabalho, adota-se este termo para indicar que um dado algoritmo ou sistema produz resultados a uma taxa compatível com a velocidade de interação do usuário. Não se pretende, no entanto, impor as condições mais restritivas de tempo de resposta atribuídas a sistemas formalmente definidos como de tempo real.

Vídeo-avatar: Representação virtual de um usuário humano, baseada na sua imagem obtida através de um dispositivo de aquisição de vídeo e atualizada a taxas interativas.

Z-Buffer: Técnica da computação gráfica utilizada para permitir a renderização em ordem arbitrária de primitivas gráficas, fazendo com que a oclusão entre elas seja visualizada corretamente. O nome da técnica vem do fato de que se utiliza uma matriz numérica auxiliar que contém a profundidade normalizada do último fragmento que foi renderizado em cada posição da imagem que está sendo sintetizada. 


\section{ApÊndice A - Formato do aRquivo de Configuração da FerRamenta CONFIGURÁVEL DE TESTES}

A ferramenta configurável de testes desenvolvida para avaliar o desempenho das técnicas propostas nesta tese utiliza um arquivo de configuração que segue o padrão XML. A seguir encontra-se uma explicação de cada um dos possíveis marcadores que podem ser escritos neste arquivo.

\section{Configuração Geral}

$<$ usesynth $>\mathrm{N}<$ /usesynth>

$\mathrm{N}=0$ : utilizar uma sequência de quadros de vídeo capturados de um par de câmeras.

$\mathrm{N}=1$ : utilizar uma sequência de quadros de vídeo sintéticos, que serão especificados pelos parâmetros synthbase, synthfocal, leftsynth, rightsynth, minsynth e maxsynth.

\section{Parâmetros de vídeo capturado}

$<$ rectparams>"nome de arquivo"</rectparams $>$

Indica o nome do arquivo que contém os parâmetros de retificação das câmeras.

$<$ leftstream>"diretoriolprefixo"</leftstream>

Indica o caminho do diretório contendo as imagens da câmera esquerda, mais o prefixo das imagens. Por exemplo, se o parâmetro for "c:ldadoslesq", a ferramenta de testes tentará carregar os arquivos "c:IdadoslesqNNNN.bmp" onde NNNN é o número de sequência da imagem, indo de 0000 a 9999.

$<$ rightstream>"diretoriolprefixo"</rightstream>

Indica o caminho do diretório contendo as imagens da câmera direita, da mesma forma que o parâmetro leftstream.

$<$ leftbackground>"nome de arquivo"</leftbackground>

Indica o nome do arquivo que contém o fundo de cena capturado pela câmera esquerda, para ser utilizado com o algoritmo de subtração de fundo.

<rightbackground>"nome de arquivo"</rightbackground>

Indica o nome do arquivo que contém o fundo de cena capturado pela câmera direita, para ser utilizado com o algoritmo de subtração de fundo. 
$<$ minindex $>\mathrm{N}<$ /minindex $>$

$\mathrm{O}$ valor $\mathrm{N}$ indica o número de sequência da primeira imagem a ser utilizada pela ferramenta de testes.

$<$ maxindex $>\mathrm{N}<$ /maxindex $>$

$\mathrm{O}$ valor $\mathrm{N}$ indica o número de sequência da última imagem a ser utilizada pela ferramenta de testes.

\section{Parâmetros de vídeo sintético}

$<$ synthbaseline $>\mathrm{N}</$ synthbaseline $>$

$\mathrm{O}$ valor $\mathrm{N}$ é a linha de base, expressa em metros, entre as câmeras virtuais.

$<$ synthfocal $>\mathrm{N}<$ /synthfocal>

$\mathrm{O}$ valor $\mathrm{N}$ é a distância focal, em pixels, das câmeras sintéticas. A ferramenta sintética assume que as duas câmeras sintéticas são idênticas.

$<$ leftsynth>"diretoriolprefixo"</leftsynth>

Indica o caminho do diretório contendo as imagens da câmera sintética esquerda, mais o prefixo das imagens. Por exemplo, se o parâmetro for "c:Idadoslesq", a ferramenta de testes tentará carregar os arquivos "c:IdadoslesqNNNN.bmp" onde NNNN é o número de sequência da imagem, indo de 0000 a 9999.

$<$ rightsynth>"diretoriolprefixo"</rightsynth>

Indica o caminho do diretório contendo as imagens da câmera sintética direita, da mesma forma que o parâmetro leftsynth.

$<$ minsynth $>\mathrm{N}<$ /minsynth $>$

$\mathrm{O}$ valor $\mathrm{N}$ indica o número de sequência da primeira imagem sintética a ser utilizada pela ferramenta de testes.

$<$ maxsynth $>\mathrm{N}<$ /maxsynth $>$

$\mathrm{O}$ valor $\mathrm{N}$ indica o número de sequência da última imagem sintética a ser utilizada pela ferramenta de testes.

\section{Configuração do algoritmo de mapa de profundidade}

$<$ windowsize $>\mathrm{N}<$ /windowsize $>$

$\mathrm{O}$ valor de $\mathrm{N}$ (que deve ser maior ou igual a 3) é o tamanho da janela de avaliação utilizada no cálculo de estimativas de semelhança entre pixels do par estéreo. Valor recomendado: 7

$<$ maxdisplacement $>\mathrm{N}<$ /maxdisplacement $>$ 
O valor de $\mathrm{N}$ é o máximo valor de disparidade que deve ser utilizado no mapa de profundidade. Consequentemente, este valor limita o espaço de busca dos pixels e reduz o processamento do algoritmo. Valor recomendado: 80

<numberthreads $>\mathrm{N}<$ /numberthreads $>$

$\mathrm{O}$ valor de $\mathrm{N}$ é o número de threads que serão utilizados para a execução paralela do algoritmo de mapa de profundidade. Valor recomendado depende do número de núcleos ou processadores em que a ferramenta está sendo executada.

$<$ colormode $>\mathrm{N}<$ /colormode $>$

$\mathrm{N}=0$ : Processar as imagens em escala de cinza

$\mathrm{N}=1$ : Processar as imagens em cores (formato RGB)

$<$ medianwindow $>\mathrm{N}<$ /medianwindow $>$

$\mathrm{O}$ valor de $\mathrm{N}$ é o tamanho da janela do filtro de mediana que será aplicado ao mapa de profundidade para garantir maior continuidade entre valores vizinhos. Valor recomendado: 7 . 


\section{ApÊndice B - Diagramas UML do Sistema AVMix}

Este apêndice apresenta os diagramas de classes e de sequência, seguindo a notação UML, da especificação do sistema AVMix discutida no Capítulo 6.
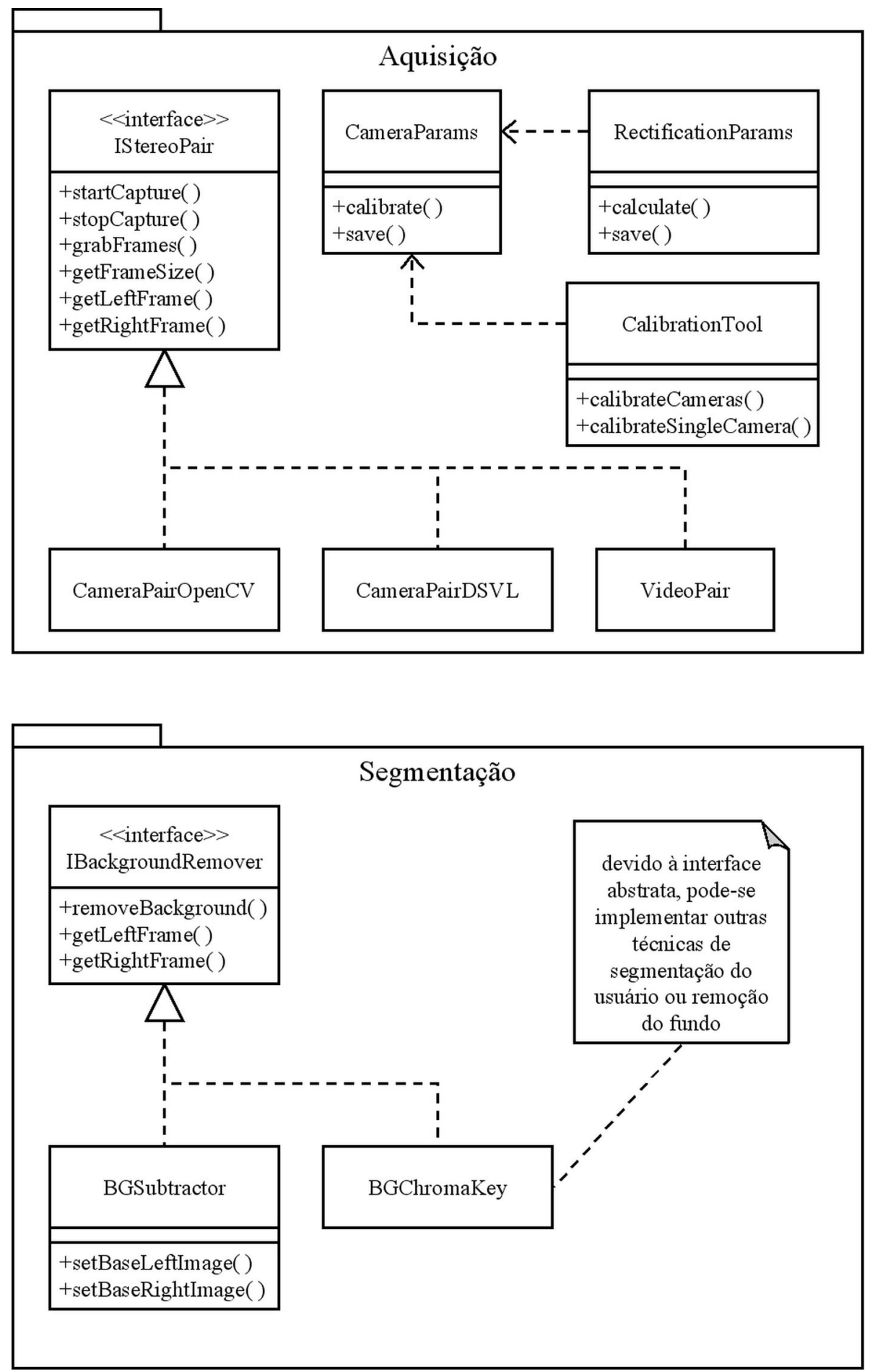

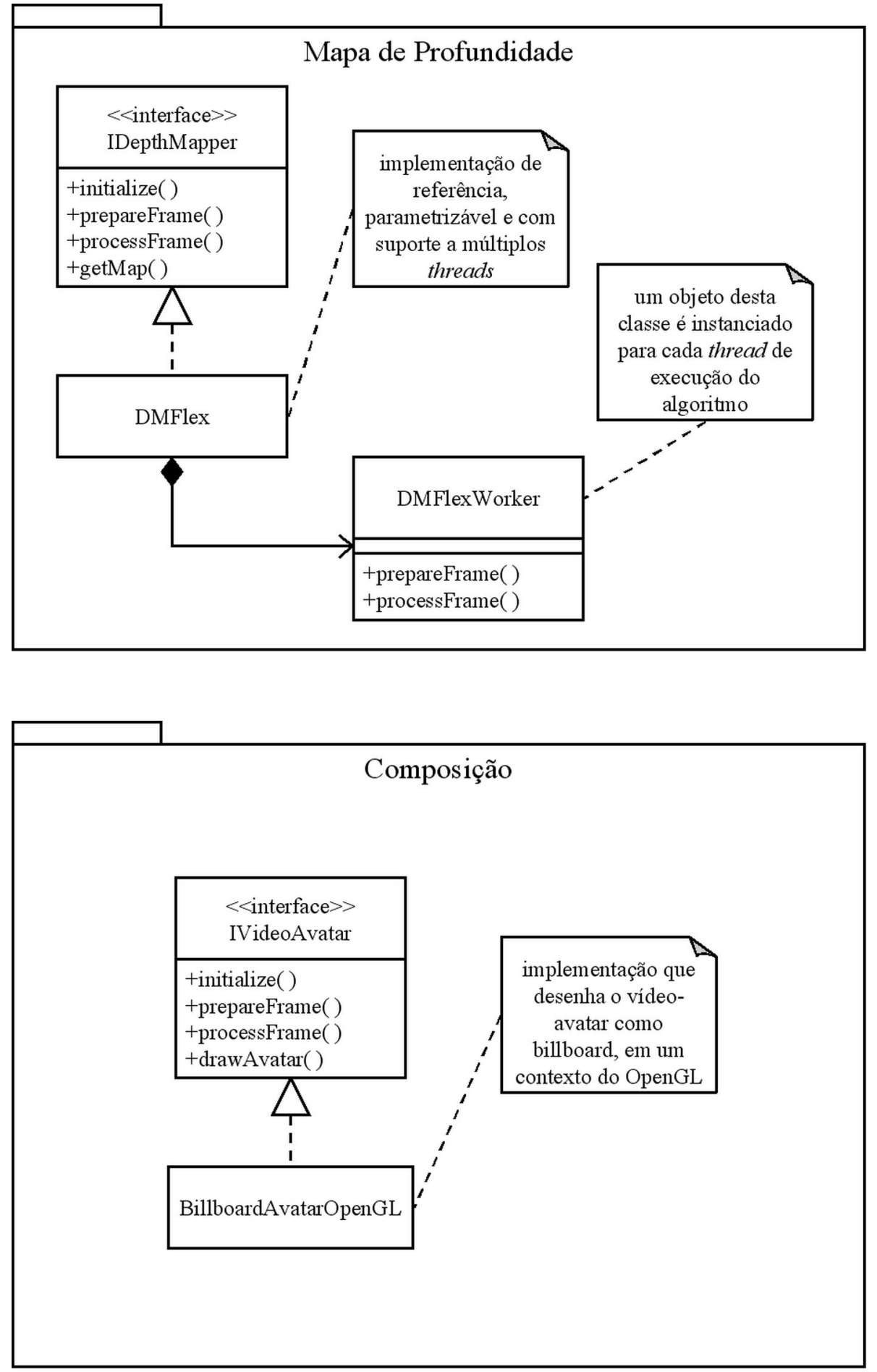


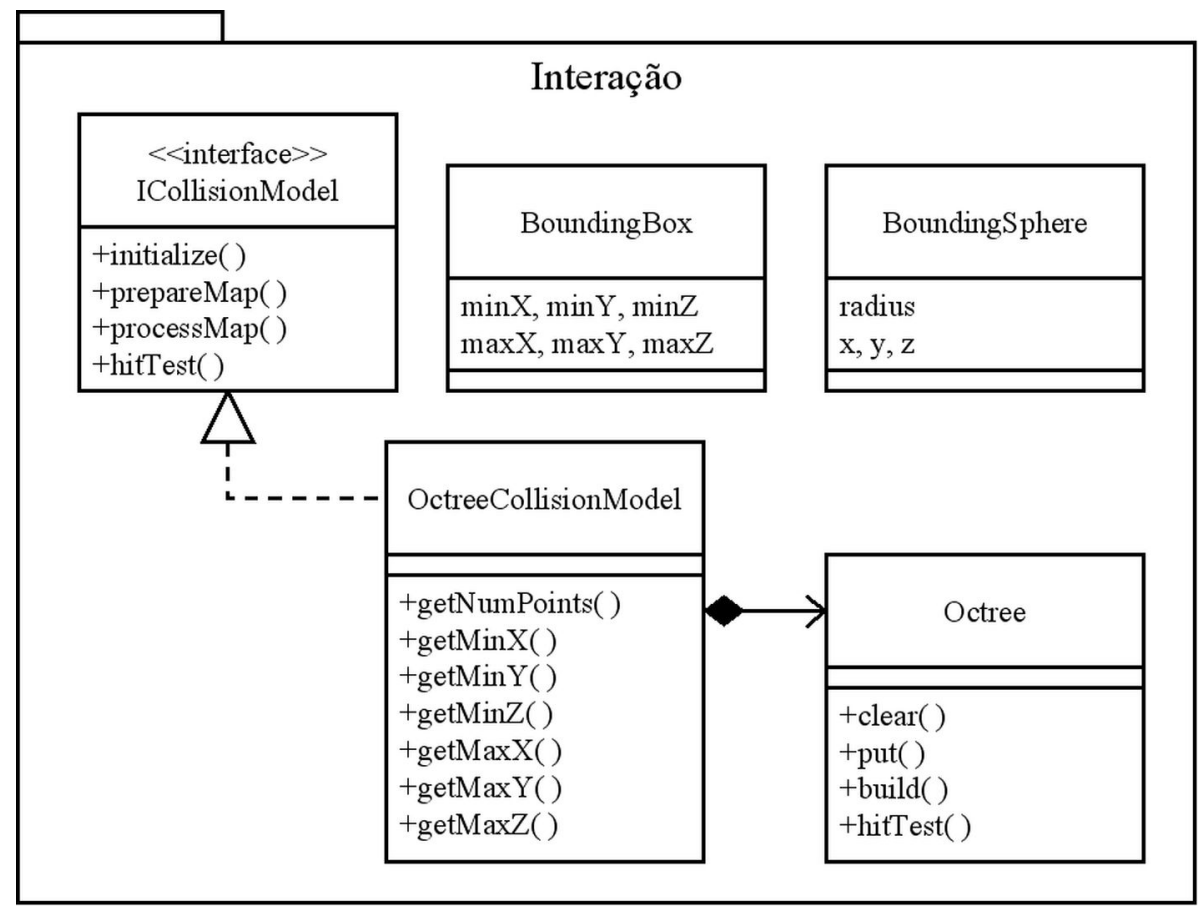

Os diagramas de sequência a seguir representam padrões de utilização das classes do sistema AVMix por uma aplicação de realidade aumentada.

\section{Captura de imagens e cálculo do mapa de profundidade}

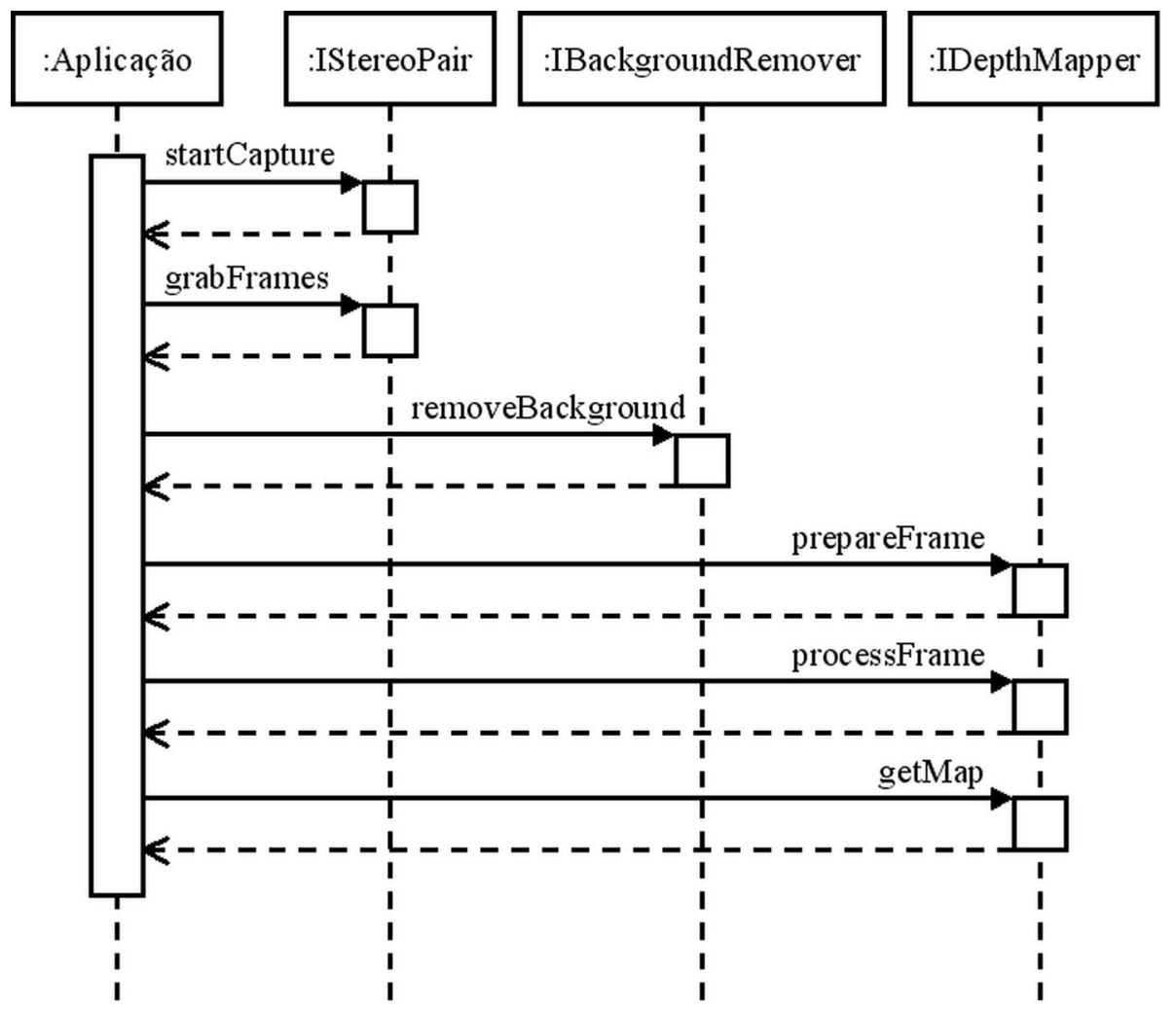




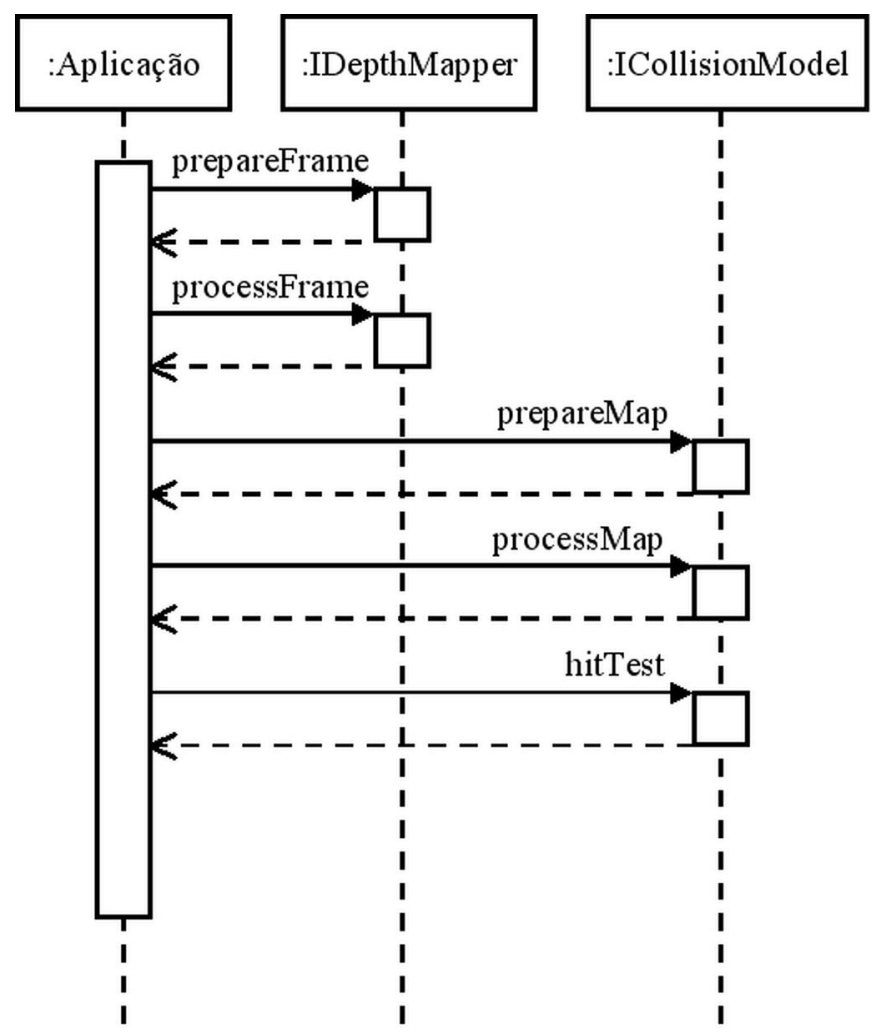

\section{Apresentação do Vídeo-avatar}

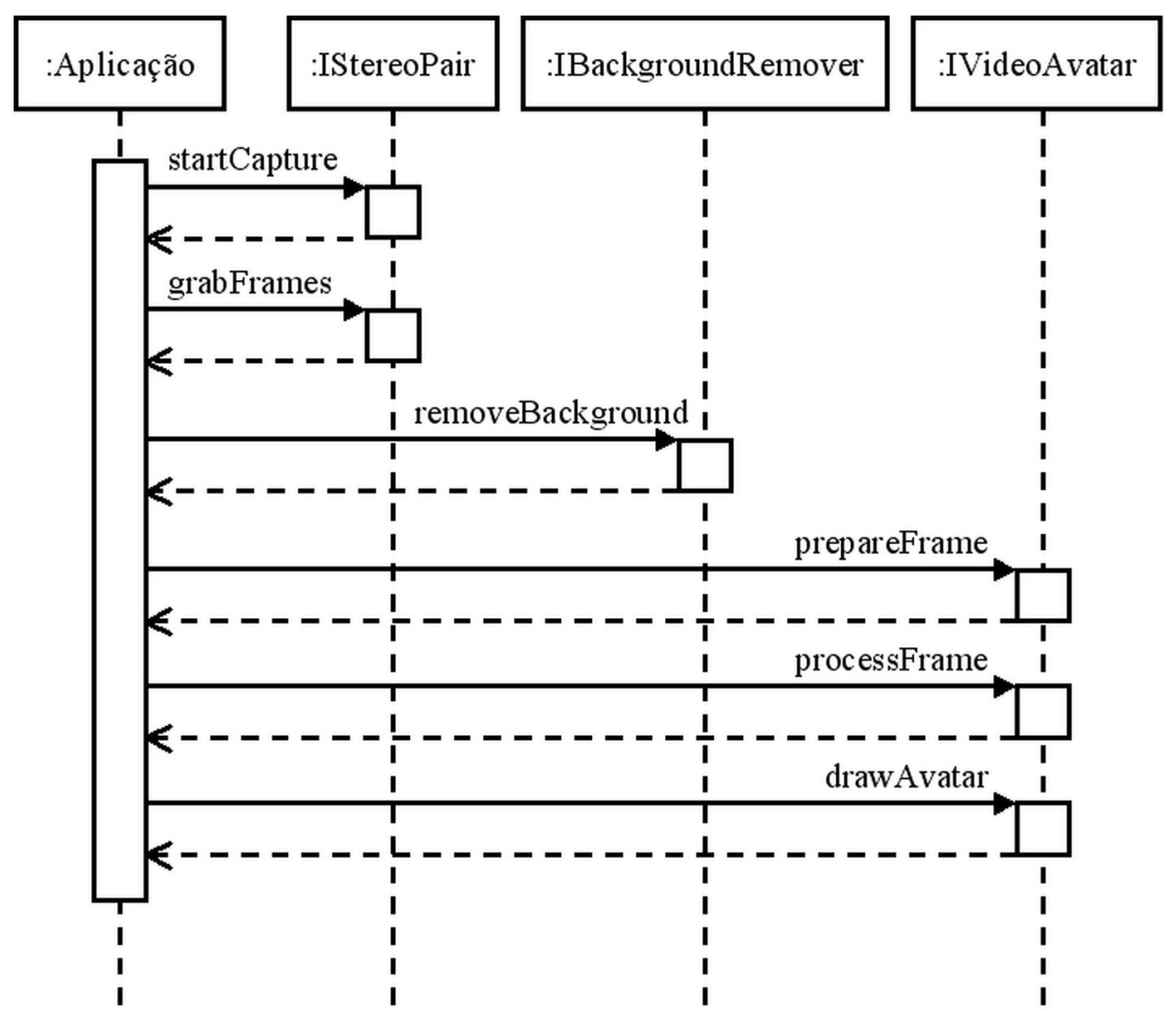

